Portland State University

PDXScholar

Summer 8-15-2013

\title{
Exploring Online Community Among Rural Medical Education Students: A Case Study
}

Ryan Tyler Palmer

Portland State University

Follow this and additional works at: https://pdxscholar.library.pdx.edu/open_access_etds

Part of the Higher Education Commons, and the Medical Education Commons

Let us know how access to this document benefits you.

\section{Recommended Citation}

Palmer, Ryan Tyler, "Exploring Online Community Among Rural Medical Education Students: A Case Study" (2013). Dissertations and Theses. Paper 990.

https://doi.org/10.15760/etd.990

This Dissertation is brought to you for free and open access. It has been accepted for inclusion in Dissertations and Theses by an authorized administrator of PDXScholar. Please contact us if we can make this document more accessible: pdxscholar@pdx.edu. 
Exploring Online Community Among Rural Medical Education Students:

\author{
A Case Study \\ by \\ Ryan Tyler Palmer \\ A dissertation submitted in partial fulfillment of the \\ requirements for the degree of \\ Doctor of Education \\ in \\ Education Leadership: Postsecondary Education
}

Dissertation Committee:

Candyce Reynolds, Chair

Larry Large

Michael Smith

Pam Miller

Portland State University

2013 
(C) 2013 Ryan Tyler Palmer 


\begin{abstract}
There is a severe shortage of rural physicians in America. One reason physicians choose not to practice, or persist in practice, in rural areas is due to a lack of professional community, i.e., community of practice (CoP). Online, "virtual" CoPs, enabled by now common Internet communication technology can help give rural physicians the CoP experience they traditionally have lacked, despite their remote practice locations. Therefore, it is important for rural medical education programs to provide technological experiences that give students the skills needed to create virtual CoPs in future rural practice contexts.

The Oregon Rural Scholars Program (ORSP) provides such a technological experience in the form of the Student Clinical Round (SCR) activity. ORSP students located in remote, rural parts of Oregon "meet" in a synchronous online space (i.e., a virtual meeting room) with a faculty member, where they participate in the SCR activity via video chat, screen and document sharing, real-time collaborative note taking, and text chatting. The literature indicates that activities like the SCR may be precursors to virtual CoPs, and therefore it is important to better understand the ORSP SCR as it could be a strategy for creating virtual CoPs among rural practitioners.
\end{abstract}

As the ORSP SCR is a novel educational approach among U.S. rural medical education programs, an intrinsic case study design was used to explore the impact of the SCR activity on one cohort of ORSP third-year medical students. Additionally, the study sought to better understand the nature of the ORSP students' experiences of having participated in the SCR. Recorded SCR sessions were coded using the Community of 
Inquiry (CoI) framework, a well validated methodology for analyzing higher education online learning. The CoI analysis revealed a movement of the group away from an individual, task focus towards a community, collaborative focus as the SCR sessions progressed. Additionally, student interview and field notes analyses revealed that the SCR experience reduced isolation, increased sense of community and positively influenced rural practice choice among the study participants.

Conclusions drawn from this study are that the online ORSP SCR experience provides a strong social constructivist learning environment, thus creating the context for virtual CoP emergence. Additionally, the SCR activity is capable of generating an actual virtual CoP, an event directly observed during the study. Recommendations call for rural medical education programs as well as current rural practitioners to adopt similar online approaches to group learning, as such approaches may provide contexts for virtual CoP formation, thus contributing to the likelihood future physicians may become and current physicians may persist as rural practitioners. 
Table of Contents

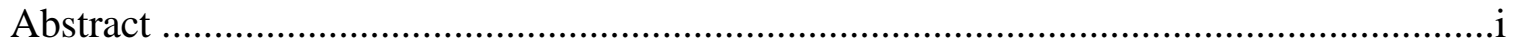

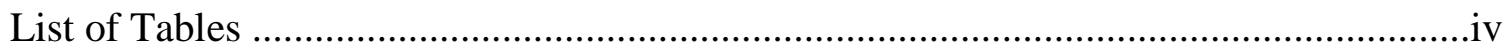

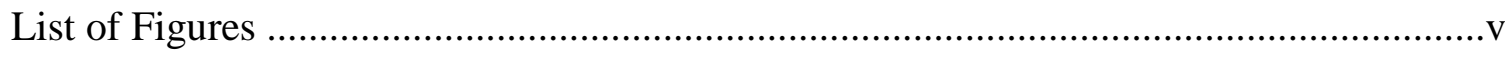

Glossary of Key Terms ........................................................................................ vii

\section{Chapter One}

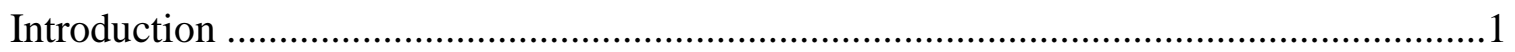

\section{Chapter Two}

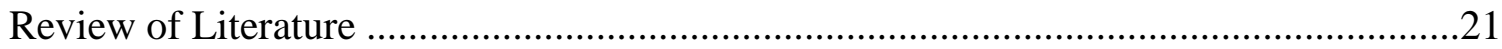

\section{Chapter Three}

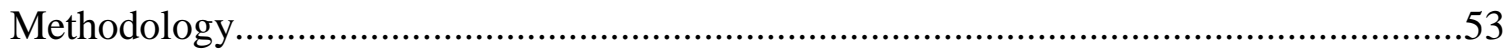

\section{Chapter Four}

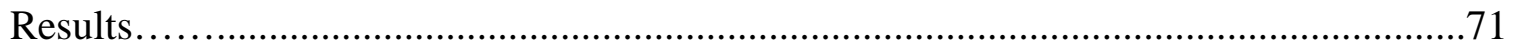

\section{Chapter Five}

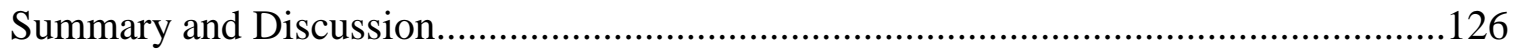

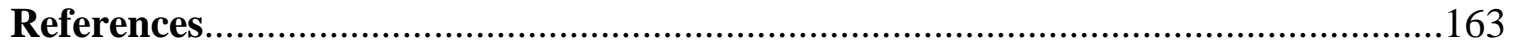

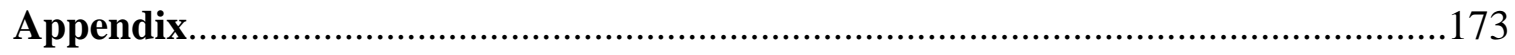




\section{List of Tables}

Table 3.1 Cognitive Presence Coding Descriptors and Indicators ..........................61

Table 3.2 Teaching Presence Coding Descriptors and Indicators...........................62

Table $3.3 \quad$ Social Presence Coding Descriptors and Indicators...............................65

Table 4.1 Summative display of all CoI codes over all four SCRs.........................83

Table 4.2 Summary of Participant Interviews................................................110 


\section{List of Figures}

Figure 1.1 Locations of past ORSP cohort overlaid on population map of Oregon ...9

Figure 1.2 Normal third-year medical student clerkship rotation compared to

ORSP student rotation. .............................................................10

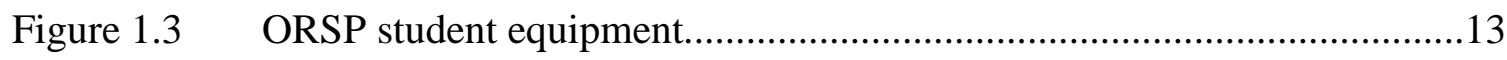

Figure 1.4 Curricular components of the OHSU Family Medicine clerkship ............14

Figure 1.5 Typical ORSP SCR activity layout .....................................................17

Figure 2.1 The Community of Inquiry framework..............................................30

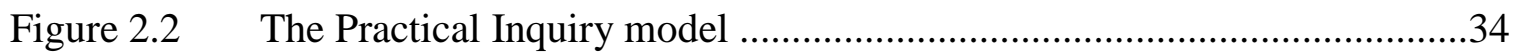

Figure 4.1 NVivo allows for codes to be inserted directly on the timeline above the

video file......................................................... 74

Figure 4.2 CoI coding structure as entered in NVivo software................................75

Figure 4.3 Coding example of vocative indicator as recorded in NVivo software.....81

Figure 4.4 Coding example of drawing in participants, prompting discussion indicator as recorded in NVivo software............................................83

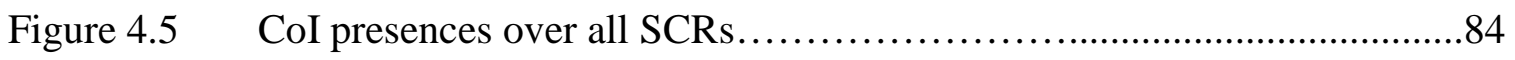

Figure 4.6 CoI presences over all SCRs (trendline included) ................................85

Figure 4.7 Responding to technical concerns indicator over all SCRs.....................87

Figure 4.8 Social presence categories over all SCRs.....................................88

Figure 4.9 Social presence indicator level codes over all SCRs..............................90

Figure 4.10 Teaching presence categories over all SCRs...................................94

Figure 4.11 Teaching presence indicators over all SCRs........................................96

Figure 4.12 Comparison of declining teacher focused indicators to increasing constructivist focused indicators.......................................99 
Figure 4.13 Cognitive presence category data over all SCRs...............................106

Figure 4.14 Cognitive presence indicator codes over all SCRs..............................107

Figure 5.1 Strategy to encourage virtual CoP formation within a multi modal online

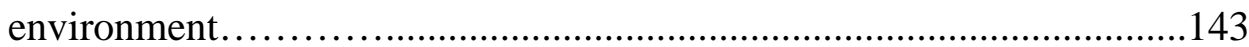




\section{Glossary of Key Terms}

Category: The second level coding hierarchy in the CoI framework.

Cognitive Presence: One of the three constructs of the CoI framework.

Community of Inquiry (CoI): Theoretical framework for analyzing online course transcripts. Serves as both the theoretical as well as research framework for this study.

Community of Practice (CoP): Groups of people who share a concern or a passion for something they do and learn how to do it better as they interact regularly. CoP's are profession/practice based.

Deliberate computer mediated space (CMS): A type of online community where individuals organize online around a shared interest, task or activity. An online course is an example of a deliberate CMS. Also commonly referred to as a "virtual community."

Indicator: The third level coding hierarchy in the CoI research framework.

Oregon Rural Scholars Program (ORSP): A program for Oregon Health and Science University third year medical students that are interested in going into rural medicine.

Presence: The first level coding hierarchy in the CoI framework.

Social Presence: One of the three constructs of the CoI framework.

Social Presence Theory: The body of research based on the degree to which a person is perceived as a 'real person' in mediated communication.

Student Clinical Rounds (SCR): An interactive learning activity that ORSP students participate in remotely via an online meeting room.

Teaching Presence: One of the three constructs of the CoI framework.

Virtual CoP: An online version of a community of practice. Virtual CoPs emerge from deliberate CMSs. 


\section{CHAPTER ONE}

\section{Introduction}

This dissertation describes an intrinsic case study exploring the online community experienced by one cohort of third-year medical students, one faculty member and one participant observer. The dissertation is organized into five chapters. Chapter One serves as an introduction to the subsequent chapters, describing the problem in practice and background to the activity being explored, as well as providing a brief introduction to the theoretical framework and methodology employed in the study. Chapter Two serves as the literature review, detailing the supporting literature and theoretical lens used for the study. Chapter Three focuses on the methodological approach of the study. Chapter Four

describes the study results. Finally, Chapter Five presents the conclusions drawn from the study, as well as recommendations for future research and practice.

\section{Background to Problem in Practice}

There is an acute shortage of physicians in rural America (Rabinowitz, Diamond, Markham, \& Wortman, 2008). One in five Americans lives in a rural area, though only 9\% of physicians practice there (Gazewood, Rollins, \& Galazka, 2006). There is also a concurrent decrease in medical student interest in primary care (Jeffe, Whelan, \& Andriole, 2010). Primary care is the field in medicine focused on first contact and continuity of care with patients. Unlike a specialist physician, who focuses on one organ system or symptom, a primary care physician focuses on the whole, or "undifferentiated" patient” (American Academy of Family Physicians, n.d.). The literature indicates that primary care physicians are more likely to practice in rural areas (Curran \& Rourke, 
2004; Geyman, Hart, Norris, Coombs, \& Lishner, 2000; Rabinowitz, Diamond, Markham, \& Hazelwood, 1999; Rosenthal, 2000; J. Rourke, Incitti, Rourke, \& Kennard, 2005). Thus the current lack of rural physicians in conjunction with the decreased interest in primary care as a career path for new physicians exacerbates what is already a health care crisis for America's rural population.

Community is an important aspect of the medical profession. Rovai (2002) identifies essential elements of community to include “ mutual interdependence among members, sense of belonging, connectedness, spirit, trust, interactivity, common expectations, shared values and goals, and overlapping histories among members” (p. 2). For the physician, community is an important part of professional practice, and is codified in practices such as journal clubs, grand rounds and continuing medical education activities. These elements of physician community traditionally take place face-to-face both formally and informally. Specifically, a physician community can be identified as Communities of Practice (CoP) (Wenger, 1999) (CoPs will be discussed in detail in Chapter Two).

As physician CoPs usually take place face to face, rural practitioners that have few, if any, physician colleagues in their practice locations often lack the professional CoP available to physicians in more populated locations. Professional isolation due to lack of community has been found to be a deterrent for doctors to practice, or continue to practice, in rural areas (Whitcomb, 2005). It can be said, then, that a lack of CoPs for rural physicians contributes to the shortage of physicians practicing in rural areas.

One solution to alleviating the rural practitioner shortage problem is through medical education. The literature indicates that medical students who study in rural areas 
are more likely to return to those areas to practice (Morris \& Chen, 2009; Morris, Johnson, Kim, \& Chen, 2008; Woloschuk \& Tarrant, 2002). However, while programs have been established to immerse medical students in rural medical experiences, few have addressed the inherent lack of CoPs inherent to rural practice. Rural medical students that lack the skills to create CoPs when they go into rural practice risk perpetuating the cycle of poor persistence in rural practice as physicians. It is important, then, to incorporate CoP skills training in rural medical education programs so that future rural physicians have the skills they need to persist in rural practice.

Yet there is a reason rural practitioners have traditionally lacked the ability to form robust CoPs: distance. As stated, those professional conventions that traditionally constitute physician CoPs- journal clubs where physicians present recent medical literature of interest to their peers, grand rounds where physicians listen to a notable peers speak on medical topics of interest, lunch meetings where knowledge is passed informally from one physician to another, etc.- are all "in person" phenomena. Thus, the rural practitioner with a limited or nonexistent peer network due to the remote nature of her practice is denied the very conventions that comprise the CoPs so important to the medical profession.

Fortunately, advances in technology now provide opportunities to break down professional isolation among rural medical practitioners and learners. Specifically, online technology allows people to connect to one another both asynchronously and synchronously, with little more than an Internet connection and an Internet capable computing device. It would seem, then, that rural physicians can now transcend the 
traditional barrier of distance to form virtual, rather than in person, CoPs, thus giving rural practitioners the professional community that they have previously lacked.

However, the creation of virtual CoPs is easier said than done. One reason for this difficulty is that both virtual and in-person CoPs are largely emergent phenomena. True CoPs by definition arise out of established practices and conventions among a professional group; they cannot be deliberately planned. Therefore, deliberate attempts to create or impose a CoP- virtual or otherwise- are inherently problematic.

Yet while virtual CoPs cannot be deliberately planned- and therefore taught- due to their emergent nature, those structures from which virtual CoPs emerge can be deliberately created. The structures from which virtual CoPs emerge are called deliberate Computer Mediated Spaces (CMS)ํ( (Johnson, 2001; Lueg, 2000).

A deliberate CMS is a type of online community where individuals organize around a shared interest, task or activity (Johnson, 2001). Unlike a traditional community, like a neighborhood that is traditionally organized around a place, a deliberate CMS exists in relation to an idea or a task (Johnson, 2001). Deliberate CMSs are common and can take many forms, from Facebook groups to email listserves. Important to this dissertation study is a deliberate CMS specific to education: the online course.

Online courses according to this dissertation study involve academic coursework that takes place in a virtual space, whether in a completely online course where students never meet face-to-face, or a "hybrid" course where students meet face-to-face as well as

\footnotetext{
${ }^{1}$ The literature more commonly refers to a deliberate CMS as a "virtual community." My rationale in using the term deliberate CMS rather than virtual community is to minimize reader confusion as I will rely heavily on two other terminologies that use the phrase "community" in this study- Community of Practice and Community of Inquiry. As deliberate CMS captures the essence of the definition of a virtual community, it will be substituted throughout this study.
} 
online. An online course constitutes a deliberate CMS since students are organized around a common task- satisfaction of their course requirements- in an online space. Therefore, whereas a virtual CoP cannot be deliberately created, a deliberate CMS like an online course certainly can. As the literature indicates that virtual CoPs emerge from deliberate CMSs, it is reasonable to extrapolate that incorporating deliberate CMSs into a rural medical education experience is an important first step in the development of virtual CoPs. The idea is that a student's experience with a deliberate CMS may give them the skills necessary to create their own deliberate CMSs while in rural practice, thus creating the context for virtual CoPs to emerge.

The utilization of deliberate CMSs in American rural medical education programs is minimal and not well understood (D. Kolva, personal communication, May 08, 2012; L. Day, personal communication, November 4, 2011; M. Blackburn, personal communication, May 09, 2012; M. Kennedy, personal communication, May 10, 2012). Of the 134 accredited MD training programs in the US, only a minority require students to participate in rural medical education training (Chen, Fordyce, Andes, \& Hart, 2010). Those schools that do emphasize rural training among MD students focus largely on the individual experience of the student participating in clinical practice while in the rural area. In other words, a learner's experience in the rural setting is largely comprised of an individual experience with a rural preceptor (supervising physician mentor) and the rural community in which the student is placed. While this type of apprenticeship education model is an important and necessary component of rural training, it does nothing to acknowledge or address the feelings of professional isolation inherent to the rural physician experience. Indeed, rural medical students are primarily trained to approach 
rural practice in the same isolated, location-bound fashion that constitutes the traditional rural physician experience. While some rural medical training programs do employ a deliberate CMS in the form of an online course for rural learners (D. Kolva, personal communication, May 08, 2012; M. Blackburn, personal communication, May 09, 2012; M. Kennedy, personal communication, May 10, 2012) a review of the literature revealed no program is currently focusing on the online course itself as a possible learning strategy to address the opportunities for virtual CoP development among rural physicians. A better understanding of a program that utilizes a deliberate CMS in rural training may help other medical schools understand how to leverage similar approaches to rural medical training, thus better educating future practitioners on how to create deliberate CMSs while in rural practice.

Among US rural training programs, Oregon Health and Science University (OHSU) provides a unique approach to rural medical education in its Oregon Rural Scholars Program (ORSP). The ORSP incorporates a deliberate CMS in a novel approach that consists of an online activity for student participants called the Student-led Clinical Rounds (SCR). The SCR format has ORSP students "meet" weekly in a virtual meeting room where they present clinical cases in a highly interactive, learner-focused format. A solicitation for descriptions of similar approaches on a national rural medical training program listserve yielded no uses of technology to connect rural learners to one another that resembled the ORSP program's approach (D. Kolva, personal communication, May 08, 2012; M. Blackburn, personal communication, May 09, 2012; M. Kennedy, personal communication, May 10, 2012). Therefore, the ORSP SCR appears to be a novel and highly scalable utilization of a deliberate CMS in rural medical education. As little is 
known about deliberate CMSs in medical education (or practice), and deliberate CMSs can lead to virtual CoPs, a better understanding of the ORSP SCR is important as it could be a strategy for creating virtual CoPs.

The ORSP SCR will thus be the unit of analysis for this intrinsic case study. The case study research design will be used to answer the following research questions:

1. What is the impact on learners when a deliberate CMS like the SCR is used to deliver the rural medical education experience?

2. What is the nature of ORSP student experiences participating in the SCR? Both research questions aim at providing a better understanding of a deliberate CMS in a rural medical education setting. This better understanding may ultimately provide guidance on how to create virtual CoPs in rural practice, thus assisting in reducing the shortage of rural physicians in the United States.

\section{Background to Study}

The OHSU School of Medicine has a long standing commitment to rural medical education in the form of its third-year rural clerkship rotation. In most US medical schools, medical students spend their first and second years devoted primarily to their "basic science" curriculum. The basic science curriculum is traditionally delivered in a classroom environment, with students spending most of their time attending lectures and taking exams. During the third and fourth years of medical school, students leave the classroom and take part in their clinical clerkship curriculum. During clinical clerkships medical students "rotate" through various clerkships that are usually associated with a medical specialty (Surgery, Internal Medicine, Psychiatry, etc.). At OHSU, third and fourth-year MD students have five-week clerkship rotations, with required clerkships 
taking place during the third year and elective clerkships taking place during the fourth year.

At OHSU, the Rural and Community Health Clerkship is a required third-year rotation, (Family Medicine, Surgery, Psychiatry, Medicine, Pediatrics and OB-GYN are the other required rotations). This means that every medical student at OHSU (currently 130 students per class) has a required rural experience. Linda Day, $\mathrm{MD}^{2}$, is the clerkship director for the rural rotation, and is in charge of the administration and curriculum for the rural clerkship.

Four years ago Dr. Day was awarded a Health Resources and Services Administration (HRSA) federal grant to develop a more intensive rural rotation experience for select, high achieving OHSU medical students that expressed a strong interest in rural practice. Dr. Day named this the "Oregon Rural Scholars Program: (ORSP). Participation in the ORSP program continues to be competitive, with students selected based on their academic performances, independence and, most of all, their motivation to practice in rural areas.

Students selected for the ORSP program spend approximately a third of their clinical training year in frontier and remote rural locations, supervised by communitybased physicians (See Figure 1.1 for example of a past ORSP cohort's rural locations). While non-ORSP medical students spend only five weeks in a rural location, ORSP student can spend up to fourteen weeks at their rural locations. The increased time in a rural location is intended to give ORSP students a greater breadth of rural practice skills

\footnotetext{
${ }^{2}$ Linda Day is a pseudonym used to protect the identity of the study participant. A list of all pseudonyms used in this study is provided in Chapter Four.
} 
as well as encourage their affinity for rural practice. In short, whereas all OHSU students get a brief sample of what it is like to be a rural practitioner, ORSP students get to live the life of a rural physician over the course of their up-to-fourteen week experiences.

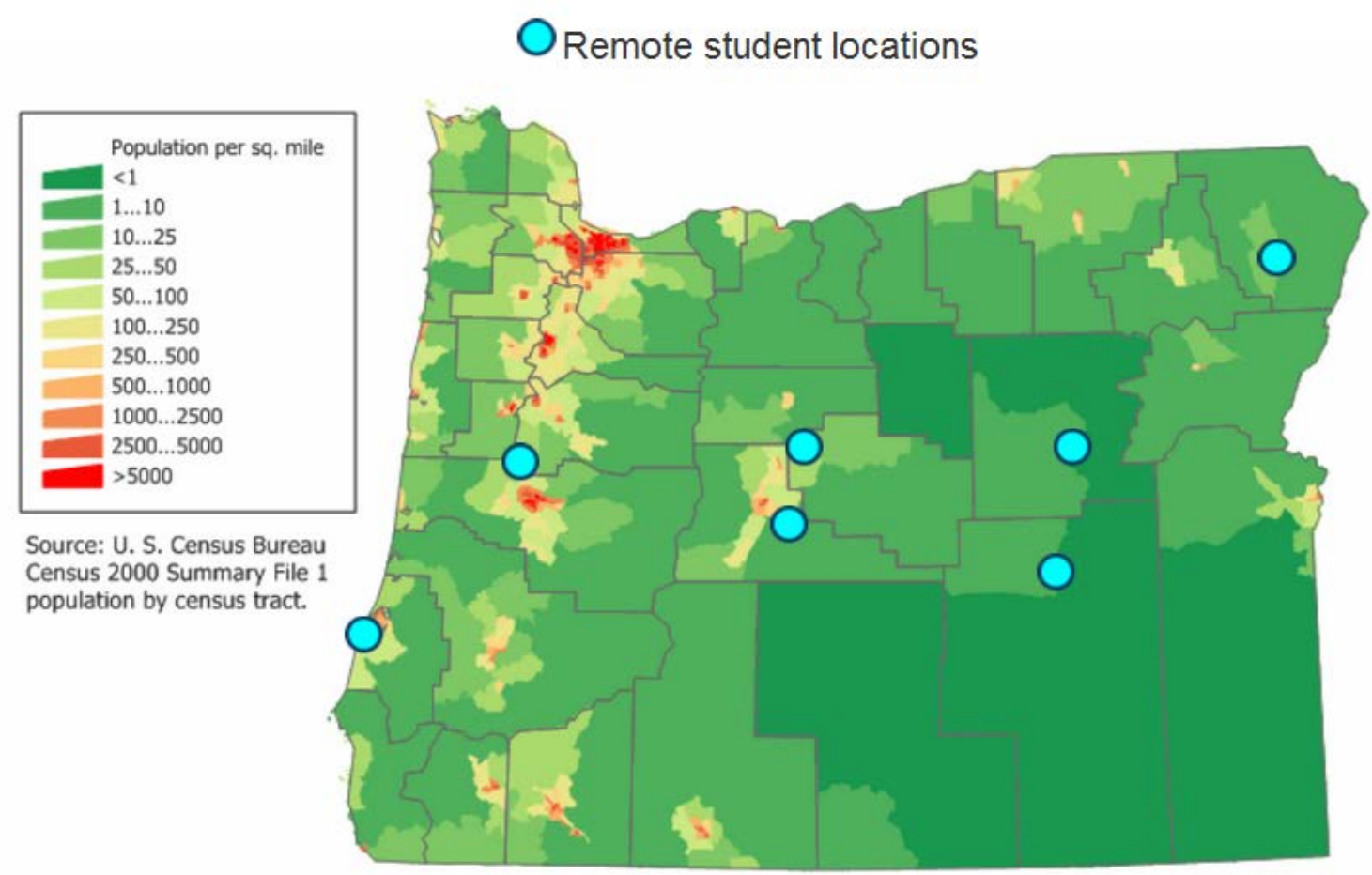

Figure 1.1: Rural locations of past ORSP cohort overlaid on population map of Oregon. There is one learner at a time per location.

The logistical implication of increasing a third-year medical student's time in a rural area means extending their rural rotation beyond the normal five-week clinical rotation schedule. As already discussed, Family Medicine as a specialty is closely linked with rural practice so students in the ORSP program combine their rural rotation and their Family Medicine rotation, effectively keeping the ORSP student in the same rural location for ten consecutive weeks (ORSP students also have the option to incorporate 
elective time into their experience, further extending their time in their rural location an additional four weeks). Figure 1.2 compares a typical third-year medical student's clerkship rotation schedule with that of an ORSP student.

\section{3rd Year Clerkship Rotations}

- Normal 3rd year student

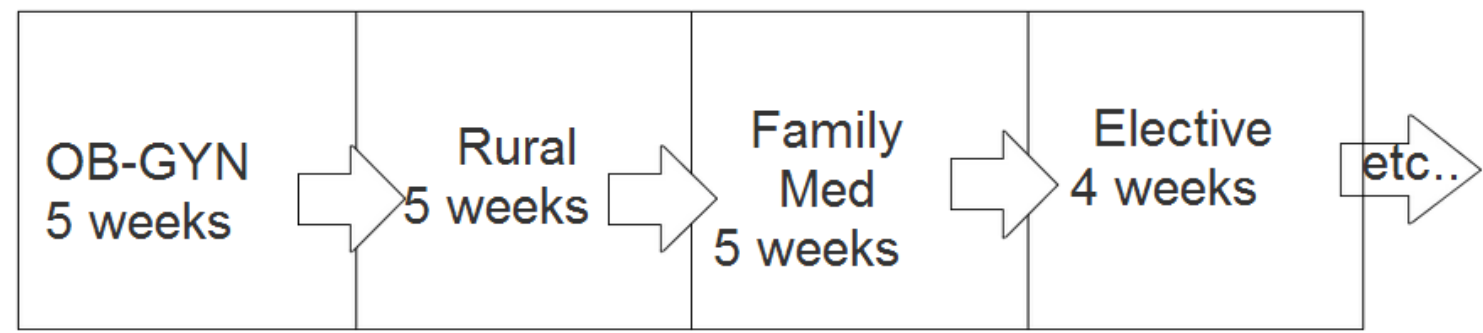

- ORSP student

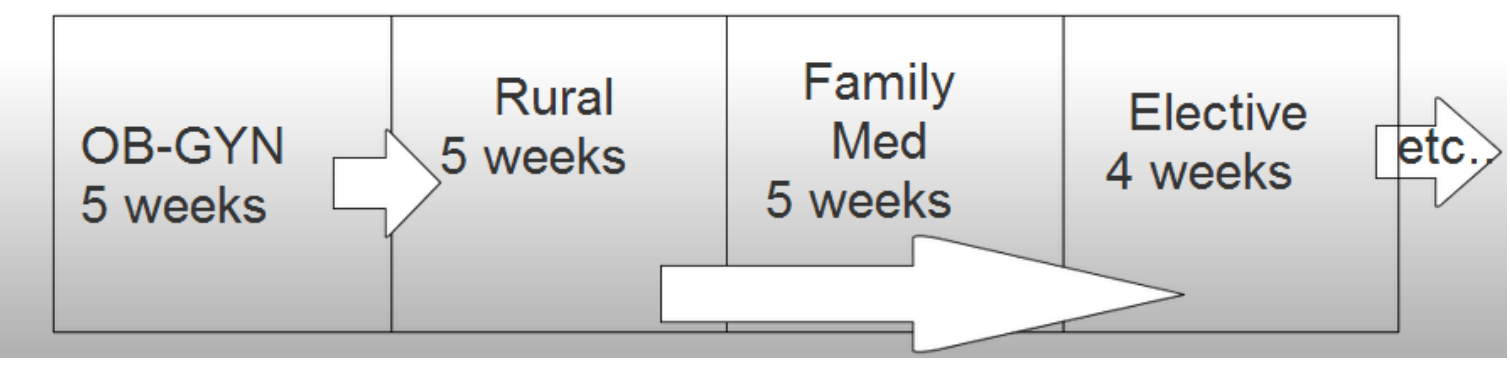

Figure 1.2: Normal third year medical student clerkship rotation compared to ORSP student rotation. Each arrow indicates a change in student location.

Having ORSP students satisfy their Family Medicine rotation at a rural location poses several logistical challenges. Namely, the Family Medicine clerkship takes place on the OHSU campus yet ORSP students must somehow participate in the required rotation learning activities remotely. Accreditation requirements specify that students participating in a required curriculum away from the home campus must receive a curricular equivalent to the curriculum received by students participating at the home 
campus. Thus, the ORSP program provides a unique challenge in that the traditionally on-campus Family Medicine curricular activities need to be delivered to remote, offcampus ORSP students in an equivalent fashion. Failure to deliver content in a curricular equivalent fashion could potentially jeopardize accreditation for the OHSU School of Medicine. Therefore, crafting a curricular equivalent Family Medicine experience for the ORSP program was of paramount importance when developing the program.

In March of 2009, I was brought onto the ORSP grant by Dr. Day to assist in converting the Family Medicine curriculum so that it could be accessed remotely by ORSP students in a curricular-equivalent fashion. Dr. Day and I had developed a close professional relationship through curricular collaboration on another course at OHSU. Dr. Day knew I had an interest in distance education and Internet technology and asked me to be her distance-learning director for the ORSP program. I was tasked with developing the technological infrastructure for the program as well as providing technical and instructional support during the ORSP rotations. Our time frame was relatively tight, with the first ORSP students going out into the field on July 1, 2009.

A few key assumptions played heavily into how the ORSP technology infrastructure was constructed. One was that the limited technology budget $(\$ 10,000)$ necessitated our solution be inexpensive. Another assumption was that the technology had to be relatively simple so students could easily access their coursework while in the field. Additionally, I am not an IT specialist and did not want to create a complex system I could not adequately support, therefore the technology we used needed to be "out of the box" rather than proprietary. Finally, we wanted to counteract the feelings of professional isolation inherent to rural practice by giving students a way to consistently access the 
Internet at their rural location, something that was often not available previously to students due to the often highly remote locations of their rural rotation sites.

Briefly, to keep costs down, technology simple and ORSP students connected I created a system that relied on inexpensive hardware in the form of netbook computers. Netbooks are stripped down mini laptops that are surprisingly capable and cost less than \$350 apiece. In addition to a netbook computer, each ORSP student receives a mobile broadband modem, also called an aircard (See Figure 1.3 for a visual example of a netbook and an aircard). Aircards use cell phone "3G" data connections to access the Internet at fast broadband speeds so that an ORSP student has access to the Internet whenever she is in range of a $3 \mathrm{G}$ equipped cell phone tower (this is the exact same process a smartphone uses to access the Internet). Thus, ORSP students are issued a Verizon 3G aircard and are able to get speedy, reliable access to the Internet in some of the most remote parts of Oregon. 


\section{Student Equipment}
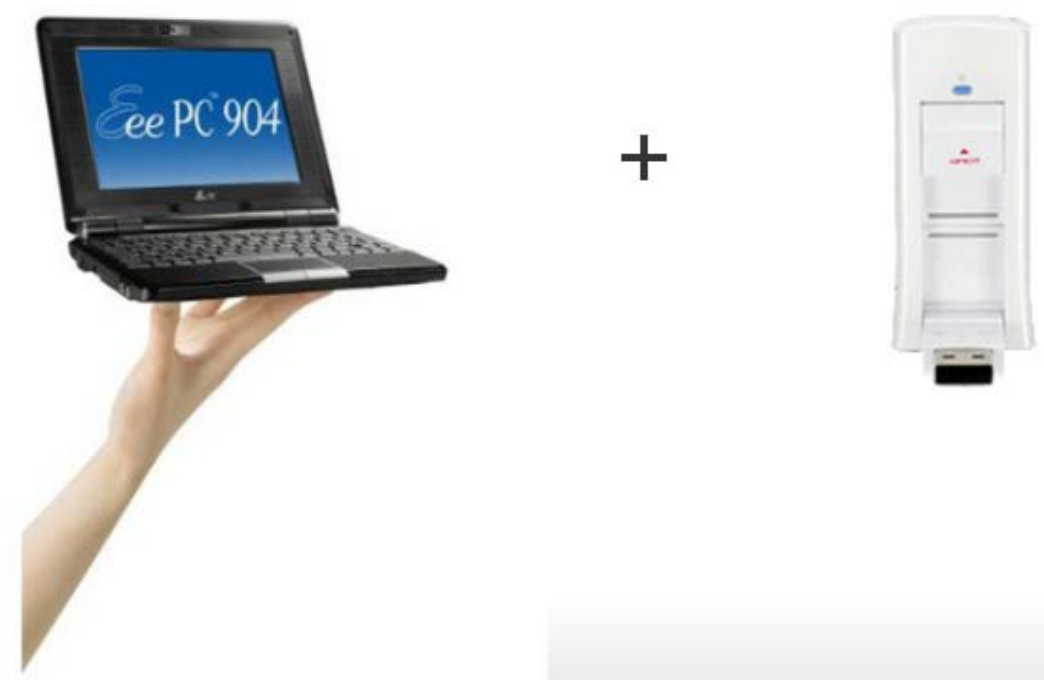

Figure 1.3: ORSP student equipment: Netbook and Verizon enabled 3G data modem (aircard).

The ORSP technology infrastructure is leveraged to give ORSP students the curricular equivalent of their Family Medicine rotations while in their rural setting. As the vast majority of the Family Medicine clerkship curriculum takes place in clinical settings, ORSP students gain most of their "curricular equivalency" at their rural locations through the hours they spend in clinical practice. However, in addition to clinical work, the Family Medicine clerkship curriculum consists of a five-week lecture series, an essay/reflection assignment, a written exam, a clinical skills exam (OSCE), a simulated electronic health record (EHR) training session, and a group learning activity called a the SCR (see Figure 1.4 for the Family Medicine clerkship curricular 
breakdown). All activities except for the SCR and simulated EHR activities are made asynchronously available online to rural students, meaning students can satisfy the requirements of these components of the curriculum on their own time. For example, lectures are recorded and posted on the clerkship web site for ORSP students to watch on their own time and exams are proctored at the rural location when it is convenient for the student and the proctor.

\section{FM Clerkship Curriculum Components}

Students are in clinic all but one day a week (Thursdays)

- Thursday Mornings

o Lectures (every week)

o OSCE (1 time event)

o Final Exam (1 time event)

\section{- Thursday Afternoons}
o 4 SCRs
o 1 simulated EHR training session

Figure 1.4: Curricular components of the OHSU Family Medicine Clerkship

On the other hand, the SCR and the EHR simulation debriefing are synchronous activities in which students must participate in "real time" in order to experience curricular equivalents to on-campus activities (as the SCR is the unit of analysis for this case study, the EHR simulation activity will not be discussed or analyzed). Therefore, six to eight ORSP learners, all of whom are individually placed at remote, rural sites across Oregon, must "meet" in real time as a group online in a curricular equivalent 
fashion. The challenge of coordinating such a meeting becomes evident when one better understands what the SCR activity entails.

The SCR. The theoretical underpinning of the SCR activity is social constructivism (Galloway, 2001; Vygotsky \& Cole, 1978). Briefly, a social constructivist learning environment is one that honors multiple perspectives of reality ("Social Constructivist Theories,” n.d.). Constructivists believe that reality is constructed through human activity. Members of a society together invent the properties of the world. According to Kukla (as cited in Kim, 2001) "For the social constructivist, reality cannot be discovered: it does not exist prior to its social invention” (Assumptions of Social Constructivism section, para. 2). Thus, in a social constructivist learning activity knowledge creation is a social, interactive phenomenon among learners.

Each week for the SCR activity, three to four students prepare a presentation of a clinical case they have observed in clinic to present to their peers and faculty facilitator (the faculty facilitator remains with the same SCR group for the entire clerkship rotation). There are four SCR activities during the five-week rotation (the fifth week is the simulated EHR training session that will not be included in this study). The SCR takes place for approximately two hours once a week, with each student completing a total of three SCR presentations during the rotation.

The SCR mirrors the common physician convention of teaching rounds. Teaching rounds are informal meetings held regularly by clinicians in which specific problems in patient care as well as case presentations of patients with specific conditions are discussed (Free Online Medical Dictionary, Thesaurus and Encyclopedia (n.d.). Similar to in-person teaching rounds, ORSP students presenting an SCR are instructed to make 
their presentations interactive, with the presenter continuously querying his peers about next steps in the diagnostic process (Students do this by asking their peers questions such as "What are you thinking now about the patient?," "Any ideas what the next step in diagnosis is," "Any questions I may have missed that you would ask?,"' etc.) The faculty group leader is a facilitator of learning in the process, interjecting coaching, probing questions, and reflective feedback during the presentation process. In short, the SCR supports a social constructivist learning environment so there is no "right" answer except for that one determined by the group.

The highly interactive nature of the SCR works well in a face-to-face classroom environment. It is much more difficult, however, to replicate the SCR activity in an online environment so that it is the curricular equivalent of the in-person activity. To add further complexity, the budgetary and logistical realities of the ORSP do not allow for expensive video-conferencing hardware and software solutions to bring learners together for the online SCRs. Instead, we have crafted a solution that allows ORSP students to fully interact with both video and voice, guide peers through PowerPoint presentations, and even share their computer desktops- all from their ORSP issued netbooks and 3G aircards. This is all done using the Internet-based Adobe Connect software, which is more generally known as a "synchronous online space."

A synchronous online space as used in an educational setting is one in which learners and instructors participate in a “real time” online environment (DeMaria \& Bongiovianni, 2010; McBrien, Cheng, \& Jones, 2009). Participants are able to communicate via one or more combinations of live video, Internet enabled telephony (i.e. VOIP), live chat, etc.. Synchronous online spaces are software enabled, with some 
software examples being Adobe Connect, Elluminate Live!, and Google Hangouts. As learners need to "meet” in real time for the SCR activity, a synchronous online space is necessary to create a curricular-equivalent experience. The Adobe Connect software is used as the ORSP synchronous online space because OHSU has an institutional contract for the software and thus access to an Adobe Connect meeting room is inexpensive (See Figure 1.5 for example of an SCR activity in the Adobe Connect meeting room).

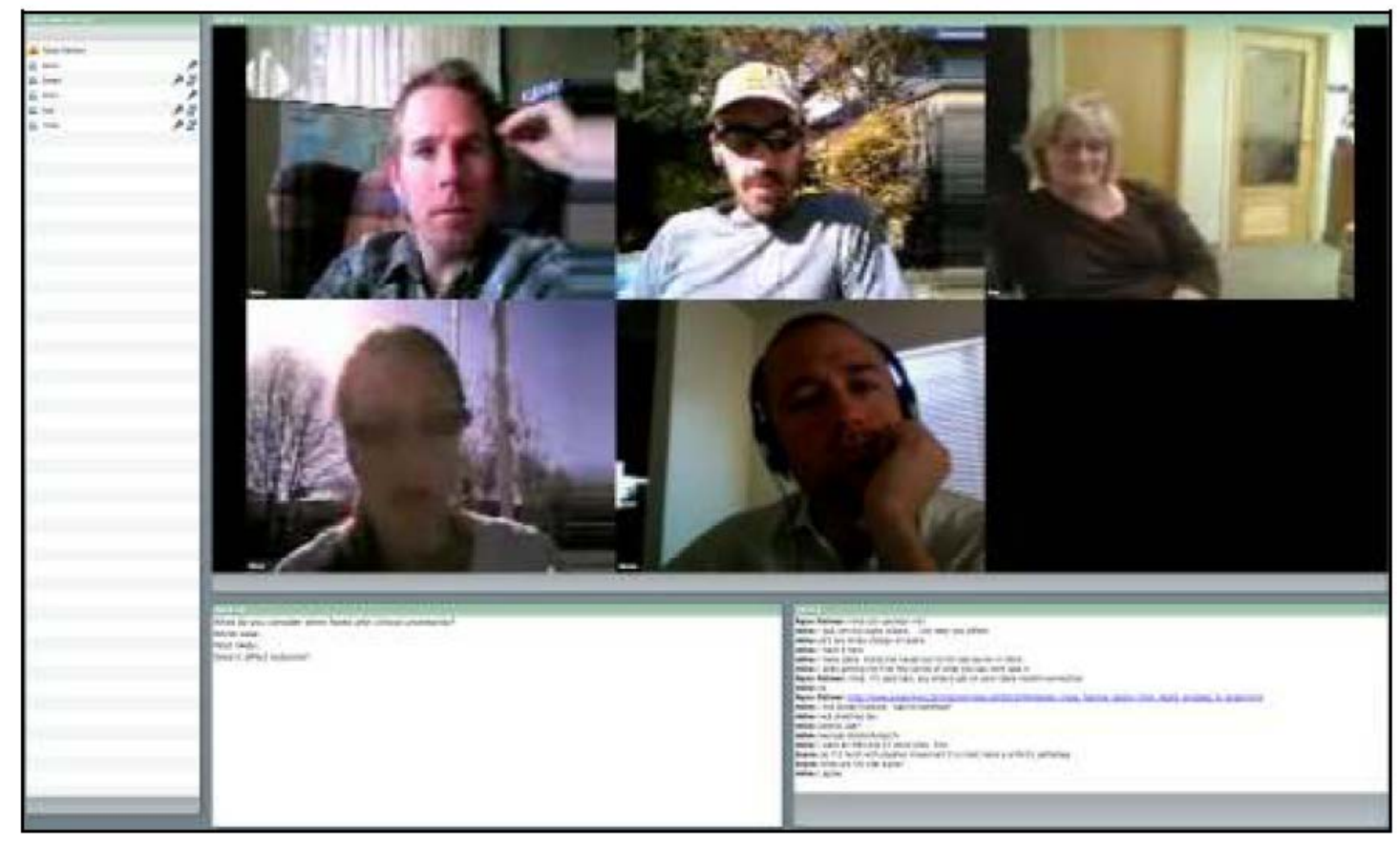

Figure 1.5: Typical ORSP SCR activity layout with 4 students and one faculty member in the Adobe Connect meeting room. The meeting room operator is also present though his webcam is not enabled (individuals pictured are not participants in this study and have given permission to use their images).

Since the ORSP program officially launched in July of 2009, the ORSP has gone through many iterations of the SCR activity setup, with continual adjustments made in order to minimize technical issues and create a feeling of connectedness among students participating in the activity. We have now reached a place where the ORSP SCR runs 
smoothly with few-to-no technical glitches distracting from the educational experience. Indeed, we have created a unique and- due to its simplicity and cost effectivenessscalable solution to effectively implementing a deliberate CMS in a rural medical education program (Palmer \& Dodson, 2011). Indeed, there are currently no other known US rural medical education programs that utilize a deliberate CMS to the same extent as does the ORSP (D. Kolva, personal communication, May 08, 2012; L. Day, personal communication, November 4, 2011; M. Blackburn, personal communication, May 09, 2012; M. Kennedy, personal communication, May 10, 2012).

The novelty of the ORSP program's use of a deliberate CMS in the form of the SCR warrants the case study exploration that takes place in this dissertation. Again, the ORSP uses a deliberate CMS to robustly connect spatially dispersed rural learners to one another. As virtual CoPs emerge from deliberate CMSs, the online SCR may provide a critically important opportunity to better understand how virtual CoPs can emerge from deliberate CMSs in a rural medical education/practice context. This case study will explore in depth the impact and experience of the ORSP SCR on one cohort of learners, with the hope that, through a better understanding of the ORSP SCR, there may also be a better understanding of virtual CoP emergence in rural education and practice settings.

\section{Introduction to Study Design}

In this study, I will use an intrinsic case study design to explore the following two research questions:

1. What is the impact on learners when a deliberate CMS like the SCR is used to deliver the rural medical education experience?

2. What is the nature of ORSP student experiences participating in the SCR? 
Video recordings of SCR sessions will be coded to answer research question one and interviews and field notes will be coded to answer research question two. Research question one will utilize the Community of Inquiry (CoI) framework (Garrison, Anderson, \& Archer, 2000) as both a theoretical and research lens, using the predetermined CoI coding structure to code the four SCR sessions analyzed for this study. Briefly, the CoI framework has served as a prevalent, well researched model for exploring what happens in deliberate CMSs, primarily in the form of online higher education courses. A detailed explanation of the CoI framework will take place in Chapter Two. For research question two, interviews with ORSP students will explore the student experience of having participated in the SCR. Additionally, participant observer field notes will be analyzed as another data source to explore research question two. Both research questions will contribute to a better understanding of how using a deliberate CMS in a rural medical education experience may help give future rural physicians the skills needed to create virtual CoPs in practice, thus contributing to the likelihood these physicians may persist in rural practice.

\section{Delimitations}

There are a few key delimitations to this study. First, the intrinsic case study design of the study makes the ability to generalize the study's findings challenging. Additionally, the ORSP program is unique to OHSU and to Oregon, also limiting the ability to generalize this study's findings. However, the aim of qualitative research is not necessarily to create findings that are intended to be generalized (Creswell, 2007; Marshall \& Rossman, 2011) and therefore the implications of this dissertation will 
hopefully create more questions than answers, thus motivating further lines of inquiry into what is an important subject matter. 


\section{CHAPTER TWO}

\section{Literature Review}

Chapter Two of this dissertation will focus on a detailed review of the literature. This literature review will be divided into two sections. The first section will delve deeper into the problem in practice through a discussion of CoPs (Wenger, 1999) and their importance to the physician profession. The difficulty of creating virtual CoPs will be discussed as well as the connection between CoPs and deliberate CMSs. These concepts will be connected back to the SCR activity to emphasize the importance of exploring the SCR to better understand the use of a deliberate CMS in a rural medical education program.

The second section of the literature review will provide an in-depth review of the Community of Inquiry (COI) theoretical framework, which will serve as the theoretical lens by which the SCR activity is explored in this case study.

\section{Problem in Practice: Rural Physician Shortage- A Community of Practice Crisis}

Oregon is primarily a rural state. With one major metropolitan area (Portland), the majority of the state exists and a significant portion of the population live in rural, remote areas. Though definitions vary, the US census classifies approximately 99\% of the land in Oregon and a third of the population as rural (Crandall \& Weber, 2005). As of 2010, 852,523 of Oregon's 3,831,074 citizens were classified as living in rural areas. Some of the land in Oregon is so sparsely populated that it is classified as "frontier" by the Federal Government (Crandall \& Weber, 2005). Therefore the extreme shortage of physicians in rural America (Rabinowitz et al., 2008) discussed in Chapter One affects Oregon acutely. 
One strategy to alleviate the rural practitioner shortage problem is through medical education. The literature indicates medical students that study in rural areas are more likely to return to those areas to practice (Morris \& Chen, 2009; Morris et al., 2008; Woloschuk \& Tarrant, 2002). One such program of study is the ORSP.

While rural medical education programs like the ORSP experientially immerse medical students in the world of the rural physician, they do not necessarily address a primary deterrent to practicing in a rural area: lack of professional community. As previously stated, professional isolation is a deterrent for physicians to practice or continue to practice in rural areas (Whitcomb, 2005). According to Whitcomb (2005) rural physicians often leave their rural practice after a few years "because they feel isolated professionally, they worry about finding themselves in medical situations they are unable to manage, and they are unable to take time away from their practices to pursue continuing medical education opportunities" (2005, p. 715). In this light, the community that rural physicians often lack can be defined as a Community of Practice (CoP) (Wenger, 1999).

Communities of Practice. CoPs are defined as "groups of people who share a concern or a passion for something they do and learn how to do it better as they interact regularly" (Wenger, 2006. 2nd text box). Wenger identifies three critical characteristics that constitute a CoP. The first is domain. A CoP differentiates itself in that its members share a common domain of interest. Membership in a CoP "implies a commitment to the domain, and therefore a shared competence that distinguishes members from other people" (Wenger, 2006, Domain section, para. 1). The second characteristic of a CoP is community. Members of a domain engage in joint activities and discussions, help each 
other, and share information. Their relationships enable them to learn from one another (Wenger, 2006). The third and final characteristic of a CoP is practice. Individuals meeting around a shared interest is not enough to constitute a CoP. Rather, members of a CoP must be practitioners. These practitioners "develop a shared repertoire of resources: experiences, stories, tools, ways of addressing recurring problems-in short a shared practice. This takes time and sustained interaction" (Wenger, 2006, Practice section). CoPs among physicians are common. Typical professional activities of the physician profession, such as journal clubs, continuing medical education, quality improvement efforts and grand rounds, are all shared activities of physician CoPs (Confessore, 1997; Parboosingh, 2002). Even seemingly simple acts of professional physician collegiality help to reinforce physician CoPs. "Physicians who, for instance, meet regularly for lunch may not realize that their discussions are a main source of their knowledge about how to care for patients" (Parboosingh, 2002, p. 231).

Yet while institutional and social conventions of being a physician reinforce physician CoPs, these CoPs are primarily held in person. Continuing medical education classes, grand rounds, journal clubs, etc. all traditionally take place with a group of physicians in the same room at the same time. Thus, a rural practitioner, cut off from her professional colleagues, is deprived of the common face-to-face interactions vital to sustaining CoPs that are readily available to physicians in more populated locations. Advances in technology and Internet videoconferencing software (e.g. Skype) make connecting with others easy and inexpensive. Therefore, an important question to ask is if this Internet technology can be leveraged to create a "virtual" CoP among physicians that are geographically separated from one another. If so, then rural physicians 
could potentially transcend isolation due to distance with a virtual CoP, thus helping to alleviate one of the primary deterrents to practicing in rural areas.

Virtual CoPs. The literature indicates CoPs are not necessarily dependent on geographical location and can, theoretically, occur virtually as well as face-to-face. This is because the focus of a $\mathrm{CoP}$ is on learning and knowledge production (C. Johnson, 2001; Wenger, 1999), two qualities independent of concurrent geographical location. According to Wenger (1999), learning is a social activity and therefore CoPs can emerge from participation in shared activities. Therefore, the act of learning is more important in the formation of a CoP than the physicality of location. Indeed, it seems altogether reasonable to believe that technological innovations can create distributed learning environments that can potentially lead to CoP formation. According to Wenger (2006) :

New technologies such as the Internet have extended the reach of our interactions beyond the geographical limitations of traditional communities, but the increase in flow of information does not obviate the need for community. In fact, it expands the possibilities for community and calls for new kinds of communities based on shared practice. (Web section)

To connect back to the problem in practice, if CoPs can be created virtually then it seems critically important to the professional wellbeing of rural physicians to incorporate robust virtual CoPs into the context of their rural practices. Virtual CoPs may help alleviate feelings of professional isolation felt among rural practitioners, and in so doing increase the likelihood the physicians will persist in their rural practices. Ultimately, this scenario could help address the shortage of rural physicians in the US. If rural medical education experiences increase the likelihood medical students will go into rural practice, 
it seems important in such programs to teach future rural physicians the importance of utilizing virtual CoPs while in rural practice, as well as the skill set needed to create them in a rural practice context.

Yet while creating virtual CoPs is theoretically possible, skepticism remains in the literature regarding the reality of being able to actually do so. Kimble \& Hildreth (2004) directly question the practicality of implementing a CoP in a virtual space. This skepticism is supported by Lueg (2000) in his analysis of three case studies involving the formation of virtual CoPs. Lueg (2000) concludes that the definition of CoPs is largely based on situated, real-world learning and that moving a CoP to a virtual space brings up a new set of issues given the change in environment. Specifically, Lueg (2000) argues that what is often mistaken in the literature as a virtual CoP is in fact a deliberate CMS.

A deliberate CMS is different than a traditional community in that traditional communities are usually defined by place and have norm based membership. In contrast a deliberate CMS exists in relation to an idea or a task rather than a place (Johnson, 2001). Thus, individuals in a deliberate CMS organize online around a shared interest, task or activity whereas members of a traditional community, like a neighborhood, are organized around a place and usually attended in person. Therefore, it can be said that deliberate CMSs have a certain degree of intentionality about them as members intentionally choose what ideas and tasks to organize around as opposed to a traditional community, where a factor like the location of one's home can determine the community one lives in.

It is the intentionality of a deliberate CMS that creates difficulties when applying the concept of a CoP to a virtual space. CoPs emerge out of work-related practices and traditions, and as such are emergent rather than intentionally created. For example, two 
physicians meeting for lunch every week are not doing so because they have intentionally set up a CoP, they are doing so because meeting for lunch is a tradition they share as colleagues. The knowledge creation that emerges from these lunch meetings is the result of the CoP that emerges from the weekly lunch meetings. Thus, CoPs can be viewed as emergent phenomena while deliberate CMSs are intentionally created. Further, whereas unintentional spontaneous interactions in face-to-face situations may naturally give rise to a CoP, there is always an intentional "first step" when trying to create a CoP virtually, and that first step is a deliberate CMS. Another way to view this is when one attempts to create a virtual CoP, one is actually creating a deliberate CMS. This is because the group members are intentionally organizing online around a task, which happens to be the creation of a CoP; however, in doing so they are actually fulfilling the very definition of a deliberate CMS. A virtual CoP may arise from the deliberate CMS, but the deliberate CMS must precede it. Therefore, attempts to create virtual CoPs alone are misguided: instead a deliberate CMS must be the first step.

Schwen \& Hara (2003) highlight the difficulty of creating virtual CoPs. The authors look at four case studies in which attempts were made to create virtual CoPs in various settings, including consulting and legal firms. The authors find significant issues associated with the deliberate attempts to set up CoPs virtually. Schwen \& Hara (2003) conclude "communities of practice are about content—about learning as a living experience of negotiating meaning - not about form. In this sense they cannot be legislated into existence or defined by decree. They can be recognized, supported, encouraged, and nurtured, but they are not designable reified units" (p. 262). 
Johnson's (2001) review of the CoP literature further supports Schwen and Hara's (2003) conclusions. Johnson (2001) states that a virtual or organizational community (which I refer to in this study as a deliberate CMS) is the designed community and that the CoP emerges from the designed community. To this conclusion, Johnson (2001) states "legitimate task-oriented reasons need to exist for the community of practice to emerge in the first place. Simply setting up a virtual community infrastructure without this premise will not automatically cause a community of practice to form" (p. 53). CoPs can form from deliberate CMSs, but "scaffolding is necessary" (Johnson, 2001, p. 53). Johnson's (2001) conclusions serve as further support that the creation of virtual CoPs is an indirect process. A deliberate CMS must be created first to create the context from which a virtual CoP can arise.

Summary of problem in practice literature review. If CoPs cannot be intentionally created, but rather emerge from deliberate CMSs, then it would seem that rural physicians should first focus on the creation of robust deliberate CMSs with the hopes that CoPs emerge from them. Myriad Internet-based technological solutions could be leveraged by the rural physician to create deliberate CMSs (e.g. Facebook closed group, proctored email listserve, etc.). From these deliberate CMSs, virtual CoPs could form, giving the rural physician the professional community she needs and was denied previously due to geographical distance.

It would seem important, then, in rural medical education immersion programs that students have the experience of a deliberate CMS within the context of their rural practice experience. Students that experience a deliberate CMS can potentially bring this experiential knowledge with them to their future rural medical practices. Rural physicians 
engaging in deliberate CMSs are then potentially more likely to form emergent virtual CoPs, thus alleviating professional isolation.

As discussed in Chapter One, ORSP students do engage in a deliberate CMS. Recall that a deliberate CMS is a type of online community where individuals organize online around a shared interest, task, or activity (Johnson, 2001). With ORSP students, the activity that constitutes the deliberate CMS is the SCR. Also recall that the ORSP's use of a deliberate CMS is novel among US medical schools (D. Kolva, personal communication, May 08, 2012; May 10, 2012; M. Blackburn, personal communication, May 09, 2012; M. Kennedy, personal communication). It is therefore important to better understand what is happening within this SCR activity. This may lead to a deeper understanding of a phenomenon that could help rural physicians become more capable of creating deliberate CMSs while in practice, thus creating the context for emergent virtual CoPs. Rural physicians engaged in virtual CoPs may ultimately gain the professional community they have traditionally lacked, thus increasing the likelihood they may persist in rural practice. Additionally, a better understanding of the ORSP's approach may establish a "best practice" use of a deliberate CMS, which could assist other rural medical programs to implement similar approaches, further increasing the chance of the formation of virtual CoPs among future rural physicians.

I have now presented why the SCR activity is important to explore as a deliberate CMS. It is novel first step towards creating a virtual CoP, the study of which warrants a case study design. To explore the SCR activity, it is necessary to identify a theoretical framework for describing what is happening within the deliberate CMS. Such a 
framework is the Community of Inquiry (CoI) (Garrison et al., 2000) and will be the focus of the second part of this literature review.

\section{Theoretical Framework: Community of Inquiry Literature Review}

The CoI framework serves two functions in this study. The first is that CoI serves as the theoretical lens through which to explore what is the impact of the ORPS SCR activity on a group of learners. The second function of CoI is to serve as the research framework for this study by offering a coding scheme for SCR observations. Details on the research framework of CoI will be discussed in Chapter Three.

CoI is used as the theoretical framework for this study because:

1. It is one of the most well researched and utilized frameworks for examining deliberate CMSs in the form of online coursework and therefore is reasonable to apply to this study's exploration of the SCR activity.

2. The CoI framework is rooted in social constructivist learning theory. As the SCR learning activity is also rooted in social constructivism, it makes sense to use CoI to analyze the SCR.

3. As the name indicates, the CoI framework focuses on online community. The SCR activity is a deliberate CMS that requires online community, thus a framework based on online community is an appropriate lens for this study.

The next portion of this literature review will delve deeper into the CoI framework. A general explanation of the CoI framework will be given, including key 
theoretical underpinnings of the model. Research key to validating the model, including criticism, will also be discussed.

\section{Community of Inquiry}

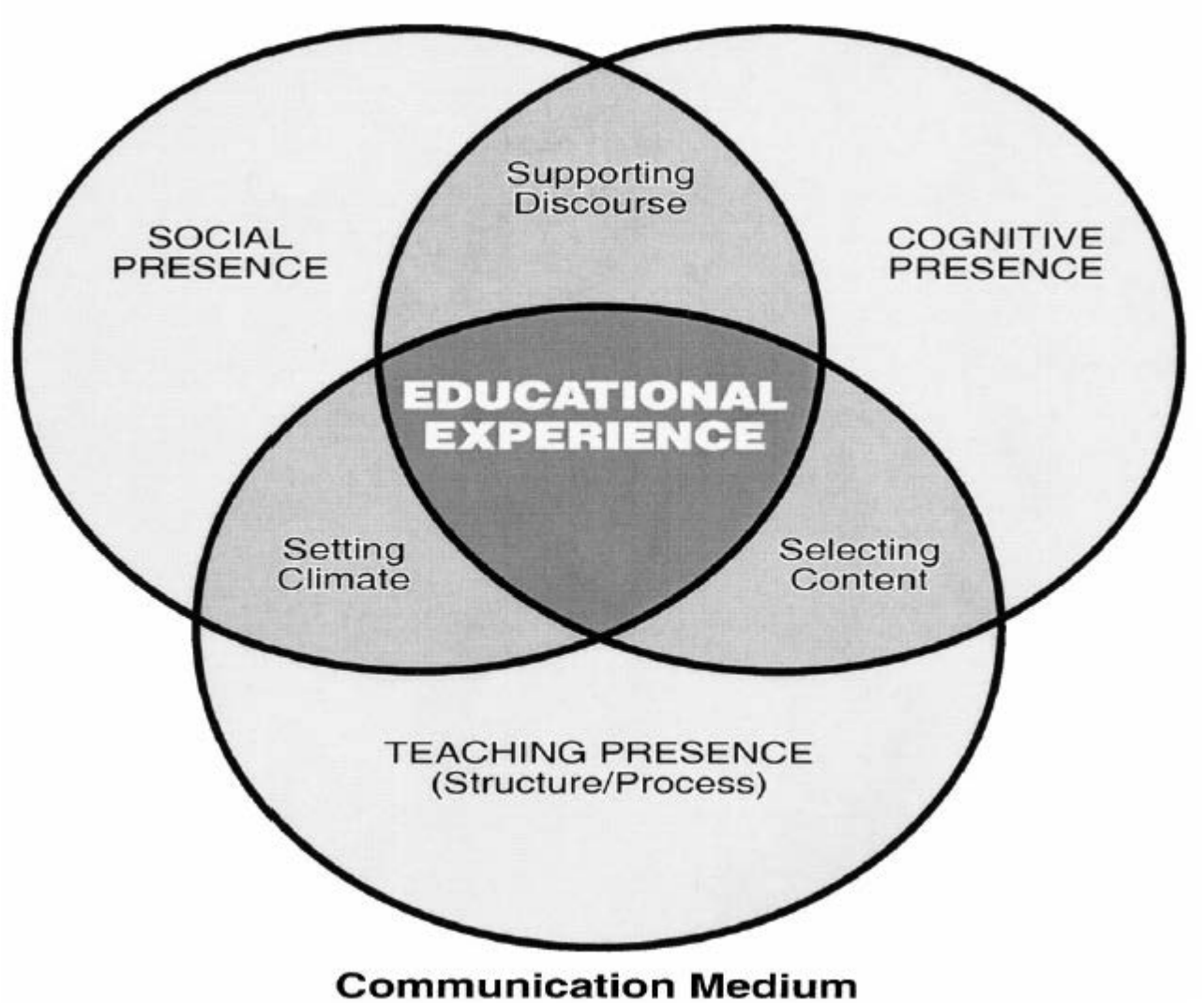

Figure 2.1: The Community of Inquiry Framework (Garrison et al., 2000, p. 88).

Background to the Community of Inquiry framework. The CoI theoretical

framework (see Figure 2.1 for a visual representation of the CoI framework) is based on constructivist learning theory ( Garrison et al., 2000; Garrison, 2011; Garrison, 2009). The type of constructivism best associated with CoI is the social constructivism of Vygotsky (Vygotsky \& Cole, 1978). In his examination of interaction and children's learning, Vygotsky (1978) argued that problem solving under adult guidance or by 
collaborating with more capable peers contributed to learning and independent problem solving. Though the focus of Vygotsky's research was with children, his findings have been widely applied to adult learning. From this application it can be said that learning occurs as an interactive, social process with peers, hence the term "social constructivism"(Galloway, 2001).

Social constructivism has grown in popularity as a pedagogical framework for online learning as it creates the framework for a higher level of critical thinking in a medium that has multiple means of communication, such as chat, blogs, forums, etc. (So \& Brush, 2008). As social constructivism is a collaborative, interactive concept, applying it to an online learning environment also helps create a shared sense of learner community by peers required to interact to create knowledge (Garrison, 2011). Dickey (2004) recommends a social constructivist framework to all online learning course designs in order to reduce the feelings of isolation among learners. Thus, one can say that social constructivism as a pedagogy helps to reduce feelings of e-learner isolation by creating a shared sense of community among spatially dispersed learners. Additionally, So \& Brush (2008) find that students that perceive high levels of collaborative learning report a higher level of satisfaction with their online learning courses.

Social constructivism and the CoI framework. The genesis of the CoI framework can be attributed to Garrison et. al (2000). At the time of the CoI model's creation, online learning was growing in popularity due to the rising accessibility to the Internet. The CoI framework arose from the need to provide a theoretical framework for education researchers interested in studying the phenomenon of online learning (recall that online coursework is a form of a deliberate CMS). Garrison et. al (2000) describe the 
CoI framework as "a template or tool for researchers to analyze written transcripts, as well as a guide to educators for the optimal use of computer conferencing as a medium to facilitate an educational transaction" (p. 87). A "worthwhile educational experience" (Garrison et al., 2000, p. 88) occurs in online learning if three elements are present in the deliberate CMS: Teaching presence, Social presence and Cognitive presence. With all three presences active, Garrison et. al (2000) posit that deep, meaningful learning consistent with constructivist learning outcomes results (Garrison, 2011). As social knowledge creation is the focus of the CoI framework, CoI is a process, rather than outcome, based model (Akyol et al., 2009). In other words, the CoI model detects those elements Garrison et al. (2000) theorize are essential in an online course for higher order, constructivist learning to occur. CoI does not predict if learning will occur but rather suggests that the context is present for social constructivist learning to emerge in the online environment.

The CoI framework has become one of the most popular theoretical tools for researching higher education online coursework. The germinal publication on CoI (Garrison et al., 2000) is the most highly cited article ever in The Internet and Higher Education (Garrison \& Arbaugh, 2007). Numerous educational studies and doctoral and master's theses have utilized the CoI model as their theoretical framework as well as the instrument of their research (Rourke \& Kanuka, 2009). As such, CoI stands as one of the most well validated and utilized models for researching online learning.

Constructs of the Community of Inquiry framework. I will now explore in greater detail the three main constructs of the CoI framework: Cognitive, Social and 
Teaching presence. For each, I will begin by discussing the theoretical foundations that give rise to each presence followed by a description of the CoI presence itself.

\section{Cognitive Presence.}

Theoretical background. While Vygotsky's (Vygotsky \& Cole, 1978) social constructivism serves as the underlying framework for the CoI model in general, Dewey's (1910) ideas for critical reflection underlie the Cognitive presence construct in particular. Dewey (1910) believed that critical thinking deepened the meaning of a learner's experience and therefore should be a core educational aim. Critical thinking "both authenticates existing knowledge and generates new knowledge which suggests an intimate connection with education"(Garrison, 2011, p. 43). Critical thinking is "an inclusive process of higher-order reflection and discourse" (Garrison, 2011, p. 43). From Dewey's (1910) foundational ideas on critical reflection, Garrison and Archer (2000) developed the Practical Inquiry (PI) model. PI is how critical thinking is defined within the CoI model and is the basis of the Cognitive presence construct. 
The practical inquiry model.

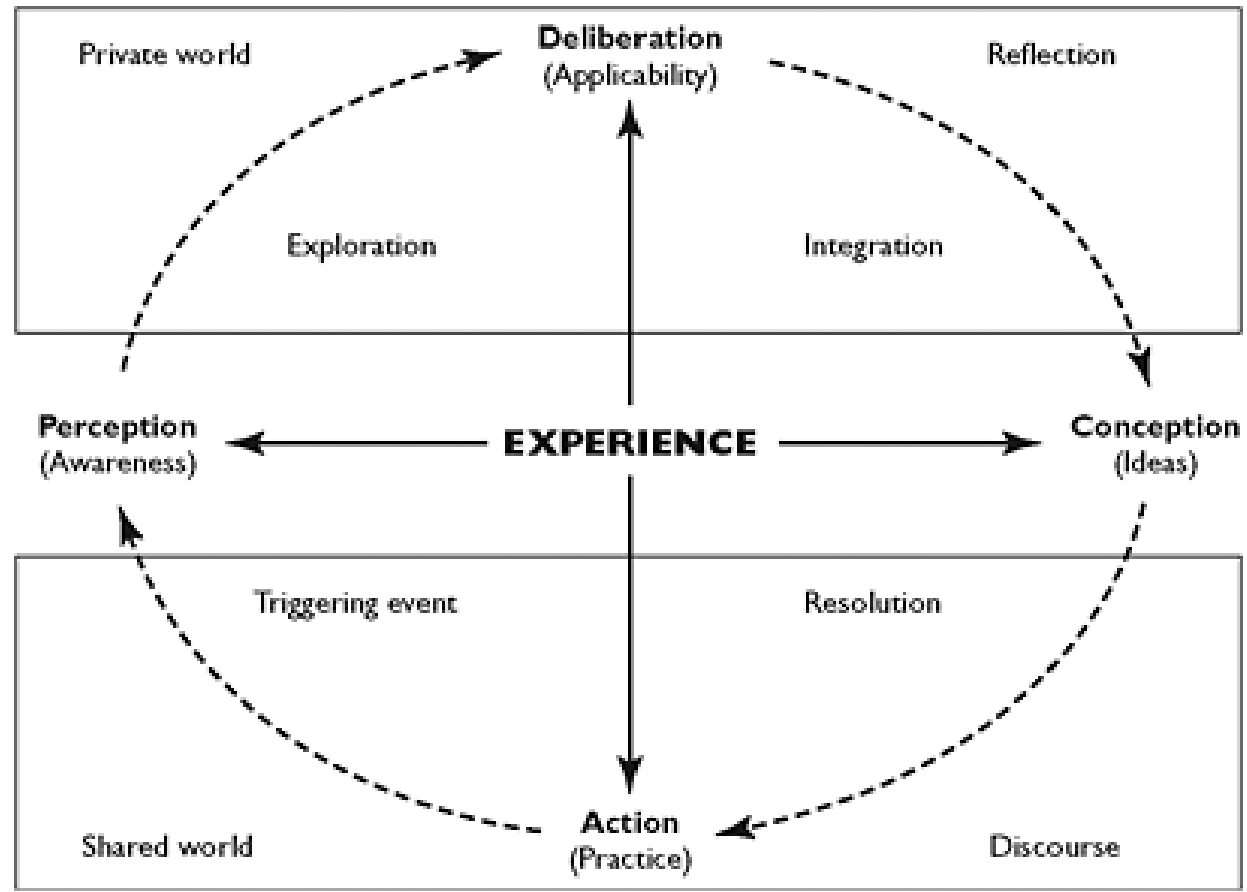

Figure 2.2: The Practical Inquiry Model (Garrison, 2011, p. 45).

The practical inquiry model. The PI model is an attempt to operationalize the constructivist critical thinking process (See Figure 2.2 for visual representation of the PI model). On the vertical of Figure 2.2 are deliberation and action. These poles represent the process of reflective thinking and describe "the rigorous process of integrating induction (arrival of generalizations) and deduction (employment of generalizations)" (Garrison, 2011, p. 45). On the horizontal axes lie perception and conception, which represent the movement of a learner between concrete and abstract thinking that make up critical thinking. "At one extreme is the divergent process of perception and analysis of facts or events [perception]. At the other extreme is the convergent process of insight and understanding associated with ideas and concepts [ideas]." (Garrison, 2011, p. 45). The 
PI model is divided into four quadrants, which "reflect the logical or idealized sequence of practical inquiry (i.e., critical thinking) and correspond to the proposed categories of cognitive presence indicators" (Garrison et al., 2000, p. 98). As will be described in Chapter Three, CoI categories and indicators are part of the coding matrix for the Cognitive presence research lens.

The PI model also describes the four theoretical events a learner goes through when engaging in constructivist critical thinking. The first event in the PI model is the triggering event (lower left quadrant of Figure 2.2). This is described as "a state of dissonance or feeling of unease resulting from an experience" (Garrison et al., 2000, p. 98). The second phase, exploration (upper left quadrant of Figure 2.2) is a learner's exploration of knowledge or information that might help to make sense of the situation, thus relieving the dissonance caused by the triggering event. In this phase learners share collaboratively and work individually to try and make sense of a situation difficult to grasp. Garrison (2011) calls this phase "the essence of a true community of inquiry" (p. 47). The third phase is integration (upper right hand quadrant of Figure 2.2). In this phase, learners refine their exploration by integrating the relevant ideas and concepts into a more parsimonious understanding of the matter (Garrison, 2011; Rourke, Anderson, Garrison, \& Archer, 1999). The final stage is resolution (lower right hand quadrant in Figure 2.2). This is where the idea or hypothesis formed out of integration is applied and tested to see if it solves the problem encountered during the triggering event. It is important to note that full resolution in the critical thinking process is rarely achieved, with questions brought up during the resolution process often triggering new problems, thus beginning the cycle again. 
In summary, the CoI theoretical framework's Cognitive presence utilizes the PI model as a tool to describe the constructivist learning event. Borrowing from Vygotsky's (Galloway, 2001; Vygotsky \& Cole, 1978) social constructivism and Dewey's (1910) notion of critical inquiry, Cognitive presence focuses on dissecting the process of "constructing and confirming meaningful and worthwhile knowledge" (Garrison, 2011, p. 50). By providing a model for coding with the PI model, researchers are able to describe constructivist learning theoretically as well as practically through a method of coding constructivist, collaborative interactions in an online space.

Social presence. Social presence is the second aspect of the CoI model. Social presence in online learning is defined as "the ability to project one’s self and establish personal and purposeful relationships" (Garrison, 2007, p. 63). As Social presence ${ }^{3}$ in the CoI model is derived heavily from social presence theory and the body of literature that surrounds it, a brief discussion of social presence theory will follow prior to a discussion of the CoI framework's Social presence construct.

Social presence theory. Social presence theory explores "the degree to which a person is perceived as a 'real person' in mediated communication" (Gunawardena, 1995, p. 151). Short, Williams, \& Christie (1976) argue that various media have different levels of sociability, with face-to-face communication being the most sociable, video communication being the second most sociable and audio being the least sociable medium. Christie (as cited in Tu, 2002) includes written media in the form of a business

\footnotetext{
${ }^{3}$ A confusing aspect of this subject matter is that the CoI Social presence is based on social presence theory. It is important to note that, while related, social presence theory and the CoI framework's Social presence construct are in fact two different things. To reduce reader confusion, when referring to the CoI model in the study, Social presence will be capitalized. When referring to other usages of social presence, such as social presence theory, social presence will not be capitalized.
} 
letter in his assessment of sociability and finds that the written medium consistently scored the lowest of all media in terms of sociability. When researchers became interested in the mediated communication that takes place in online learning, it was hypothesized that the primarily text based communications of online learning (forums, chat rooms, etc.) would, like Christie's business letter, have low social presence (Tu, 2002) .

However, a study by Perse, Burton, Kovner, Lears, \& Sen (1992) contradicts the belief that text-based online communication has low sociability. The authors examined student use of email and online bulletin boards by polling 130 college-level physics students with equal gender and class level representation using a semantic differential technique with a five-point scale. The authors found that students felt email was a sociable, warm, and personal medium. In other words, students felt email, a text-based medium, was able to create social presence that lead to interpersonal relationships with peers (Tu, 2002).

Gunawardena's (1995) mixed method study of two distance education courses that utilized online conferencing concurs with Perse et al.'s (1992) findings. Gunawardena (1995) concludes that although computer-mediated communication is perceived as a medium that is low in contextual cues such as eye contact that help to create a sense of social presence, "it can be perceived as interactive, active, interesting, and stimulating by conference participants" (Gunawardena, 1995, p. 147). Further, Gunawardena finds that the kind of interactions that take place and the sense of community that is created during an online course impact a participant's perceptions of text-based online learning as a social medium. The significance of this finding is that Gunawardena (1995) suggests that 
social presence in online media can be "cultured" by course moderators that want to create a sense of community that "promotes interaction and collaborative learning" (Gunawardena, 1995, p. 147). In other words, instructors designing an online learning course need to focus on collaborative activities and robust communication as these activities make learners in an online course feel more present with one another, similar to how they would feel in a face-to-face course.

The idea of social presence thus becomes a cornerstone in the creation of online learning communities (Gunawardena \& Zittle, 1997; Swan, 2002; Tu, 2002). Students in online learning courses need to feel social presence by feeling their communication with one another is "real" in order for the concept of community to transfer to an online context (Kear, 2011). According to Gunawardena (1995) "the development of social presence and a sense of an online community becomes key to promoting collaborative learning and knowledge building” (p. 164).

So and Brush's (2008) study of 48 graduate students taking an online course on health education supports Gunawardena's (1995) conclusion. Data were collected from a student perception questionnaire and face-to-face interviews. An analysis of the quantitative data "indicated that student perceptions of collaborative learning have statistically positive relationships with perceptions of social presence and satisfaction" (So \& Brush, 2008, p. 318).

In summary, online communication, such as email and chats, can create conditions where people feel high degrees of connection with others. In online learning, instructors can enhance feelings of "closeness" among online students by creating collaborative activities and robust opportunities for communication, even despite online 
learners not meeting face-to-face. Such opportunities for social interaction lead to a sense of online community, which is necessary for the implementation of constructivist pedagogies that produce the type of critical thinking expected of college-level coursework (Garrison et al., 2000).

Social presence construct of the COI model. Garrison et al. (2000) use the body of social presence theory research previously described as the foundation for their construct of Social presence in the CoI model (Garrison, 2011). In the CoI model "social presence ... means creating a climate that supports and encourages probing questions, skepticism and the contribution of explanatory ideas. Sustaining critical thinking and discourse requires a sense of belonging that must develop over time" (Garrison, 2011, p. 32) . Social presence in CoI is not about socio-emotional bonding, but rather about achieving academic goals (Garrison \& Arbaugh, 2007). In other words, developing Social presence is a requirement for creating a social constructivist learning environment.

Social presence in CoI is subdivided into three categories: interpersonal communication, open communication and cohesive communication (Garrison, 2011). The categories are further subdivided into indicators, which describe learner behaviors typical on online course communication. A discussion of the three categories that comprise Social presence as well as their respective indicators will follow.

Interpersonal communication. The first Social presence category, interpersonal communication, is critical in a deliberate CMS as it creates a climate of belonging and respect from which critical thinking can emerge. Interpersonal communication consists of three indicators. The first is affective emotion, which is defined as conventional or unconventional expressions of emotion such as "repetitious punctuation, conspicuous 
capitalization, emoticons" (Garrison, 2011, p. 38). The next indicator is self-disclosure, such as relating personal experiences to the group or vulnerabilities. The final indicator is use of humor, such as teasing, joking, etc.

Open communication. The second category of Social presence in the CoI model is open communication. "Open communication is built through a process of recognizing, complimenting, and responding to the questions and contributions of others, thereby encouraging reflective participation and interaction" (Garrison, 2011, p. 39). One indicator of open communication is replying to a discussion thread in an online course, such as hitting reply in a forum post. Other indicators are quoting from others' messages, referring specifically to others' messages, asking questions, complimenting and expressing appreciation, and expressing agreement.

Cohesive communication. The third category of Social presence in the CoI model is cohesive communication. Cohesive communication is comprised of those behaviors of online learners that reinforce group cohesion among their online peers. According to Garrison (2011):

Group cohesion is the dynamic state that social presence is attempting to achieve. It is cohesion that sustains the commitment and purpose of a community of inquiry, particularly in an e-learning group separated by time and space. More specifically, constructing meaning, confirming understanding, and completing collaborative activities can only be successfully achieved in a cohesive community (p.39).

One indicator of cohesive communication is vocatives, or addressing other participants by name. Another indicator occurs when a participant addresses the group with inclusive 
pronouns, such as "we" or "us." The final indicator is phatics and salutations, which are communications that serve a purely social function.

In conclusion, social presence theory explores the ability for a participant in various communication mediums to "project" their personalities into the space in order to establish purposeful relationships. As applied to online communication environments, communication must feel "real" in the vein of face-to-face communication. The literature indicates social presence can occur in online media, such as deliberate CMSs, that lack face-to-face contact. Purposeful activity in the online space is also important in creating social presence among online learners. Students that engage in collaborative activities feel higher degrees of social presence, thus creating a sense of community that gives rise to the constructivist working environments necessary for critical thinking. This assertion underlies the Social presence construct of the CoI framework, which seeks to provide both a theoretical and research structure for describing social presence in a deliberate CMS online course environment.

Teaching Presence. The third and final component of the CoI model is Teaching presence. According to Garrison (2011) "teaching presence is charged with shaping the appropriate transactional balance and, along with the learners, managing and monitoring the achievement of worthwhile learning outcomes in a timely manner" (p. 54). The three categories of Teaching presence are instructional design and organization, facilitating discourse, and direct instruction (Garrison, 2011). As the concept of transaction is key in Garrison's (2011) own definition of Teaching presence in an online course environment, a brief discussion of transactional distance theory (Moore, 1993) is appropriate. This will 
be followed by an explanation of the categories and indicators that compromise Teaching presence in the CoI framework.

Transactional distance theory. Moore's (1993) transactional distance theory is a popular typology for discussing interaction in distance-learning environments and the role that interaction plays in increasing or decreasing psychological distance the perceived psychological gap felt between learners when physically separated from one another in online learning environments) (So \& Brush, 2008). According to Moore (1993), an ideal distance learning environment has low levels of transactional distance among learners, which leads the learners to psychologically feel "closer" to one another. Moore (1993) theorizes that three types of learning events must be met for a learner to experience low levels of transactional distance in a distance learning environment, thus leading to a greater feeling of psychological "closeness" with her peers and instructors. The three types of interactions are learner-content interactions, learner-instructor interactions and learner-learner interactions.

Learner-content interactions occur when a learner gains knowledge through various types of media, such as a web-based course or video. Learner-instructor interactions take place when an instructor delivers content knowledge through interactions such as giving feedback, instruction, increasing student motivation, etc. Finally, learner-learner interactions take place when spatially dispersed learners interact with one another to achieve a certain goal, such as an assignment in an online course (Moore, 1993).

Hillman, Willis, and Gunawardena (1994) argue that a fourth interaction, learnerinterface, should be included in Moore's (1993) theory as well. Learner-interface 
interactions entail the interaction a learner has with the medium that is delivering the online/distance course. The ease or lack of ease with which a learner can access her course content is contingent upon her successful or unsuccessful interaction with the medium. Thus, a technological medium with which learners feel comfortable and which is not technologically complicated will decrease transactional distance.

Moore (1993) theorizes that distance-learning course designs that promote increased dialogue among learners rather than rigid course structure could have lower degrees of transactional distance. This assertion has been validated empirically by Saba and Shearer (1994). Charalambos, Michalinos, and Chamberlain (2004) disagree, however, arguing that increased course structure that facilitates collaborative tasks leads to rich interaction and dialogue among learners, which in turn decreases transactional distance. So and Brush (2008) concur with these findings, inferring from the literature that "collaborative learning structures" (p. 319) that allow for more control and dialogue among learners could reduce transactional distance.

Garrison (2009) synthesizes the literature by stating that Moore (1993) bases his theory on traditional, individualistic notions of distance education. Distance learning began prior to the rise of the Internet, and so the first approaches to distance education were largely by correspondence. As advances in technology came about that enabled distance learners to communicate easier online, traditional notions of the high structure, low-dialogue approach of correspondence distance education remained. However, as improvements in technology and collaborative constructivist online pedagogies increased in popularity, the need for more structure to ensure collaborative interaction became more important. Thus, in a contemporary online learning environment where interacting with 
peers is easy to do, deliberate activities must be employed to ensure that collaborative, focused dialogue takes place.

In summary, transactional distance theory (Moore, 1993) introduces the idea that the interplay of structure and dialogue in distance education are important in course design and facilitation so that distance learners can feel a sense of psychological "closeness" with one another, or low transactional distance. Both structure and dialogue are important elements of a distance education course, but too much of one or another can adversely affect the ability of distance learners to psychologically connect with other spatially dispersed peers. As communication technology has improved since Moore (1993) proposed his theory, it is now better understood that structure that supports dialogue, both in course design and instruction, is important in reducing the transactional distance experienced by spatially dispersed online learners. It is this contemporary understanding of transactional distance that serves as the foundation for the CoI's Teaching presence construct.

Teaching presence construct in Community of Inquiry framework. Teaching presence in the CoI model provides a theoretical and research framework for exploring those elements that decrease transactional distance and thus increase learner connectedness in a deliberate CMS online course environment. As with Social presence, Teaching presence is subdivided into three categories, which are further subdivided into indicators. The three categories of Teaching presence are design and organization of the course, facilitating discourse for the purpose of building understanding, and direct instruction. 
Design and organization of the course. The first element of Teaching presence, design and organization of the course, has to do with overall structure and process of an online course. Indicators include setting curriculum, designing methods (such as setting up a debate between students), establishing time parameters (such as due dates for posts) utilizing the medium effectively, establishing "netiquette" (commonly agreed upon online decorum) and making macro-level comments about the course (Garrison, 2011).

Facilitating discourse. The second element of Teaching presence is facilitating discourse for the purpose of building understanding. This element deals with the instructor's ability to gently guide and encourage discourse in a purposeful, meaningful manner so higher-level critical thinking is achieved. This can be done by an instructor pointing out important thoughts and making connections between comments from various class members. Garrison (2011) states an instructor must walk a fine line with Teaching presence so as to "negotiate something more substantial than a rambling conversation yet not just a prescriptive dissemination of information" (p. 58). Rather, the point is to encourage cognitive development and provides a positive learning environment for online learners.

Indicators of the facilitating discourse category are identifying areas of agreement/disagreement, seeking to reach consensus/understanding, encouraging, acknowledging or reinforcing student contributions, setting a climate for learning, drawing in participants/prompting discussion and assessing the efficacy of the process (Garrison, 2011, p. 59).

Direct instruction. The final category of Teaching presence is direct instruction. Direct instruction relates to the need for content expertise in instruction so as to 
accurately answer student questions and correct misconceptions. Garrison (2011) notes that this element is often forgotten in the popular "facilitator of learning" instructor approach of online courses, but "disciplinary expertise and efficient shaping of the learning experience are essential aspects of any educational process" (p. 59).

Indicators of the direct instruction category are: focusing the online discussion on specific issues, summarizing the discussion, confirming learner understanding through assessment and explanatory feedback, diagnosing misconceptions, injecting knowledge from other resources, and responding to technical concerns (such as how to upload a document) (Garrison, 2011, p. 60).

Summary of Teaching Presence. In summary, Teaching presence addresses the overall design, process and learner experience of a deliberate CMS in the form of an online course. Teaching presence has its theoretical roots in Moore's (1993) transactional distance theory, which posits specific interactions successfully implemented can reduce the transactional distance, or psychological perceptions of space, geographically distant learners perceive from one another. Garrison et al. (2000) incorporate this concept into the CoI model in the form of Teaching presence, positing that successful implementation of course design, facilitation of discourse and direct instruction can create collaborative environments that not only reduce feelings of distance but, more importantly, create a context for critical thinking and learning to emerge.

\section{CoI Literature Discussion}

In this next section, I will discuss literature key to validating the CoI framework. I will then discuss criticisms of the CoI framework. Finally, I will discuss how this body of 
literature supports my rationale for using the CoI framework as my theoretical framework for this study.

Since its inception, the CoI framework has served as a robust theoretical framework for both quantitative and qualitative education researchers. The framework has been used in "hundreds of studies" (Garrison, 2009, p. 100) and in doing so stands out as one of the most well researched frameworks for the study of online learning. As the amount of CoI literature is extensive, Garrison and Arbaugh's (2007) review of the CoI research literature provides a robust synthesis of the current research on the subject and serves as the source of the conclusions to follow.

The CoI Social presence literature indicates a strong relationship between Social presence and learning outcomes. Additionally, activities that foster increased Social presence also enhance the learner's satisfaction with using the Internet as a means for delivering educational content. A key finding is that while Social presence alone will not ensure critical discourse in online learning, it is extremely difficult for such discourse to emerge without a strong Social presence foundation. Several studies cited by Garrison \& Archer (2007) also indicate that Social presence is a precursor to Cognitive presence, as increased sociability leads to increased interaction among learners, thus providing the context for collaborative constructivist learning to emerge.

The Cognitive presence literature indicates that online learners often experience difficulty moving from the exploration phase of the PI model to the more advanced reflection and discourse phases. This may be a fault of task design, since if instructors do not specify the type of discourse they would like recorded by students, the higher level PI aspects might not be documented for researchers to code. "If there are no shared goals 
requiring a collaborative solution or artifact the transcripts of online discourse will not reveal discourse that has moved to the resolution phase" (Garrison \& Arbaugh, 2007, p. 162). Thus, ensuring that the learning activity is properly constructivist in nature is necessary to move learners into the advanced phases of Cognitive presence. Indeed, "the role of instructors in cultivating cognitive presence is significant, in terms of how they structure both the content and participant interactions" (Garrison \& Arbaugh, 2007, p. 163).

In literature regarding Teaching presence, clear and consistent course structure that supports engaged instructors and students emerges as the most consistent predictor of successful online courses. Thus, a course with high instructional design and organization (one element of Teaching presence) will lead to a more successful online course, with successful meaning a course capable of eliciting high-level critical thinking from learners. Leadership is needed from faculty in the form of facilitating discourse (another component of Teaching presence) so that students are "forced" to engage in collaborative discourse. Students that do not have this type of structure primarily fall victim to engaging in "serial monologues" (Chang, Paulus, Pawan, \& Yalcin, 2003, p. 119).

While the majority of CoI research performed to date has been qualitative, key quantitative research has also been conducted using the CoI model. Garrison, ClevelandInnes, \& Fung (2004) developed a survey instrument to assess role adjustment in an online asynchronous community of inquiry. Through a factor analytic process the authors determined that the instrument does in fact reflect the CoI theoretical model. Arbaugh et al. (2008) refine Garrison et al's (2004) instrument through the development of a 38 question CoI survey. Arbaugh et al. (2008), also successfully validate their survey 
instrument through factor analysis, resulting in an instrument that successfully measures Social, Cognitive and Teaching presence in online learning environments. Arbaugh (2008) applies the CoI survey instrument to students from 55 online MBA courses and finds "strong empirical support for the [CoI] framework and its ability to predict both perceived learning and delivery medium satisfaction in online management education" (Arbaugh, 2008, p. 1). Thus, while the majority of CoI research to date has been exploratory in nature, quantitative research has yielded instruments that both validate and measure the CoI theoretical framework empirically.

CoI criticism. The most direct criticism of the CoI framework comes from Rourke and Kanuka's (2009) review of the CoI research literature. The authors question what they perceive as Garrison et al.'s (2000) central claim that the CoI model is predictive of deep and meaningful leaning among an online community of learners. Rourke and Kanuka (2009) reviewed 252 quantitative studies that used the CoI model. Rourke and Kanuka (2009) found that, of the studies, learning was defined as perceived learning and that this perceived learning was usually measured as a single item on a closed-form survey. The authors question the validity of such a subjective measure of student learning and thus conclude that the extensive body of literature on the CoI model does not support that CoI framework produces deep and meaningful learning. It is important to note that Rourke and Kanuka (2009) are concerned with the empirical studies on CoI, and define the success of the CoI model in terms of experimental design, with the three presences- Social, Cognitive and Teaching- as independent variables and "deep and meaningful learning" as the dependent variable (p. 23). 
Akyol et al. (2009) refute Rourke and Kanuka (2009). First, the authors challenge Rourke and Kunuka's (2009) central claim that the thesis of the CoI model is to predict deep and meaningful learning. Akyol et al. (2009) disagree that the CoI is a predictive model, stating that CoI is "first and foremost a process model" (p. 124). While Garrison et al. (2000) allow for the possibility of deep and meaningful learning to emerge from the context explored by CoI, the CoI framework itself is not a predictive model. Evidence of this theoretical, process emphasis of CoI is found in the CoI model's constructivist roots in which the focus is on how learners construct knowledge rather than on a more positivist focus on learning outcomes. Further, the large number of studies using the CoI framework validates CoI as a useful theoretical framework.

Additionally, Akyol et al. (2009) take issue with the comprehensiveness of Rourke and Kanuka's (2009) literature review, as well as their accuracy in identifying true empirical studies relating to CoI, arguing that many of the "quantitative" studies in Rourke and Kanuka (2009) are actually qualitative. The result of such oversight, argue Akyol et al., is a selective literature review that "misrepresents CoI research by excluding recent research studies and including the research studies that have no relationship to the CoI framework" (p. 129). Finally, Akyol et al. (2009) question Rourke and Kanuka's (2009) discounting of "subjective" self reports of student learning as a valid measure for higher-order thinking, especially in the light that there is no readily agreed upon measurement tool for deep and meaningful learning. In the absence of such an agreed upon measurement, any data, albeit subjective, is still data nonetheless and therefore helpful in better understanding CoI. 


\section{CoI Framework Justification}

The CoI model provides an appropriate theoretical framework to describe what is happening with the unit of analysis for this study, the SCR activity. As one of the most well utilized theoretical frameworks for researching deliberate CMSs in the form of online coursework, the CoI model is entirely applicable to the deliberate CMS SCR activity. Another rationale for using the CoI framework is the similarities between the SCR and the CoI model. First and foremost, the SCR is a fundamentally social constructivist pedagogy due to its base in authentic real-world tasks (students use actual patient cases they have seen during their rural experience to present to the group) as well as social knowledge construction. Second, the SCR has low transactional distance, with the refinements described by Palmer and Dodson (2011) leading to a relatively "glitch free" technology experience that allows students to interact with peers robustly within a structure that focuses interactive discourse. Finally, the interactive nature of the Adobe Connect software used to host the SCR activities should lead to high levels of Social presence for learners. The SCR activity should contain all presences of the CoI modelSocial, Cognitive and Teaching- and therefore studying it with the CoI framework is appropriate.

\section{Introduction to Methodology}

In addition to providing a theoretical framework to explore deliberate CMSs in the form of online coursework, the CoI model provides a practical, well validated framework to analyze the transactions that take place during online coursework. The CoI model does this by providing a parsimonious coding framework that describes the 
Teaching, Cognitive, and Social presences deemed necessary for higher-level constructivist learning to take place in a deliberate CMS.

As the ORSP SCR activity is a deliberate CMS in the form of an online course, applying the CoI model to the transactional records of the activity is appropriate.

Therefore, for this study the CoI framework will be used to explore in detail the impact of the SCR activity upon ORSP student learners (research question one). The CoI model will not only provide a well validated coding scheme from which to explore what is going on within the SCR, but it will also indicate whether the SCR is a deliberate CMS capable of producing the collaborative constructivist knowledge creation that also is found in virtual CoPs. In addition, the CoI coding will reveal more granular exploratory data regarding the existence of CoI's three presences - Teaching, Cognitive and Social- as well as the relative strength and weakness of each of the presences. 


\section{CHAPTER THREE}

\section{Methodology}

Chapter Three contains a detailed discussion of the research methodology, study design, research site, subjects and instruments used. I will describe how SCR transcription coding, field notes and follow-up interviews with ORSP students were key components of the methodology used to explore the impact of SCR activity on ORSP student learners. Data analysis and obtaining informed consent from subjects will also be discussed.

It is clear that rural areas need more doctors and medical students that train in rural areas have been found to be more likely to return to those areas to practice. Rural medical education is thus important in addressing the paucity of physicians going into rural practice. In addition to getting students to practice in rural areas is the additional issue of rural physician persistence. Indeed, many rural physicians leave rural practice due to a lack of professional community or, more specifically, a lack of a CoP. This is because an important aspect of being a physician is having robust CoPs, yet due to the remote nature of rural practice, CoPs are hard to come by in a rural context. Therefore, it seems reasonable to believe that it is important to train future practitioners participating in a rural medical experience how to create virtual CoPs in rural contexts. Though the literature indicates virtual CoPs cannot be deliberately created, as they are phenomena that emerge from deliberate CMSs, it is possible to create a deliberate CMS that can lead to a virtual CoP. 
The ORSP employs a deliberate CMS to provide a novel approach to rural medical education in the form of the SCR. As the SCR approach is novel, it will be qualitatively explored using the CoI framework. A detailed exploration of the SCR will contribute to a better understanding of how using a deliberate CMS in rural medical education may help give future rural physicians the skills needed to create virtual CoPs in practice, thus contributing to the likelihood these physicians may persist in rural practice.

To review, this study poses two research questions. The first research question is: What is the impact on learners when a deliberate CMS like the SCR is used to deliver the rural medical education experience? A better understanding of what is happening with the SCR may help prompt other medical schools to employ similar approaches, thus ultimately helping better train future rural physicians how to create the context necessary for virtual CoPs to emerge while in practice. To explore what is happening in the SCR, the CoI model was used as a research framework to code against the four recorded SCR activities during one ORSP rotation.

My second research question seeks to understand: What is the nature of ORSP student experiences of participating in the SCR? To better understand this research question, interview questions asked ORSP students what their experiences were during the SCR, especially those related to their feelings of connectedness to their distance peers. Additionally, interview questions explored the likelihood that ORSP students would utilize similar uses of technology while in rural practice.

\section{Research Perspective}

The research perspective of this dissertation is qualitative. Key to the choice of this research perspective is the exploratory, descriptive nature of the research questions. 
Further, the utilization of the CoI framework works well for this study as the CoI framework has been primarily utilized as a tool for qualitative research (Garrison, 2011). While there have been some quantitative applications of the CoI model (Arbaugh, 2007, 2008; Arbaugh et al., 2008; Rourke \& Kanuka, 2009), the primary application of the model has been qualitative (Akyol \& Garrison, 2008; Garrison, 2007; Garrison et al., 2000; Garrison \& Arbaugh, 2007; Garrison, 2011; Garrison, Cleveland-Innes, Koole, \& Kappelman, 2006; Rourke et al., 1999; Swan, 2002).

Further, this study employs an intrinsic, single case-study design. Johnson and Christensen (2012) define a case study as "research that provides a detailed account and analysis of one or more cases" (p. 395). A case is defined as a "bounded system" (Johnson \& Christensen, 2012, p. 395) or a holistic system of interrelated parts. In this study, the system is the five-week ORSP experience of six rural medical education students.

An intrinsic case study is where "the researcher's primary interest is in understanding a single case....Here the researcher describes, in depth, the particulars of the case to shed light on it" (Johnson \& Christensen, 2012, p. 396). Additionally, the intrinsic case study design is employed due to the unique nature of the ORSP approach to rural medical education. Intrinsic case study designs are used to explore cases that represent a unique situation (Creswell, 2007; B. Johnson \& Christensen, 2012; Yin, 2009) of which the ORSP SCR activity is one. Both Lin (2009) and Johnson and Christensen (2012) identify an intrinsic, single case study design as appropriate when a researcher "attempts to learn about a little-known phenomenon by studying a single case in depth" (Johnson \& Christensen, 2012, p. 396). Indeed, a review of the rural medical education 
literature revealed no other evidence of other US medical schools utilizing a deliberate CMS to connect remote rural medical learners in a fashion similar to the ORSP program. Thus, this in-depth case study of one ORSP cohort's experience with the SCR contributes to a better understanding of an approach that is truly novel and that other medical schools may want to incorporate into their own rural programs to help with the rural physician workforce issue.

\section{Target Population and Participant Selection}

The target population of this study was eight participants in one ORSP cohort. The cohort participated in the ORSP rotation from September 1, 2012 - October 8, 2012. The cohort consisted of six third-year medical students, one faculty instructor, and a participant observer who was the ORSP distance learning director. The selection was a convenience sample (Creswell, 2007), as I worked with the ORSP program and thus had easy access to the participants and SCR activity from which I collected data. In my role as distance-learning director for the ORSP, I developed the technological infrastructure of the ORSP SCR prior to the launch of the ORSP program (Palmer \& Dodson, 2011). I also prepared all technological issues for the program, including maintenance of hardware (netbooks, mobile broadband cards) and software (Adobe Connect and Sakai) platforms. In addition, I participated in all SCR activities as the meeting "operator," making sure the technology ran smoothly during the meeting, student presentations were loaded and technical issues were troubleshot. I thus had ongoing access to the ORSP students throughout their participation in SCR activities and this study. 


\section{Participant Informed Consent}

Participants were informed via email approximately one month prior to the ORSP orientation that their SCR activity was going to be part of a dissertation study. The email described the nature and scope of the study and also included the consent form for review. Participants were informed that a more detailed discussion on the project would take place at the ORSP orientation and that consent forms would be signed at that time.

A detailed discussion and attainment of informed consent from participants took place during ORSP orientation on Monday, September 3, 2012. Students were informed of the following:

- The SCR activity was to be the subject of a dissertation research project.

- The recorded written and spoken transactions of the online SCR activities were to be coded for the research study.

- Participants would be asked to participate in voluntary follow up interviews after the conclusion of the five week rotation.

- Participation in the research study was voluntary and any transactions by participants that opted-out of the study would not be used in the analysis process, nor would opted out participants be asked to participate in follow up interviews.

- Participant names would be changed to obscure participant identities however, though every attempt would be made to ensure privacy, due to the small sample and small cadre of students admitted to the ORSP program made it so complete privacy could not be guaranteed. 
- Interviews would not take place until after clerkship grades were submitted so student participants would not feel candid answers to questions would jeopardize their final grades.

- Students that participated in the study would be given a \$5 Starbucks gift card as a gesture of gratitude.

\section{Data Collection}

In accordance with case study data procedures outlined by Yin (2009) "data triangulation," or collection of multiple types of data, was an integral part of this study's design. Utilizing multiple sources of data add to the reliability of a case study's findings, as each source can help lead a researcher to "converging lines of inquiry" (Yin, 2009, p. 115). In other words, the conclusions of a case study have greater reliability as multiple sources of data collection were used.

Three sources of data were analyzed for this study. The first data source was the recorded SCR sessions, the second data source came from participant interviews, and the third data source was my own participant observer field notes. Brief descriptions of each data source will now follow.

Recorded SCRs. The recorded SCR sessions served as observations that were then coded using the CoI framework. To review, SCR activities took place within twohour timeframes. During each SCR, three to four pre-assigned students presented cases based on patient issues they had seen during the past week in clinic. Typically a student progressed through a PowerPoint presentation that described their case along with their 
clinical reasoning process. When one student's presentation concluded, the next student began until all students assigned to present on a particular day had done so.

All SCRs were video recorded via the Adobe Connect software platform that was used to host the virtual meeting. Recordings were routinely made as archival documentation for the ORSP program as well as provide learning tools for current students. Thus, recording the SCRs for this study was not a new process, though the content of the recordings had never been analyzed before. Per the ORSP and OHSU Adobe Connect room policies, all meetings recorded on Adobe Connect are stored securely on Adobe, Inc. servers indefinitely. Recordings are made private by default, and can only be shared by the meeting administrator.

Interviews. In-depth interviews took place after the ORSP rotation concluded. According to Lin (2009), in-depth interviews "ask key respondents about the facts of a matter as well as their opinions about events" (p. 107). Thus, student participant interviews helped me explore my second research question: What is the nature of ORSP student experiences participating in the SCR? The interview style was open-ended, with general questions being asked about the students' experiences with the technology as well as their thoughts on future use of the technology in rural practice. (See Appendix for list of open-ended interview questions).

Field Notes. My third data source was the field notes I took during the SCRs. Field notes were taken for each live session.

\section{Data Analysis}

Transcript coding. After the conclusion of the ORSP rotation, all four SCR recordings were coded and analyzed using the CoI framework. As described in Chapter 
Two, transactions were coded for Teaching presence, Social presence and Cognitive presence. There are three levels of codes for the CoI framework. "Presence” is the highest level code. Each presence has a secondary-level code called “categories.” Each category is comprised of tertiary level codes, called “indicators.” All levels of CoI code were used in the analysis of the SCR recordings (the actual coding process that transpired for this study will be described in detail in Chapter Four). The development of the coding scheme for CoI has been an iterative process refined over a decade of CoI research. Garrison's (2011) most recent book on researching using the CoI framework provided a concise, upto-date summary of the best practices of coding used to date and thus served as the source coding scheme for this study. The following are examples of the coding framework used for the three presences.

Cognitive presence. As previously discussed, the coding model for Cognitive presence is the Practical Inquiry model. To review, the Practical Inquiry model operationalizes the constructivist learning process. The phases of the process, in the following order, are triggering event, exploration, integration and resolution. Table 3.1 outlines Garrison’s (2011) coding scheme for Cognitive presence using the CoI model which i used in this study. 
Table 3.1

Cognitive Presence Coding Categories and Indicators (Garrison, 2011, p. 52)

\begin{tabular}{|c|c|}
\hline Category & Indicator \\
\hline Triggering event & $\begin{array}{l}\text { Recognize problem } \\
\text { Puzzlement }\end{array}$ \\
\hline Exploration & $\begin{array}{l}\text { Divergence } \\
\text { Information exchange } \\
\text { Suggestions } \\
\text { Brainstorming } \\
\text { Intuitive leaps }\end{array}$ \\
\hline Integration & $\begin{array}{l}\text { Convergence } \\
\text { Synthesis } \\
\text { Solutions }\end{array}$ \\
\hline Resolution & $\begin{array}{l}\text { Apply } \\
\text { Test } \\
\text { Defend }\end{array}$ \\
\hline
\end{tabular}


Teaching presence. As previously discussed, the categories for Teaching presence are design and organization, facilitating discourse, and direct instruction. Table 3.2 Garrison's (2011) coding scheme for Teaching presence which is used in this study. Table 3.2:

Teaching Presence Coding Descriptors and Indicators

\begin{tabular}{|c|c|c|}
\hline Category & Indicator & Example Indicator \\
\hline \multirow[t]{6}{*}{$\begin{array}{l}\text { Design and Organization } \\
\text { (Garrison, 2011, p. 56) }\end{array}$} & Setting curriculum & $\begin{array}{l}\text { "This week we will be } \\
\text { discussing..." }\end{array}$ \\
\hline & Designing methods & $\begin{array}{l}\text { "I am going to divide you } \\
\text { into groups, and you will } \\
\text { debate..." }\end{array}$ \\
\hline & Establishing time parameters & $\begin{array}{l}\text { "Please post a message by } \\
\text { Friday..." }\end{array}$ \\
\hline & Utilizing medium effectively & $\begin{array}{l}\text { "Try to address issues that } \\
\text { others have raised when } \\
\text { you post" }\end{array}$ \\
\hline & Establishing netiquette & $\begin{array}{l}\text { "Keep your messages } \\
\text { short” }\end{array}$ \\
\hline & $\begin{array}{l}\text { Making macro-level } \\
\text { comments about course } \\
\text { content }\end{array}$ & $\begin{array}{l}\text { "This discussion is } \\
\text { intended to give you a } \\
\text { broad set of tools/skills }\end{array}$ \\
\hline
\end{tabular}




\begin{tabular}{|c|c|c|}
\hline & & $\begin{array}{l}\text { which you will be able to } \\
\text { use in deciding when and } \\
\text { how to use different } \\
\text { research techniques" }\end{array}$ \\
\hline \multirow[t]{4}{*}{$\begin{array}{l}\text { Facilitating Discourse } \\
\text { (Garrison, 2011, p. 59) }\end{array}$} & $\begin{array}{l}\text { Identifying areas of } \\
\text { agreement/ disagreement }\end{array}$ & $\begin{array}{l}\text { "Joe, Mary has provided a } \\
\text { compelling counter- } \\
\text { example to your } \\
\text { hypothesis. Would you care } \\
\text { to respond?” }\end{array}$ \\
\hline & $\begin{array}{l}\text { Seeking to reach } \\
\text { consensus/understanding }\end{array}$ & $\begin{array}{l}\text { "I think Joe and Mary are } \\
\text { saying essentially the same } \\
\text { thing” }\end{array}$ \\
\hline & $\begin{array}{l}\text { Encouraging, } \\
\text { acknowledging, or } \\
\text { reinforcing student } \\
\text { contributions }\end{array}$ & $\begin{array}{l}\text { "Thank you for your } \\
\text { insightful comments" }\end{array}$ \\
\hline & Setting climate for learning & $\begin{array}{l}\text { "Don't feel self-conscious } \\
\text { about 'thinking out loud' } \\
\text { on the forum. This is a } \\
\text { place to try out ideas after } \\
\text { all” }\end{array}$ \\
\hline
\end{tabular}




\begin{tabular}{|c|c|c|}
\hline & $\begin{array}{l}\text { Drawing in participants, } \\
\text { prompting discussion }\end{array}$ & $\begin{array}{l}\text { “Any thoughts on this } \\
\text { issue?” "Anyone care to } \\
\text { comment?” }\end{array}$ \\
\hline & $\begin{array}{l}\text { Assess the efficacy of the } \\
\text { process }\end{array}$ & $\begin{array}{l}\text { "I think we’re getting a } \\
\text { little off track here” }\end{array}$ \\
\hline \multirow[t]{6}{*}{$\begin{array}{l}\text { Direct Instruction } \\
\text { (Garrison, 2011, p. 60) }\end{array}$} & & \\
\hline & Present content/questions & $\begin{array}{l}\text { "Bates says... what do you } \\
\text { think" }\end{array}$ \\
\hline & $\begin{array}{l}\text { Focus the discussion on } \\
\text { specific issues }\end{array}$ & $\begin{array}{l}\text { "I think that's a dead end. I } \\
\text { would ask you to } \\
\text { consider..." }\end{array}$ \\
\hline & Summarize the discussion & $\begin{array}{l}\text { “The original question } \\
\text { was... Joe said... Mary } \\
\text { said... we concluded that... } \\
\text { We still haven’t } \\
\text { addressed...” }\end{array}$ \\
\hline & $\begin{array}{l}\text { Confirm understanding } \\
\text { through assessment and } \\
\text { explanatory feedback }\end{array}$ & $\begin{array}{l}\text { "You're close, but you } \\
\text { didn’t account for ... this is } \\
\text { important because..." }\end{array}$ \\
\hline & Diagnose misconceptions & "Remember, Bates is \\
\hline
\end{tabular}




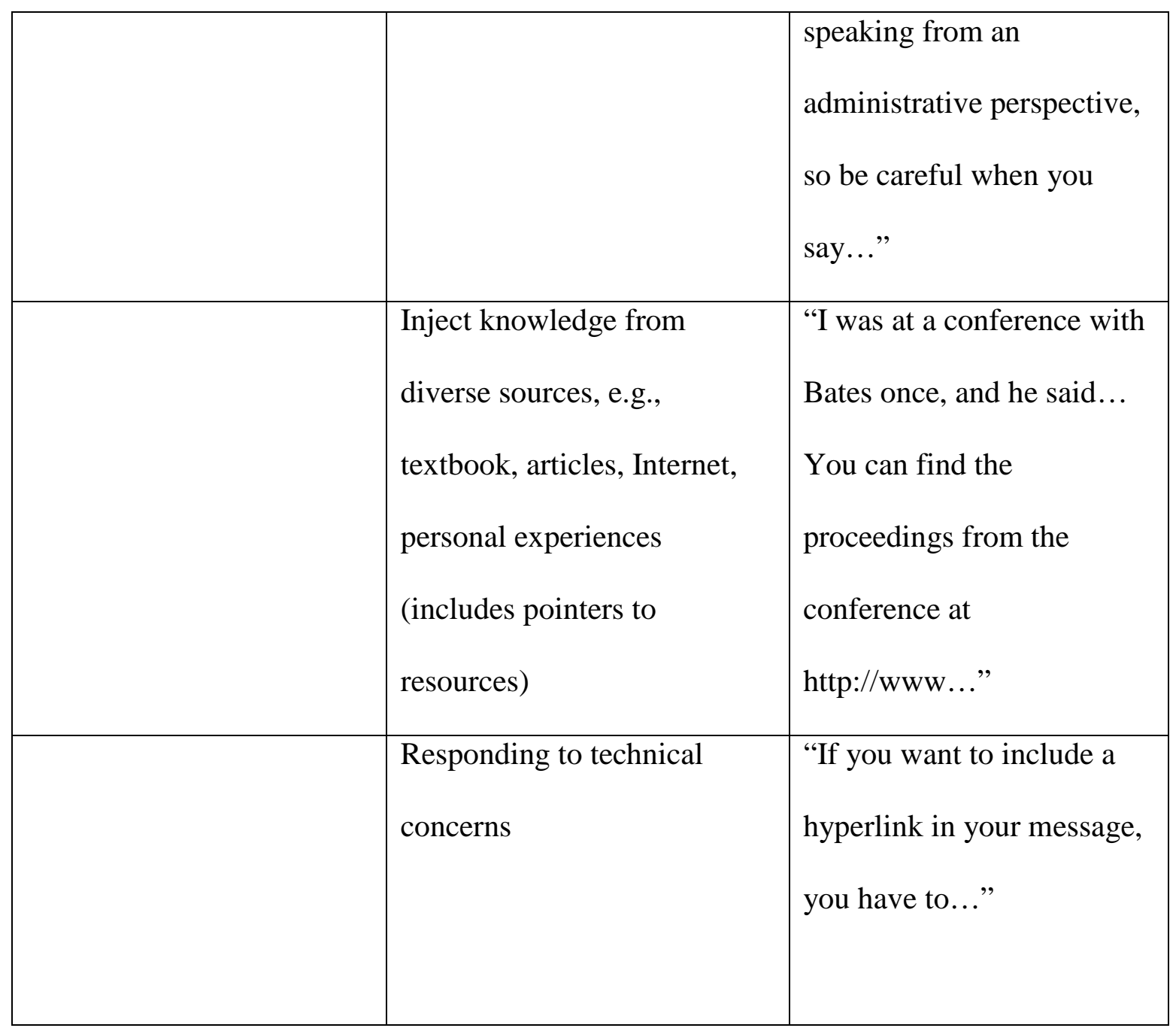

Social presence. As previously discussed, the categories used to indicate Social presence are interpersonal communication, open communication; and cohesive communication. Table 3.3 outlines Garrison's (2011) coding scheme for Social presence which was used in this study:

Table 3.3:

Social Presence Coding Descriptors and Indicators (Garrison, 2011, p. 38)

\begin{tabular}{|l|l|l|}
\hline Category & Indicator & Example \\
\hline
\end{tabular}




\begin{tabular}{|c|c|c|}
\hline $\begin{array}{l}\text { Interpersonal } \\
\text { communication }\end{array}$ & Affective expression & $\begin{array}{l}\text { Conventional expressions of } \\
\text { emotion, or unconventional } \\
\text { expressions of emotion, } \\
\text { including repetitious } \\
\text { punctuation, conspicuous } \\
\text { capitalization, emoticons }\end{array}$ \\
\hline & Self-disclosure & $\begin{array}{l}\text { Presents biographies, details } \\
\text { of personal life outside of } \\
\text { class, or expresses } \\
\text { vulnerability }\end{array}$ \\
\hline & Use of humor & $\begin{array}{l}\text { Teasing, cajoling, irony, } \\
\text { understatements, sarcasm }\end{array}$ \\
\hline Open communication & Continuing a thread & $\begin{array}{l}\text { Using reply feature of } \\
\text { software, rather than } \\
\text { starting a new thread }\end{array}$ \\
\hline & $\begin{array}{l}\text { Quoting from others' } \\
\text { messages }\end{array}$ & $\begin{array}{l}\text { Using software features to } \\
\text { quote others' entire } \\
\text { messages, or cutting and } \\
\text { pasting selections of others' } \\
\text { messages }\end{array}$ \\
\hline & $\begin{array}{l}\text { Referring explicitly to } \\
\text { others' messages }\end{array}$ & $\begin{array}{l}\text { Direct references to } \\
\text { contents of others' posts }\end{array}$ \\
\hline
\end{tabular}




\begin{tabular}{|c|c|c|}
\hline & Asking questions & $\begin{array}{l}\text { Students ask questions of } \\
\text { other students or the } \\
\text { moderator }\end{array}$ \\
\hline & $\begin{array}{l}\text { Complimenting, expressing } \\
\text { appreciation }\end{array}$ & $\begin{array}{l}\text { Complimenting others or } \\
\text { contents of others' } \\
\text { messages }\end{array}$ \\
\hline & Expressing agreement & $\begin{array}{l}\text { Expressing agreement with } \\
\text { others or content of others' } \\
\text { messages }\end{array}$ \\
\hline \multirow[t]{3}{*}{ Cohesive communication } & Vocatives & $\begin{array}{l}\text { Addressing or referring to } \\
\text { participants by name }\end{array}$ \\
\hline & $\begin{array}{l}\text { Addresses or refers to the } \\
\text { group using inclusive } \\
\text { pronouns }\end{array}$ & $\begin{array}{l}\text { Addresses the group as we, } \\
\text { us, our, group }\end{array}$ \\
\hline & Phatics, salutations & $\begin{array}{l}\text { Communication that serves } \\
\text { a purely social function: } \\
\text { greetings, closures }\end{array}$ \\
\hline
\end{tabular}

One potential issue in using the CoI coding framework was that the SCR takes place in the synchronous online space of Adobe Connect while the CoI model has primarily been used to code asynchronous online transcripts (e.g. student forums). 
However, Garrison (2011) indicates the CoI framework can also be utilized in "blended" online environments, that is, environments that utilize both asynchronous and synchronous elements. It therefore seems reasonable to use the CoI model to code synchronous SCR activities.

In order to code the synchronous online learning environment of the SCR, I used the qualitative coding software NVivo. NVivo allowed me to import the SCR recordings and code using the CoI framework along the timeline of the video recordings. A detailed description of this process as well as the results the process yielded will be presented in Chapter Four.

Interviews. As previously stated, interview transcripts were analyzed to explore the second research question: What is the nature of ORSP student experiences participating in the SCR? Interviews took place via phone in January of 2013 and student participants were asked four open-ended questions (see Appendix) regarding their experiences using the SCR technology as well as their feelings of connectivity to their peers. Interview transcripts were subjected to categorical aggregation. In categorical aggregation, "the researcher seeks a collection of instances in the data, hoping that issuerelevant meanings will emerge" (Creswell, 2007, p. 163). Instances and common themes revealed in the transcripts were "clustered." Marshall and Rossman (2011) define clustering as "creative work in which the researcher creates diagrams of relationshipsoutlines according to what is most overarching" (p. 148). This interview coding process was also conducted utilizing NVivo software. Details of that process, as well as the results from the process, will be discussed in Chapter Four. 
Field Notes. Field notes were taken by me during the live SCR activities. Field notes were analyzed using the same categorical aggregation technique used to code interview transcripts. Details of that process, as well as the results from the process, will also be discussed in Chapter Four.

\section{Role of the Researcher}

My role as a researcher in this case study was that of a participant observer. According to Yin (2009) a participant observer researcher plays an active, rather than passive, role in his observation of a case study. Indeed, a participant observer may actually participate in the events being studied. As previously discussed, my role as the distance-learning manager in the ORSP program afforded me the unique opportunity to participate as an "operator" for each SCR session, as well as work with participants outside of the SCR on technology issues. Further defining my role as participant observer, all ORSP participants knew me well prior to the study due to interactions they'd had with me during a previous longitudinal course at OHSU. Finally, I had a longterm working relationship with the faculty member that participated in this study, Dr. Linda Day.

\section{Potential Bias}

My close association with the ORSP program as well as my involvement in the study as a participant observer created several opportunities for bias (Yin 2009) in this study. One prominent issue was my ability to potentially influence the transactions during the SCR sessions. For example, in my role as session operator I had the opportunity to interject and alter the natural transactional process during SCRs to favor community aspects of the CoI framework. I addressed this potential bias by essentially "doing my 
job" as distance learning director. During the SCRs, my role was to interact with the process as minimally as possible. I stayed in the background and only interjected to logistically keep the learning process moving. As such, I believe I minimized this potential for bias during the research process.

Another potential for bias I had as a participant observer was that, being a part of the SCR activities for the past three years, I had a "hunch" the community would be robust due to previous personal observations I'd made over time. This is the reason I employed an external framework, the CoI model, to analyze my data. Using an a priori, pre-determined coding framework like CoI not only provided a well validated, readymade coding scheme, but it also distanced me from the data. By using an external coding framework to code my observations I thus avoided the potential introduction of bias through the creations of of creating coding schemes that might favor my expected results.

\section{Methodology Conclusion}

In summary, this study utilized a qualitative research perspective in the form of an intrinsic case study of one ORSP cohort's experience with the SCR activity. Three data sources were used to triangulate study results. The first data source was recorded SCR activities that were coded using the CoI framework. The second data source was open ended interviews that were subjected to categorical aggregation and clustering to determine results. The third data source was participant observer field notes that were also subjected to categorical aggregation and clustering to determine results. 


\section{CHAPTER FOUR}

\section{Results}

To review, this dissertation utilized an intrinsic case study design to explore the following research questions:

1. What is the impact on learners when a deliberate CMS like the SCR is used to deliver the rural medical education experience?

2. What is the nature of ORSP student experiences participating in the SCR?

Recorded SCRs were used as the primary data source for the exploration of question one. These data were coded utilizing the CoI theoretical framework. Interview data as well as field notes were used to explore research question two. Interview transcripts and field notes were subjected to categorical aggregation (Cresswell, 2007) to derive the analysis framework that was used for both the interview and field note sources.

\section{Participant Pseudonyms}

As previously discussed, six third-year medical school students, one faculty member and one participant observer participated in this study. Attendance was $100 \%$ for all four SCRs and each student also participated in one 10-15 minute interview (the faculty member was intentionally not interviewed as part of the study). Four students were male and two were female. To protect participant privacy, student names were changed in this study. The following pseudonyms were used for student participants: James, Billy, Jimmy, Trent, Heather and Darcy.

As previously stated, one faculty member participated in this study. This faculty member was an Associate Professor of Family Medicine, female, and was present for all 
SCR sessions. To protect the subject's privacy, this study will refer to the faculty member as Dr. Linda Day.

\section{Chapter Layout}

This chapter will describe the results of the data analysis process for the SCR activity as well as the separate coding analysis used for the student interviews and field notes. It will be organized around the three data sources in the following order: CoI analysis of SCR videos, categorical analysis of interviews, and categorical analysis of field notes.

The CoI analysis section will begin with a brief review of the coding structure of the CoI framework. A description of the coding software used for the CoI analysis, NVivo, as well as the data collection technique will follow. This technique description will entail how the SCRs were coded using the CoI framework as well as some general examples of the coding process for each of the three CoI presences (Social, Cognitive and Teaching). After general examples of CoI codes in the SCR are provided, a description of the code patterns across the four SCR sessions will be given. To describe the patterns, each CoI presence will be explored individually from the CoI coding hierarchical levels of presence, category and indicator. In exploring the data for each presence, patterns and trends observed in the coding across the four SCRs will be described.

The sections describing the categorical analyses of the interview and field note data will be organized similarly to one another. Both sections will begin with a description on how the data were gathered. This description will be followed by an explanation of how codes for both data sources were derived using the categorical 
aggregation technique (Cresswell, 2007). Finally, examples from the interviews and the field notes will be provided for each code.

\section{COI Analysis}

SCR dates. The four SCR sessions took place over the months of September and October of 2012. All SCRs took place online in the Adobe Connect meeting room. SCR 1 took place on September fourteenth, 2012 and lasted one hour and forty-four minutes. SCR 2 took place on September twentieth, 2012 and lasted two hours and eight minutes. SCR 3 took place on October fourth, 2012 and lasted two hours and twenty-seven minutes. Finally, SCR 4 took place on October eighteenth, 2012 and lasted two hours and twenty-four minutes. ${ }^{4}$

\section{Coding software.}

As previously described, all coding and analysis for this dissertation were done using the proprietary qualitative research software NVivo (Version 10). NVivo was chosen as it allows for direct coding of videos. Due to the multi-modal nature of the simultaneous interactions within the Adobe Connect meeting room (e.g. students talking on the video pod while others chatted in the chat pod), the video recordings themselves were coded, rather than textual transcripts. NVivo allowed this functionality by allowing me to insert codes (or "nodes" in NVivo terms) directly on the timeline of the video recording (See Figure 4.1 for visual representation of the coding process). NVivo also allowed for textual coding, and this coding functionality was utilized for the field note analysis.

\footnotetext{
${ }^{4}$ SCR 1 was shorter than the other SCRs due to one fewer presentation being scheduled that day than on the other three sessions. The scheduling of student presentations was done externally by the Family Medicine clerkship coordinator with each student presenting three times over the course of four sessions.
} 


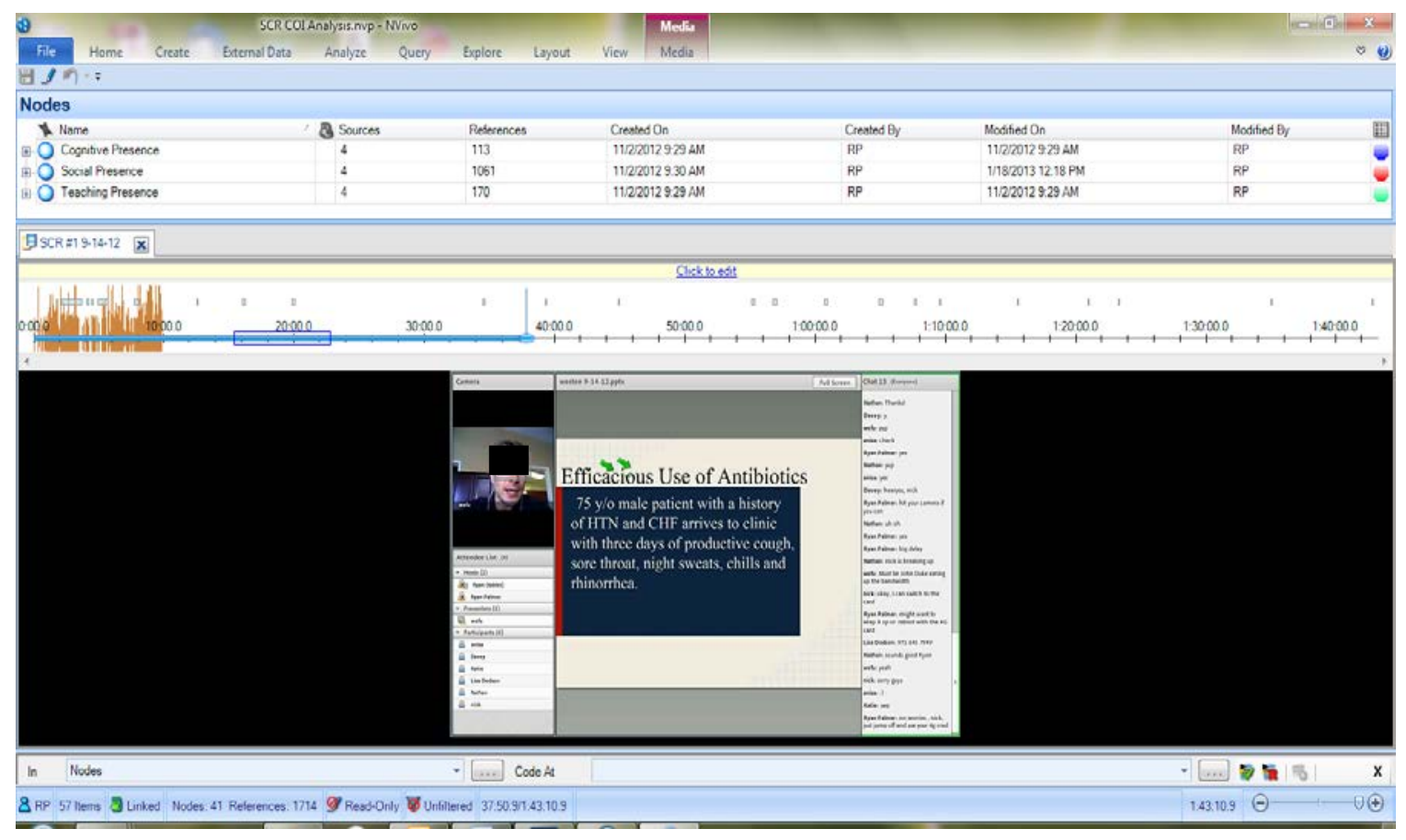

Figure 4.1: NVivo allows for codes to be inserted directly on the timeline above the video file.

SCR data extraction technique. All SCR sessions were recorded via the Adobe

Connect meeting interface. Briefly, the Adobe Connect software allows a meeting "host" (a role performed by me during the SCR sessions) to record a meeting. The recording is placed in the Adobe Connect "cloud," and the host is able to share the recording as streaming media with anyone who may want to view it after the fact (a viewing experience similar to that of watching videos on YouTube). The software also allows the host to "offline" a recording, meaning the video can be saved directly to a computer's hard drive for offline (i.e. non-Internet connected) viewing. As I needed to import video files into the NVivo software in order to code them, I "offlined" all four recorded SCRs for import into NVivo. I then converted the offlined files to a format compatible with NVivo and imported them into the software for analysis (there were no changes to the data outside of file format type that occurred as a result of the conversion). 
Summary of codes used. The codes used for the SCR video data came directly from the CoI framework. As described in Chapter Three, the definitive source for CoI codes used in this analysis came from E-Learning for the 21st Century (2011) by the original generator of the CoI framework, Dr. Randy Garrison. Garrison (2011) served as a recent comprehensive source for the CoI framework as it effectively summarized a decade worth of CoI research. Additionally, I personally communicated with Dr. Garrison via email asking if the codes/indicators he listed in E-Learning for the 21st Century (2011) were the most up to date codes to use in my study. Dr. Garrison verified that they were indeed the most up to date codes to use for a CoI analysis (personal communication, 10/12/12).

The CoI coding structure as entered into NVivo for analysis is represented in Figure 4.2. Data for this study was analyzed at all three levels of the CoI hierarchy. To review, the first level hierarchy is “presence.” Presences are written in capital letters in Figure 4.2. The second level hierarchy is “category.” Categories are underlined in Figure 4.2. The third and final level is "Indicator." Indicators are written in italics in Figure 4.2 (Indicators will be written in italics hereafter). All CoI coding levels are illustrated in Figure 4.2.

\section{COGNITIVE PRESENCE}

a. Exploration- Inquisitive (divergent)
i. Brainstorming
ii. Divergence
iii. Information exchange
iv. Intuitive leaps
v. Suggestions 
b. Integration- Tentative (convergent)
i. Convergence
ii. Solutions
iii. Synthesis

c. Resolution
i. Apply
ii. Defend
iii. Test

d. Triggering Event- Evocative (inductive)
i. Puzzlement
ii. Recognize a problem

\section{SOCIAL PRESENCE}

a. Cohesive communication

i. Addresses or refers to the group using inclusive pronouns

ii. Phatics, salutations

iii. Vocatives

b. Interpersonal Communication

i. Affective expression

ii. Self Disclosure

iii. Use of humor

c. Open Communication

i. Asking questions

ii. Complimenting, expressing appreciation

iii. Continuing a thread

iv. Expressing agreement

v. Quoting from others' messages

vi. Referring explicitly to others' messages

III. TEACHING PRESENCE

a. Direct instruction

i. Confirm understanding through assessment and explanatory feedback

ii. Diagnose misconceptions

iii. Focus the discussion on specific issues

iv. Inject knowledge from diverse resources

v. Present content- questions

vi. Responding to technical concerns

vii. Summarize the discussion

b. Facilitating Discourse

i. Assess the efficacy of the process

ii. Drawing in participants, prompting discussion

iii. Encouraging, acknowledging, or reinforcing student contributions

iv. Identifying areas of agreement-disagreement

$v$. Seeking to reach consensus-understanding

vi. Setting climate for learning

c. Instructional Design and Organization 


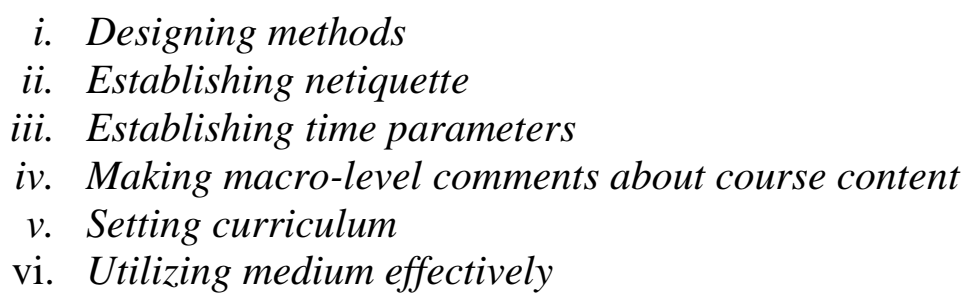

Figure 4.2. CoI coding structure as entered in NVivo software.

\section{Unit of analysis in coding process.}

An important choice researchers coding with CoI must make is how to determine the unit of analysis for coding ${ }^{5}$ (Garrison et al., 2006). Specifically, a researcher must determine what unit in the data should constitute a code: word, sentence, phrase, etc.. Garrison et al (2006) recommend that "in determining a unit it is argued that the message unit may be a good compromise..." (p. 2). This statement served as my guideline in using the CoI framework. Specifically, when I encountered an instance of a CoI indicator in the video transcript (e.g. a student making a funny comment, hence the "use of humor" indicator for social presence), I would mark the code at the point the instance took place, though I would not necessarily code for the entire length of the indicator. Specifically, when a student told a joke, I would not code the entire joke, but rather the point at which the joke took place. I coded at the beginning of an indicator only because, due to the multi-modal nature of the SCR Adobe Connect meeting room, several indicators would often take place at the same time from different participants. As such, I found it to be much more effective to code at the point an indicator started so I could capture multiple

\footnotetext{
${ }^{5}$ Not to be confused with the unit of analysis for the study, which was the SCR activity.
} 
indicators efficiently. It is important to note that my coding process was decided upon prior to coding, so the coding process was consistent across all four SCRs.

Participant participation. As previously stated, all participants in this study were present for all SCRs. For the SCRs, student participants were assigned to present for three SCR presentations and all students met this requirement. The SCR assignment asked students to keep SCR presentations between 15-20 minutes, and students all kept within these boundaries. Discussions that followed SCR presentations were usually around 10 minutes. Thus, all students presented approximately three times for thirty minutes over the span of four SCRs.

The codes in this study were not assigned to individual participants, thus I was not able to measure how much a student participated based on the CoI codes. I made the decision not to associate individual codes with participants for two reasons. The first reason I chose not to associate individual codes with participants was that associating codes with individuals fell outside the scope of my research question: What is the impact on learners when a deliberate CMS like the SCR is used to deliver the rural medical education experience? "Learners" is a plural term and therefore I was interested in exploring the experience of the group of learners rather than the experience of individual learners. The second reason I chose not to associate codes with individuals was that it would have added an additional layer of complexity to the coding process, a complexity as I've stated was unnecessary based on my research question. The process for coding the SCRs with the CoI framework was laborious, and coding at the individual participant level would have added work to the coding process to little effect in better answering the research question. 
Despite not having coded participants individually, I can say as a participant observer that all participants contributed to and participated in group activities in an approximately equal capacity. The fact that each student participant had the same amount of assigned SCRs as well as time to present the SCRs is one measure of the approximate equality of participation. Additionally, in my role as participant observer I did not note any one member of the group participating any more or less throughout all four SCRs. Thus, it can be assumed for this study that participants participated in an approximately equal capacity during the SCRs.

Coding hierarchy. As indicated earlier, the CoI framework includes three tiers of codes. The highest tier is presence. There are three presences, cognitive, social and teaching. The sub-level to presence is category. Each presence has several categories. For example, Social presence is made up of the categories open communication, interpersonal communication and cohesive communication. The final level of coding is indicator. Each category is made up of indicators. For example, the indicators for interpersonal communication (which resides beneath social presence) are affective communication, self-disclosure and use of humor (See Figure 4.2 for a graphical presentation of the CoI coding hierarchies).

Though I coded at the indicator level only for this study, I also wanted to collect data at the category and presence levels. To do so, I set up my coding structure in NVivo to simultaneously code at the category and presence level when I coded for an indicator. For example, when I coded for the indicator use of humor, a code was simultaneously generated for the interpersonal communication category as well as for Social presence. 
Setting up my codes this way gave me the ability to display and analyze data from all three levels of the CoI coding hierarchy.

General coding examples. To clarify how the coding process took place, I will now provide a few examples of how indicators were coded during data analysis and how coding those indicators simultaneously coded the associated categories and presences codes.

The first example is of the indicator vocatives (one person addressing another person by name). In SCR 1, Jimmy responded to a question from Billy with the following: "The crummy answer, Billy, for what we did for the patient is we sent him to neurology." (SCR 1, 1:20.59). In this example, "Billy" is the coding unit of analysis for the indicator vocatives. The checked boxes in Figure 4.3 illustrate how in coding for the indicator vocatives with NVivo I was also simultaneously coding the category cohesive communication as well as for Social presence. Recall the NVivo software automatically coded at the higher level hierarchies for me when I coded an indicator so adding in the additional codes did not require additional effort. 


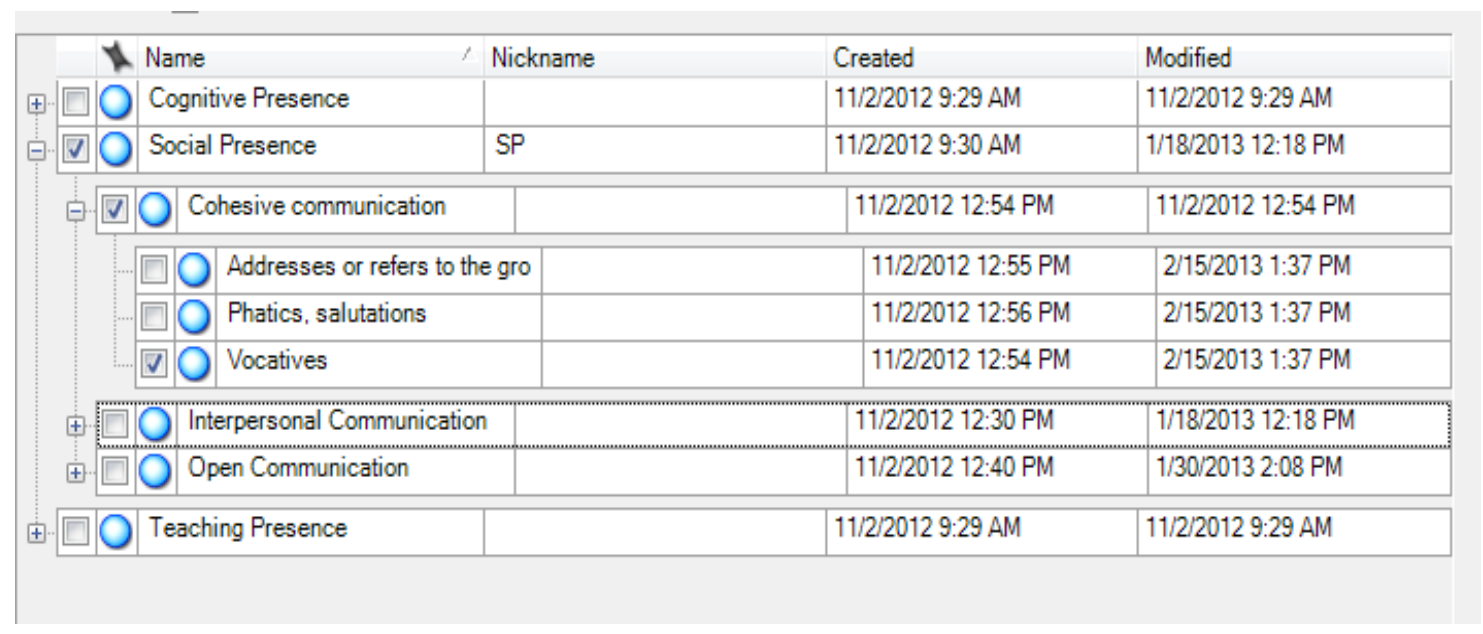

Figure 4.3: Coding example of vocative indicator as recorded in NVivo software. The checkmarks indicate all codes generated for one coding instance.

Another example of my general coding process involved the indicator drawing in participants, prompting discussion. During SCR 3, Trent gave an SCR presentation on skin conditions. At one point he displayed pictures of different skin conditions and asked his peers to discuss what they thought the conditions were:

Trent: (Using pointer on screen to indicate a group of pictures) Okay, what do you guys think, what are these over here? (SCR 3 55.22.3) In this example, Trent's question was the unit of analysis for the indicator drawing in participants, prompting discussion. As is illustrated below in Figure 4.4, by coding for drawing in participants, prompting discussion, I was also simultaneously coding Trent's question under the category facilitating discourse as well as for Teaching presence. 


\begin{tabular}{|l|l|l|l|l|}
\hline \multicolumn{3}{|c}{ Automatically select descendant nodes } \\
\hline
\end{tabular}

Figure 4.4: Coding example of drawing in participants, prompting discussion indicator as recorded in NVivo software.

The ability to simultaneously code at multiple levels of the CoI hierarchy gave me the ability to break out and combine the data from the SCRs in multiple configurations. Indeed, this ability to creatively query the data was important as the sheer amount of data produced by the CoI analysis of this study alone was notable. To illustrate, Table 4.1 displays all coding data captured in this study. The totals include all levels of codes (presence, category, and indicator) totaled together for each SCR. 
Table 4.1

Summative display of all CoI codes over all four SCRs

\begin{tabular}{|l|l|}
\hline & Total Codes \\
\hline SCR 1 & 953 \\
\hline SCR 2 & 1396 \\
\hline SCR 3 & 1305 \\
\hline SCR 4 & 1148 \\
\hline
\end{tabular}

SCR 1 had the fewest codes at 953 (this being the session in which there was one fewer presentation than in the others). SCR 2 had the most codes at 1,396, followed by SCR 3 at 1,305. Finally, SCR 4 had 1,148 total codes. Though these code totals represent "triple dipping” in that one indicator code was also counted as a category code as well as a presence code, the fact that I could query these data on all levels made each level important and unique from the next , thus warranting all code levels being totaled as part of the whole. In conclusion, the number of codes I analyzed for this study was quite large.

In order to make sense of the large amount of coding data this study generated, I first went back to research question one: What is the impact on learners when a deliberate CMS like the SCR is used to deliver the rural medical education experience? To best describe the impact of the SCR, I decided to analyze the data by looking for the patterns over time for each presence. In the following sections, I will describe how I looked at the patterns of the codes over time for each presence to best answer research question one. 
CoI all Presences level analysis. Figure 4.5 describes the Social, Teaching and Cognitive presence codes over all SCRs. Social presence was the highest detected presence. Teaching presence was the second highest presence, followed by Cognitive presence.

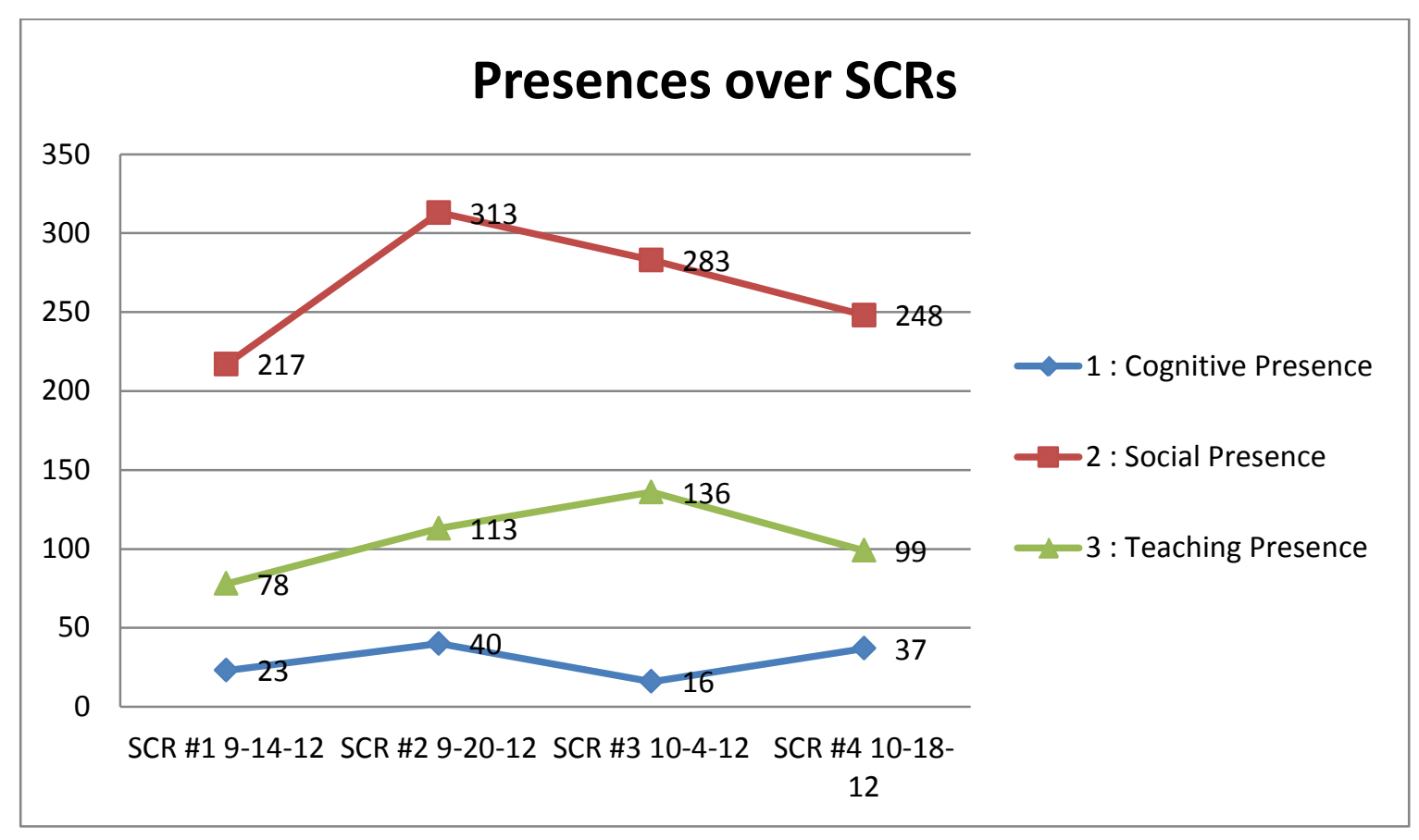

Figure 4.5: CoI presences over all SCRs (numbers indicate number of individual codes)

Reviewing Figure 4.5, it is apparent that the highest and second-highest presences, Social and Teaching, actually decreased on the final SCR while the lowest presence, Cognitive, increased slightly. By introducing basic concepts of trend analysis (Johnson \& Christensen, 2012) to look at changes in presences over the four SCRs, it is evident that all presences were trending upward through SCR 4 (see Figure 4.6). 


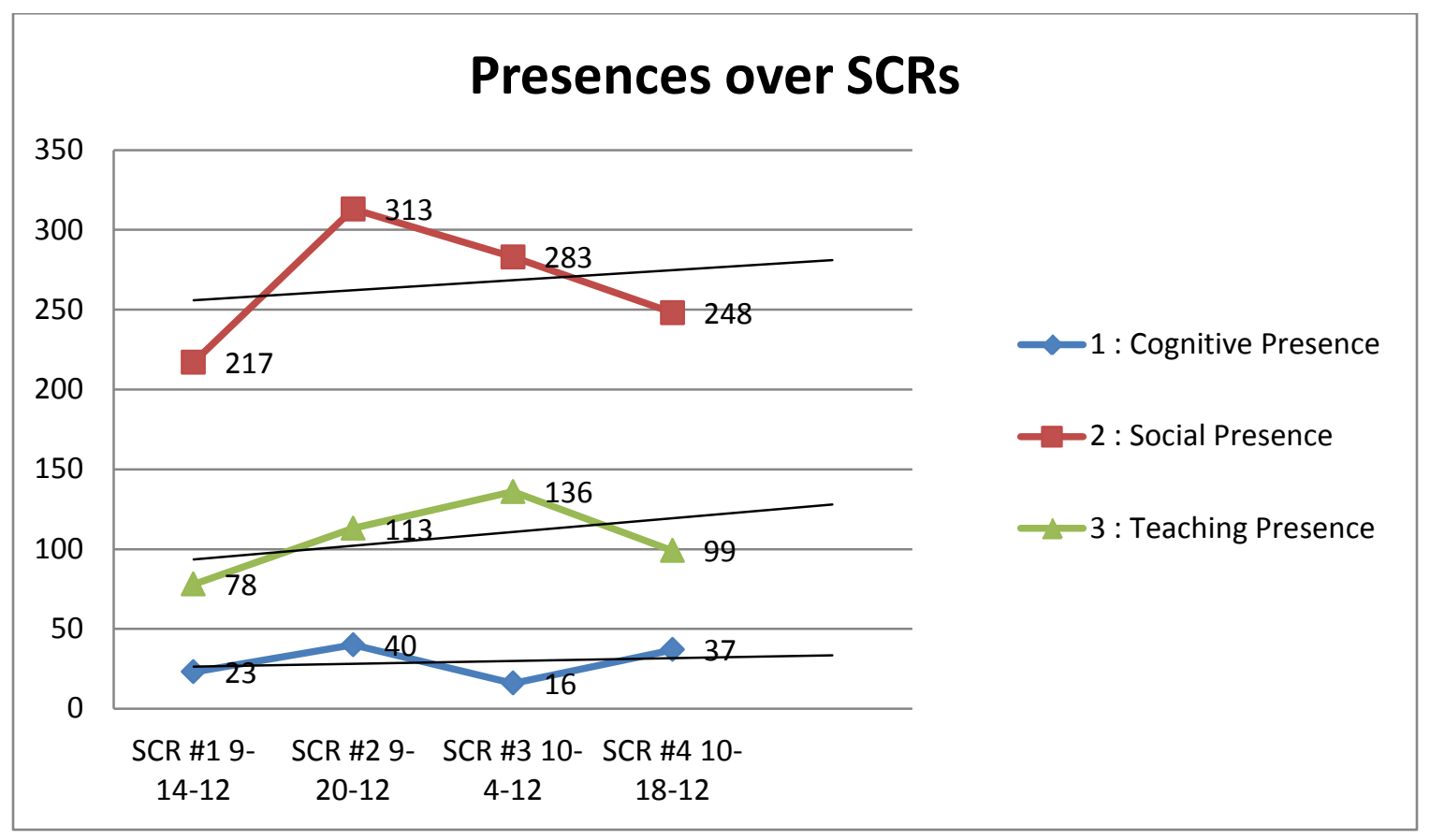

Figure 4.6: CoI presences over all SCRs (trendline included)

In other words, based on the coding of the four SCRs, all presences might possibly have continued their upward trend if the SCR activity was to continue.

CoI individual Presences level analysis. Now that I have reviewed the pattern of all three presences combined, I will now look at each presence individually from the presence, category and indicator coding levels, describing observed patterns for each coding level.

Social presence analysis: Presence level hierarchy. The fact that Social presence was the highest presence in this study is supported by the CoI literature. Specifically, ORSP students knew one another prior to the SCRs and the literature indicates this could have an accelerating effect on Social presence (Garrison, Anderson, \& Archer, 2010; Garrison, 2011). Also, the fact that the SCR meetings were synchronous also made high levels of Social presence more likely. According to Garrison (2011), "consideration needs 
to be given to an initial face-to-face or synchronous online meeting of the group. This can have an accelerating effect on establishing social presence and can shift the group dynamics much more rapidly toward intellectually productive activities (p. 41).”

Despite the group's familiarity with one another prior to the SCR activity, it is important to note that Social presence was at its lowest level during SCR 1 and then escalated significantly during SCR 2. In other words, there was a noticeable "jump" in Social presence between SCR 1 and SCR 2.

The low levels of Social presence in SCR 1 may be attributed to the group adjusting to the technology of the online meeting room. As a participant observer I spent much of my effort during SCR 1 troubleshooting technical concerns, such as telling students how to turn on their computer microphones and webcams. Additionally, SCR 1 was the session with the biggest technical challenges as compared to the other three SCRs. The first technical challenge in SCR 1 came when Dr. Day had continuous trouble hearing the group due to a voice delay. Troubleshooting, I diagnosed this issue as her Internet connection being poor and had her dial in with her phone to get sound. This solved the issue but added technical "friction" to the experience of SCR 1. An additional instance of technical friction that took place in SCR 1 occurred when Trent was "booted off" the Internet in the middle of his SCR presentation. It took several minutes to get him back into the room, and by the time he did the next student had started presenting.

It is important to note that by SCR 2 the technical issues described previously as well as the students' lack of familiarity with the Adobe Connect meeting room dissipated. This observation is illustrated by reviewing the one indicator code that related directly to troubleshooting technical concerns, responding to technical concerns. Figure 4.7 
illustrates the strong downward trend of the responding to technical concerns indicator as the SCRs progressed. Notably, the downward trend in technical issues was observed simultaneously with the upward trend in Social presence.

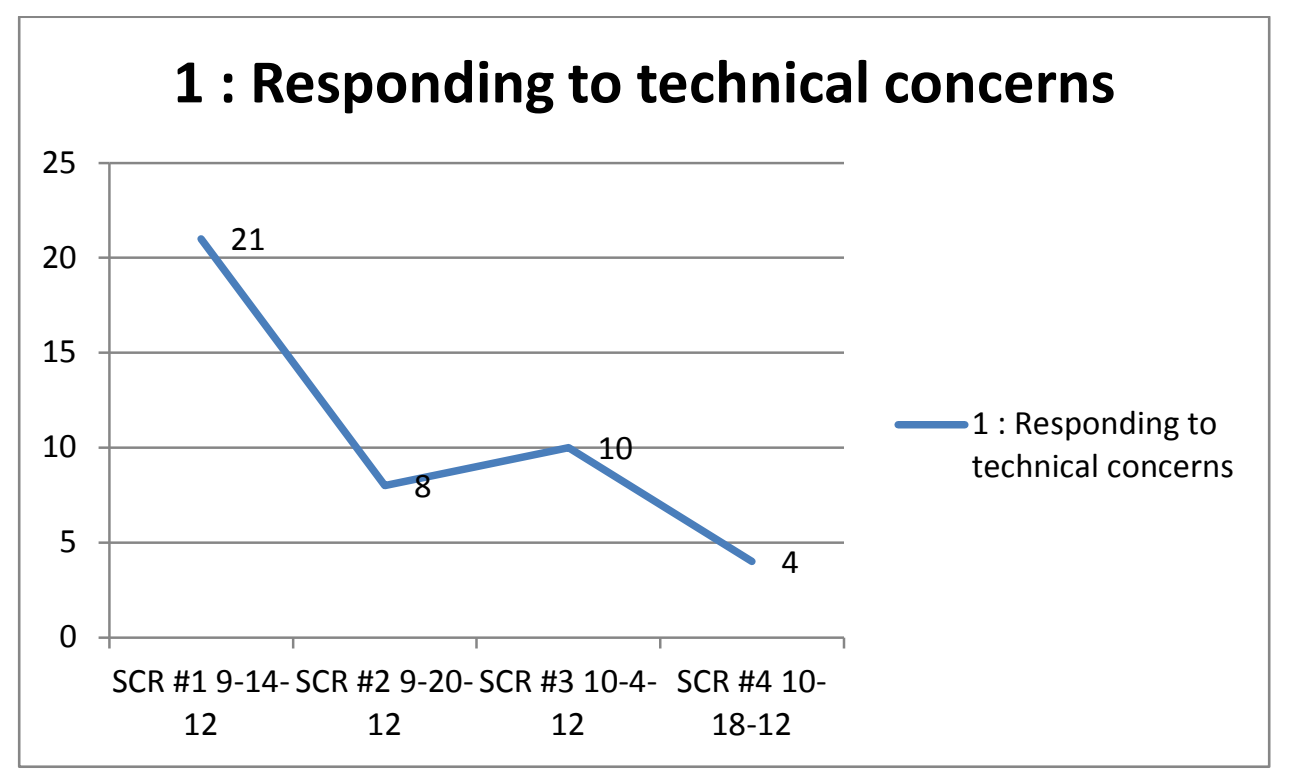

Figure 4.7: Responding to technical concerns indicator over all SCRs.

Social presence: Category level analysis. Figure 4.8 illustrates longitudinal data for the Social presence category level codes over the four SCRs. 


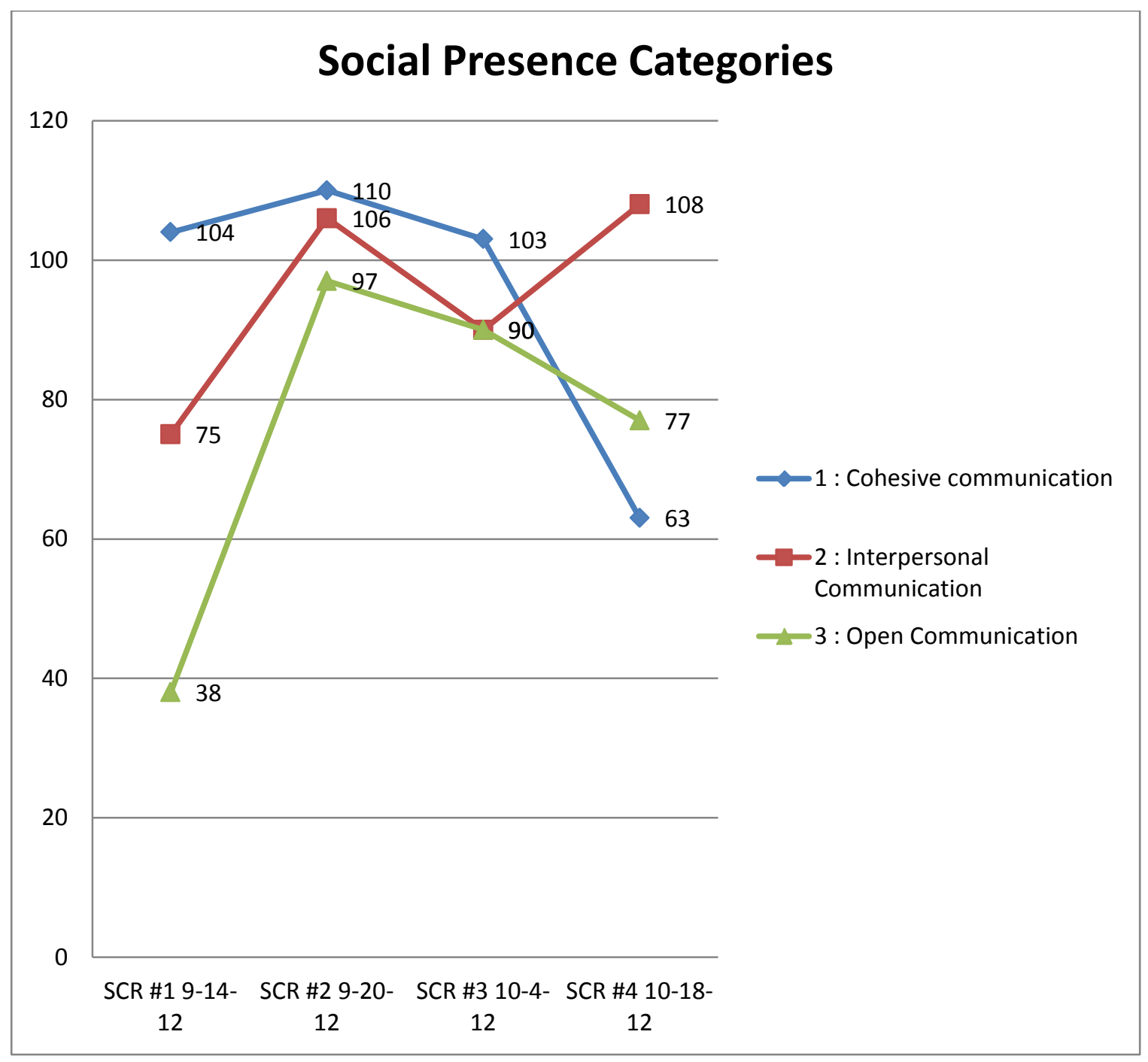

Figure 4.8: Social presence categories over all SCRs.

Reviewing the category codes reveals two patterns regarding the impact of Social presence on the group. One pattern is that all categories rose sharply between SCR 1 and SCR 2. This may lend further weight to the observation that technical problems hindered Social presence in SCR 1. When those issues decreased (as illustrated in Figure 4.7), students were able to focus more on one another and the task at hand rather than the technology, thus allowing for Social presence to thrive among group members. 
Another pattern observed in Figure 4.8 is that all Social presence categories remained fairly similar in their trends for SCRs 1-3, yet deviated between SCR 3 and 4. Specifically, the cohesive communication and open communication categories declined noticeably between SCR 3 and SCR 4 while the interpersonal communication category increased between SCR 3 and 4.

Social presence: Indicator levels analysis. Figure 4.9 outlines the patterns of Social presence indicators over all SCRs. 


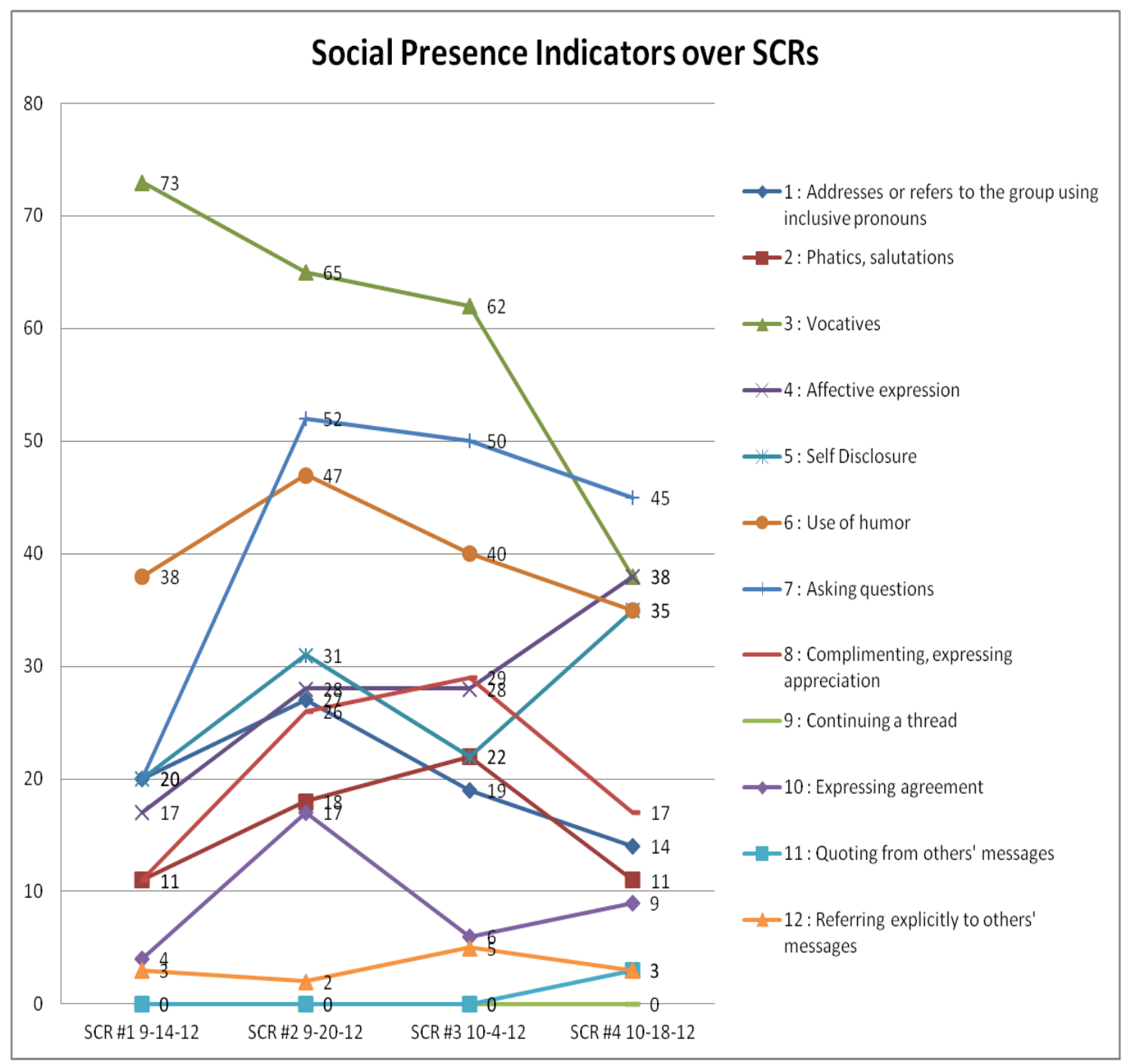

Figure 4.9: Social presence indicator level codes over SCRs

Similar to the pattern observed in the Social presence category codes, the majority of Social presence indicators declined between SCR 3 and SCR 4. However, two indicators, self disclosure and affective expression, rose noticeably between SCR 3 and SCR 4. To review, self disclosure is defined as when a participant in an online course "presents biographies, details of personal life outside of class, or expresses vulnerability" 
(Garrison, 2011, p. 38). There were 108 total codes for self disclosure recorded in this study. Some examples include:

- Heather writes in the chat box "My preceptor is 'stingy' with pain meds." (SCR 2, $58: 11.3)$

- Trent tells the group a story of a patient he saw that came in with a heart attack he had while "packing an elk out" that he had just hunted and killed. The story is humorous and telling of Trent's experience in rural Oregon as the patient did not know he had a heart attack but had just told Trent,"Man, I was packing this elk out and my chest was killing me!" (SCR 3, 14:52.0)

- Heather confirms that she has just given her SCR presentation from her bed. When asked by another peer if her other presentations were from the same place, she discloses "Always." (SCR 4 2:13.27) Additionally, affective expression, the other indicator that rose between SCR 3 and SCR 4, is defined as "conventional expressions of emotion, or unconventional expressions of emotion, including repetitious punctuation, conspicuous capitalization, emoticons" (Garrison, 2011, p. 38). There were 111 codes for affective expression recorded in this study, with some examples being:

- Heather writes into the chat box "Oh YEAH!" (SCR 2 32:38.4)

- Billy chats in "haha" in response to a joke. (SCR 4 1:36.42)

- Heather chats in "HUGE NEEDLE." (SCR 4 1:37.43)

To summarize, the Social presence indicator codes revealed a pattern where most indicators declined during the fourth and final SCR. However, two indicators rose 
notably in SCR 4, one that revealed emotion (affective expression) and the other that revealed vulnerability (self disclosure). It can be said, then, that in SCR 4 the group seemed to shift towards a more openly emotional and vulnerable relational style with one another.

Social presence analysis summary. In conclusion, the Social presence of the group was the highest recorded presence in this study. As technical issues from SCR 1 were eliminated, Social presence seemed to rise noticeably. An observation at the categorical level data of Social presence was that, as the open and cohesive communication categories decreased in the fourth and final SCR, interpersonal communication increased. At the indicator level, SCR 4 also revealed a pattern of most indicators decreasing. The only indicators that increased noticeably in the final SCR were those interpersonal indicators of affective expression and self disclosure. As affective expression and self disclosure respectively reveal emotion and vulnerability, the data suggests a movement by the group towards a deeper connection with other group members through increased displays of trust and vulnerability.

Teaching presence: Presence level analysis. The format of the SCR activity itself assured that Teaching presence would remain a strong presence through the SCR activities. Specifically, during the SCR activity, the presenter essentially became the "teacher." The presenter's task was to guide her peers through the activity that she had prepared. Thus, Teaching presence was not reserved for the SCR facilitator, Dr. Day, alone. Students themselves were perpetuators of Teaching presence every time they presented their SCRs, thus increasing the likelihood for Teaching presence codes to be recorded. 
One observation from the SCRs relating to Teaching presence was a tendency for student presenters to ask premeditated questions. I am defining premeditated questions as those where the SCR presenter, or "teacher," already knew the answer that the "students" needed to guess. This tendency naturally flowed from the nature of the SCR assignment itself, as the task of the SCR was to prepare a case and guide one's peers through the clinical reasoning process. This task-based focus in the SCR led to premeditated questions. The tendency for participants to ask premeditated questions while in an authoritative role reflected a traditional teaching relational style. I define a traditional teaching relational style as one where the authority figure has the "right" answer in mind, and the student's task is to figure out what that correct answer is. Based on my observations, the traditional teaching relational style was dominant during most SCR presentations.

Occasionally, however, a student presenter would ask a "genuine” question during the SCR. A genuine question was a question asked by a presenter for which they did not have a predetermined answer. As genuine questions forced the group to participate in a discussion rather than guess what the presenter was thinking, I have defined this as a discussion/ constructivist style of relating. In general, the data to be described in this section will illustrate a pattern of Teaching presence in the SCRs that moved from a traditional teaching relational mode to a discussion/ constructivist style of relating between group members.

Teaching presence: Category level analysis. A look at the category level codes of Teaching presence over the four SCRs suggests that the group moved away from a 
traditional teaching relational mode of interaction. Figure 4.10 illustrates the teaching presence longitudinal categorical data over the four SCRs.

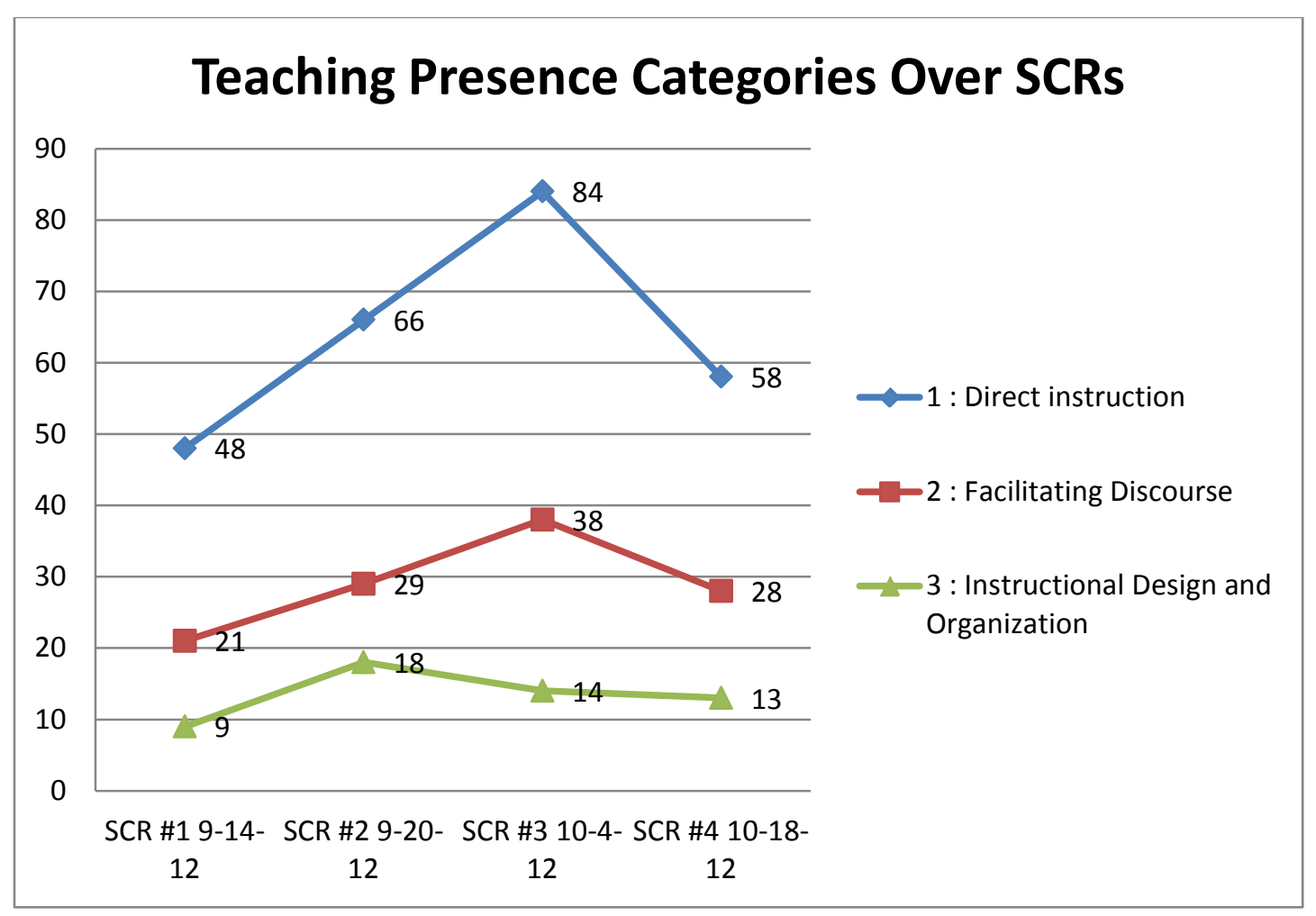

Figure 4.10: Teaching presence categories over all SCRs.

With the exception of instructional design and organization, all categories steadily increased through SCR 1 through 3 and then steeply dropped off between SCR 3 and SCR 4.The drop off for instructional design and organization was steadier, and began after SCR 2. Thus, all categories of Teaching presence decreased as the study progressed, suggesting that the group may have been moving away from the task of teaching one another as they entered SCR 4. It is also worth noting that the most significant categorical decline in SCR 4 was direct instruction. To review, direct instruction relates to the need for content expertise in instruction so as to accurately answer student questions and correct misconceptions. Thus, direct instruction is the most "teacher-centric" of the 
categories for Teaching presence, and it dropped the most significantly over time during the SCRs, supporting the observed pattern of a movement away from a traditional teaching relational style to a collaborative constructivist style of relating.

Teaching presence: Indicator level analysis. A look at the indicator level of Teaching presence also gives insight into the pattern of the group moving away from a traditional teaching relational mode. Figure 4.11 illustrates the Teaching presence indicator data over time in this study. 


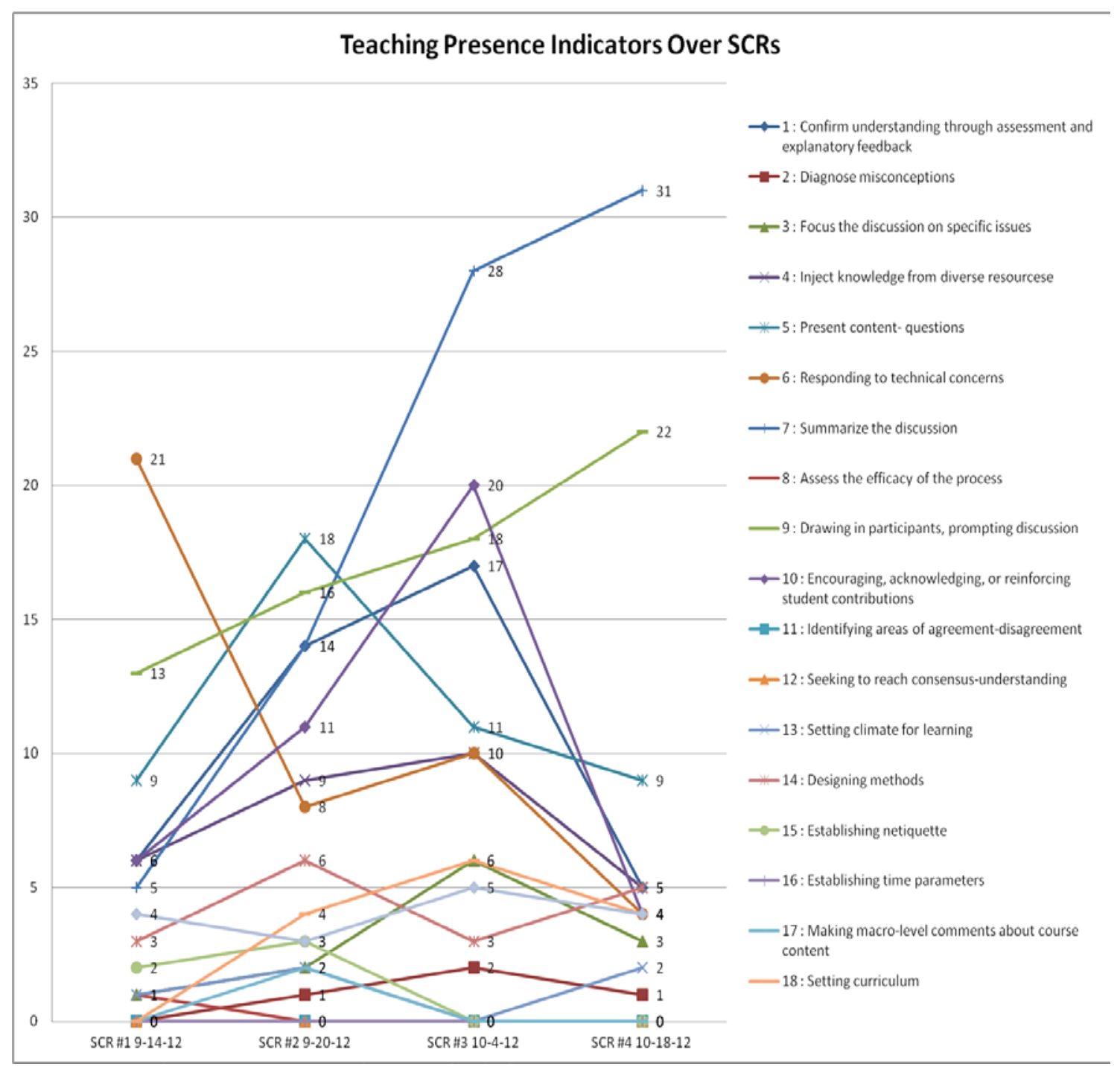

Figure 4.11: Teaching presence indicators over all SCRs.

An observation that Figure 4.11 reveals is that almost all teaching presence indicators dropped off noticeably between SCR 3 and SCR 4. The only indicators that increased noticeably from SCR 3 to SCR 4 were drawing in participants, promoting discussion and summarize the discussion. Additionally, by SCR 4 both drawing in participants, promoting discussion and summarize the discussion were detected at the 
highest levels of all teaching presence indicators over all SCRs. (There was also an increase between SCR 3 and SCR 4 for designing methods and setting the climate for learning. However, both of the previously mentioned indicators were detected at low levels throughout all SCRs and I therefore did not note them as noticeable increases). Intriguingly, both drawing in participants, promoting discussion and summarize the discussion involve discussion, lending weight to the idea that the presence began to shift away from a traditional teaching relational mode to a discussion/ constructivist style of relating between group members.

Additionally, it is notable that the two teaching presence indicators that saw the biggest drop from SCR 3 to SCR 4 were encouraging, acknowledging, or reinforcing student contributions and confirm understanding through assessment and explanatory feedback. Both of these indicators are teacher-centric. Specifically, encouraging, acknowledging, or reinforcing student contributions reflects a traditional teacher student authoritative relationship as it describes a teacher giving praise to a student. In a more constructivist model with participants being on equal footing, this type of authoritative "head patting" would be less necessary. Examples of encouraging, acknowledging, or reinforcing student contributions were:

- Jimmy (while presenting and in response to James answering a question): Yes, very good James. (SCR 1 1:11.19)

- Dr. Day: Yep, Darcy is right, it's actually depth. The biggest prognostic... (SCR 3, 1:05.36) 
- Dr. Day (to the group at the conclusion of the SCR): Ok, great. Excellent choices of topics, well done. You all have adapted very well to this technology.... (SCR 2, $1: 54.11)$

In the examples above, the praise goes to the students for doing something "right" whereas in a discussion-based, constructivist environment the only thing "right" is to be actively engaged and participating in the group learning.

The other indicator that reduced significantly from SCR 3 to SCR 4 was confirm understanding through assessment and explanatory feedback. The aforementioned indicator was perhaps the most teacher-centric indicator of all for Teaching presence. This is evidenced by the fact that Dr. Day, the facilitating faculty member of the group, was almost exclusively coded with this indicator. For example:

James: I think delayed prescription might be a way to avoid a second visit, but really it doesn't seem to avoid that problem.

Dr. Day: Yeah, and I think that's really and, um, I think you have to kind of learn from your system and from particular location and what kind of pushes, and what drives patient visits there, because it's somewhat different depending on how short of providers you may be or how quickly you can get an appointment... (SCR 1, $55: 25.1)$

Again, this code illustrates a traditional classroom-based instructional dynamic, with the teacher affirming the student's contributions. Yet in a constructivist, discussion-based environment this type of teacher-student dynamic is less desirable. The fact that the indicators understanding through assessment and explanatory feedback decreased so 
significantly in SCR 4 supports the notion that the group moved to a more discussionbased style of interacting at this point.

To better illustrate the divide between the decline of the traditional teaching relational mode and rise of the discussion/ constructivist style of relation between group members in SCR 4, I have included the indicators that represent both the "teachercentric" indicators (encouraging, acknowledging, or reinforcing student contributions and confirm understanding through assessment and explanatory feedback) as well as the "constructivist" indicators (drawing in participants, promoting discussion and summarize the discussion) in Figure 4.12.

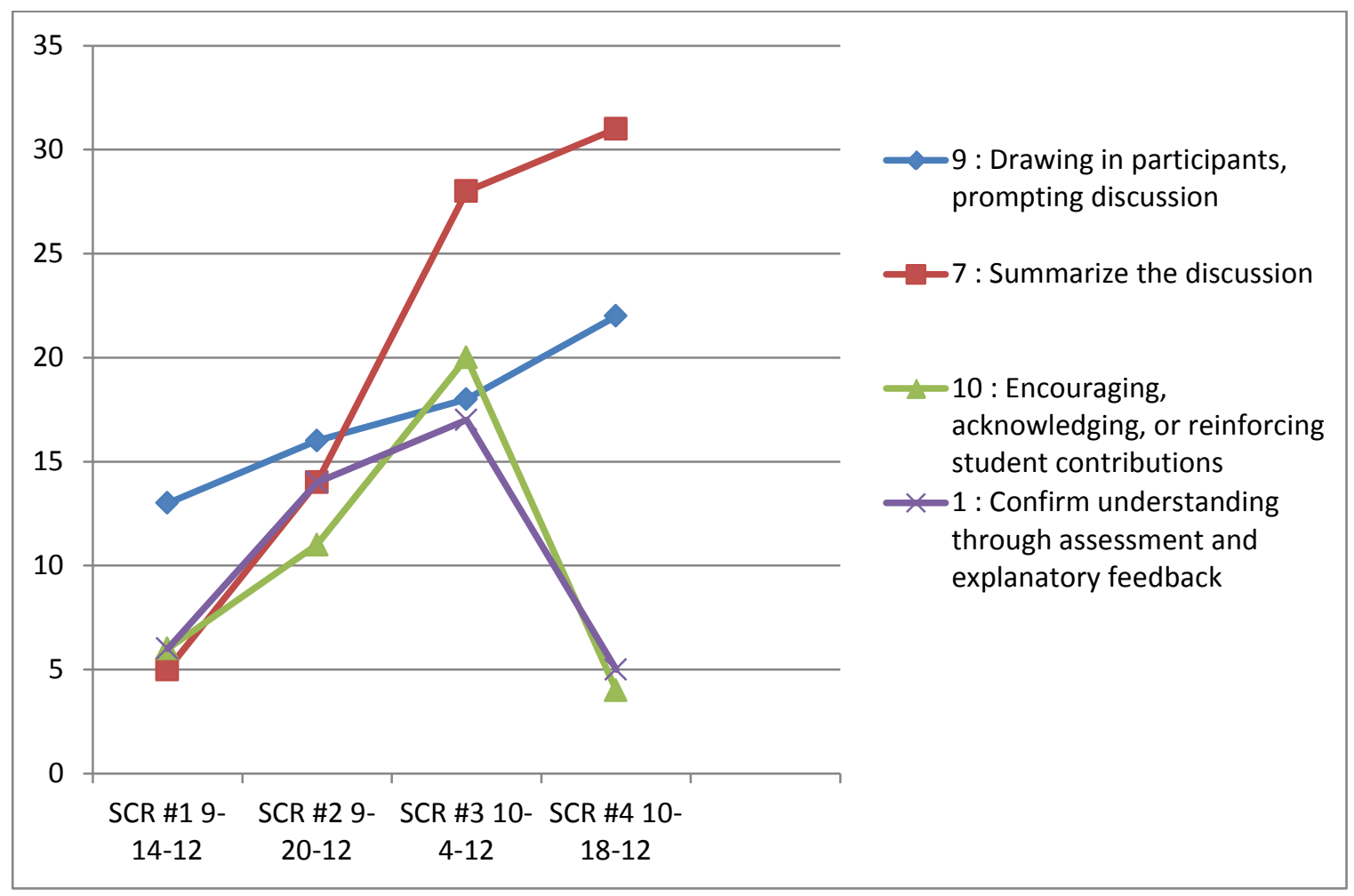

Figure 4.12: Comparison of declining teacher focused indicators to increasing constructivist -ocused indicators.

In reviewing Figure 4.12 it is clear that the discussion-focused indicators increased notably in SCR 4 while the teacher focused indicators decreased notably. 
Teaching presence analysis summary. In summary, Teaching presence was the second highest presence measured in this study, likely due to the nature of the SCR activity itself. A closer look at the data suggests that the group moved away from those categories and indicators that were more representative of the traditional classroom dynamic and more toward those categories and indicators representing a discussion based, constructivist learning environment.

\section{Cognitive presence analysis.}

I will now conclude the SCR analysis portion of Chapter Four with a discussion of the Cognitive presence coding data. Within the CoI framework cognitive presence is unique in that it is the only presence that involves an internal mechanism, the PI model. The uniqueness of this presence required me to discuss the data in a slightly different format than I did for Social and Teaching presences.

Cognitive presence was the lowest recorded presence for the four SCR activities. As previously discussed, low recording of Cognitive presence in studies utilizing the CoI framework is noted in the CoI literature. To review, Cognitive presence is operationalized through the Practical Inquiry (PI) model, with a student progressing through the four phases of PI: triggering event, exploration, integration, and resolution. A specific issue noted in the literature is that many students do not proceed to the upper-level integration and resolution phases of PI (Garrison, Anderson, \& Archer, 2001; Garrison et al., 2010). Garrison et al. (2010) posit that the reason that students often do not progress to the third and fourth phase of PI is that:

the design and expectations of the educational experience did not require students to move to these phases. This explanation has largely been supported in 
subsequent research. In short, it appears that teaching presence in the form of designing learning activities that require solutions and that provide facilitation and direction will ensure students move through the phases of the PI model in a timely manner (p. 6-7).

In other words, the reason why many students do not progress through the PI model is a fault of the types of activities in which they participate while doing online coursework, rather than a fault in the CoI coding itself.

My experience with this study supports Garrison et al.'s (2010) assertion that the nature of the educational activity can hinder student progression to the latter two phases of the PI model. The coding data from this study supports this, with the majority of codes applying to the first two categories/phases of PI, triggering and exploration.

The premeditated questioning nature of the SCR discussed in the Teaching presence section likely hindered the PI process throughout the four sessions. Though the SCR is a constructivist activity, student presenters often came into each session with a premeditated answer to their own questions. For example, in SCR 4, Darcy's SCR was about animal bites. She had observed a patient with a cat bite and led the group through the progression of the clinical case, including information on rabies treatment. At one point she presented the background on the case and asked the group "What kind of skin pathogens are you worried about?" (1:25.11). Her peers chatted in a variety of responses which she acknowledged: "gram negative? Sure." She then proceeded to her next slide that listed what she thought the top four most pressing infections from the bite were: "So, the main one's that you're going to be worried about are the ones that you mentioned, Pasteurella being one of them...." By having pre-planned what the answers to her 
questions were going to be, Darcy set up a scenario where her peers could only give answers to her direct questions. These types of premeditated questions were not conducive to the higher level critical thinking phases of the PI model.

As previously discussed, premeditated questions were common among student presenters and Dr. Day during the SCRs. The types of questions that were less common but seemed to facilitate movement to the higher levels of the PI cycle were genuine questions. Again, genuine questions were those asked by participants without a premeditated answer in mind or to clarify presentation content. Rather, genuine questions were those questions asked by a participant that truly did not know the answer to the question asked. When genuine questions were asked or statements made, the PI model would often move into the higher third and fourth levels of PI.

To better understand this phenomenon, I will look at the two instances where the highest levels of cognitive presence were recorded in this study. The first was in SCR 2 and actually had nothing to do with SCR content but rather had to do with a technical issue.

Trent was ready to start his presentation when he informed me he was having trouble and could not move his presentation slides forward. This I coded as a triggering event under the indicator recognize a problem. I troubleshot with Trent by asking him technical questions ("Do you see the arrows at the bottom of the presentation box? Have you scrolled down all the way on your screen?"). This interaction I coded at stage two of the PI model, exploration, under the indicator suggestions. Billy then interjected: "Hey, Ryan? For some reason I have complete control of Trent's presentation." This was coded at the exploration category with the indicator information sharing. At this point I realized 
that the issue was that I hadn't clicked a button to reassign presentation "control" from Billy to Trent. I promptly fixed this problem and asked Trent to try moving the slides again. This was coded at the third phase of Cognitive presence, integration, with the indicator solutions. Trent then went on to try the solution, which worked, and he proceeded with his presentation. This I coded as the highest phase of PI, resolution, with the indicator apply. Thus, Trent's genuine question regarding a technical problem moved the group through the full phase of the PI model.

The other event that produced a full PI cycle was an impromptu presentation by Trent in SCR 4. At the start of SCR 4, Trent asked if he could quickly present something that he had seen in clinic recently. Trent was not scheduled to present for SCR 4 and so his request to present was completely voluntary. Trent's "presentation" that followed was actually Trent using the group to help him answer a clinical question regarding a case he and his clinical preceptor were having trouble diagnosing. In this way, Trent's presentation itself was a genuine question. In terms of Cognitive presence, Trent's triggering event came from genuinely not knowing the next answer ("I just don't know if there's anything else I should be thinking about"). In assisting Trent in answering his clinical question, the group moved to the next PI phase, exploration, as is evident in the following chat box excerpt:

JAMES: yikes. I like your thinking with US possibly followed by CT

JAMES: sounds structural

JAMES: horseshoe kidney

BILLY: vasospasm type stuff

DR. DAY: what are the general categories in the diff $\mathrm{dx}$ 
DARCY: le edema

(SCR 4 16:09.1)

In this exchange, group members were exhibiting multiple exploration category indicators, such as brainstorming and information sharing. The group then moved to the Integration level of PI as the brainstorming became more specific. Dr. Day moved the group to the third PI phase with a synthesis indicator, as she brought together the consensus of the group's chat brainstorming into a professional recommendation.

Interestingly, Dr. Day also moved the group into the fourth and final PI phase, resolution. This happened after Dr. Day gave a clinical recommendation for Trent. Jimmy made a good natured joke regarding the recommendation Dr. Day had given, citing the test she suggested and then asking how much the patient smoked (the patient was a seven- month-old child). Essentially, Jimmy was humorously testing the validity of Dr. Day's recommendation. A resolution phase defend indicator code was applied when Dr. Day defended her choice to Jimmy (also good-naturedly) by reminding him that smoking tests were in fact a good idea for children due to second-hand smoke. In summary, Trent's genuine question posed to the group facilitated a movement through the full PI cycle.

In conclusion, two events during this study progressed through the full PI cycle for Cognitive presence. Both situations came from genuine questions that in turn forced the group to assist in active problem solving, i.e. critical thinking. An additional observation was a full progression through the PI cycle was often stifled by students' tendencies to ask premeditated, rather than genuine, questions during the SCR activity. Genuine to this point, I often observed a student’s desire to "just get through the activity" stifling the PI process. 
A good example of such stifling took place in SCR 2 during a presentation by James. James's presentation began to bring up enthusiasm among his peers, and the students started to chat in a series of questions to James regarding his topic. At first James deflected: "Good question, Trent, one second," but as the questions continued James eventually asked his peers to hold off on their questions until he finished getting through his case:

James: Alright, hold your ideas for a second, we're still moving through the case.

Uh, but, good questions, though. (SCR 2, 44:38.0)

The questions subsequently stopped and the PI model was not able to move forward. The shift was notable enough for me to have written the following note:

IMPORTANT POINT: James tells his peers to hold their chat questions until he gets through the case. Clearly the spontaneous nature is throwing him off and frustrating him. In shutting them down, he essentially relegates their questions to social events because they are not triggering any further discussion. This in essence reinforces the typical one-way instructor-student paradigm, and I can see how that shuts down true critical thinking.

In summary, the Cognitive presence data was the lowest recorded of all three CoI presences. This may have been due to the nature of the SCR activity which encouraged a premeditated questioning style, thus hindering the progression of the PI model. In the rare instances where the full cycle of PI was reached, "genuine" rather than premeditated questions instigated the full progression through the PI cycle. 
Cognitive presence: Category level analysis. Figure 4.13 illustrates the longitudinal category data for Cognitive presence in this study. The pattern of codes indicates that all but one category of Cognitive presence rose in the final SCR. The only phase that decreased in SCR 4 was the first and least sophisticated stage of PI, triggering event.

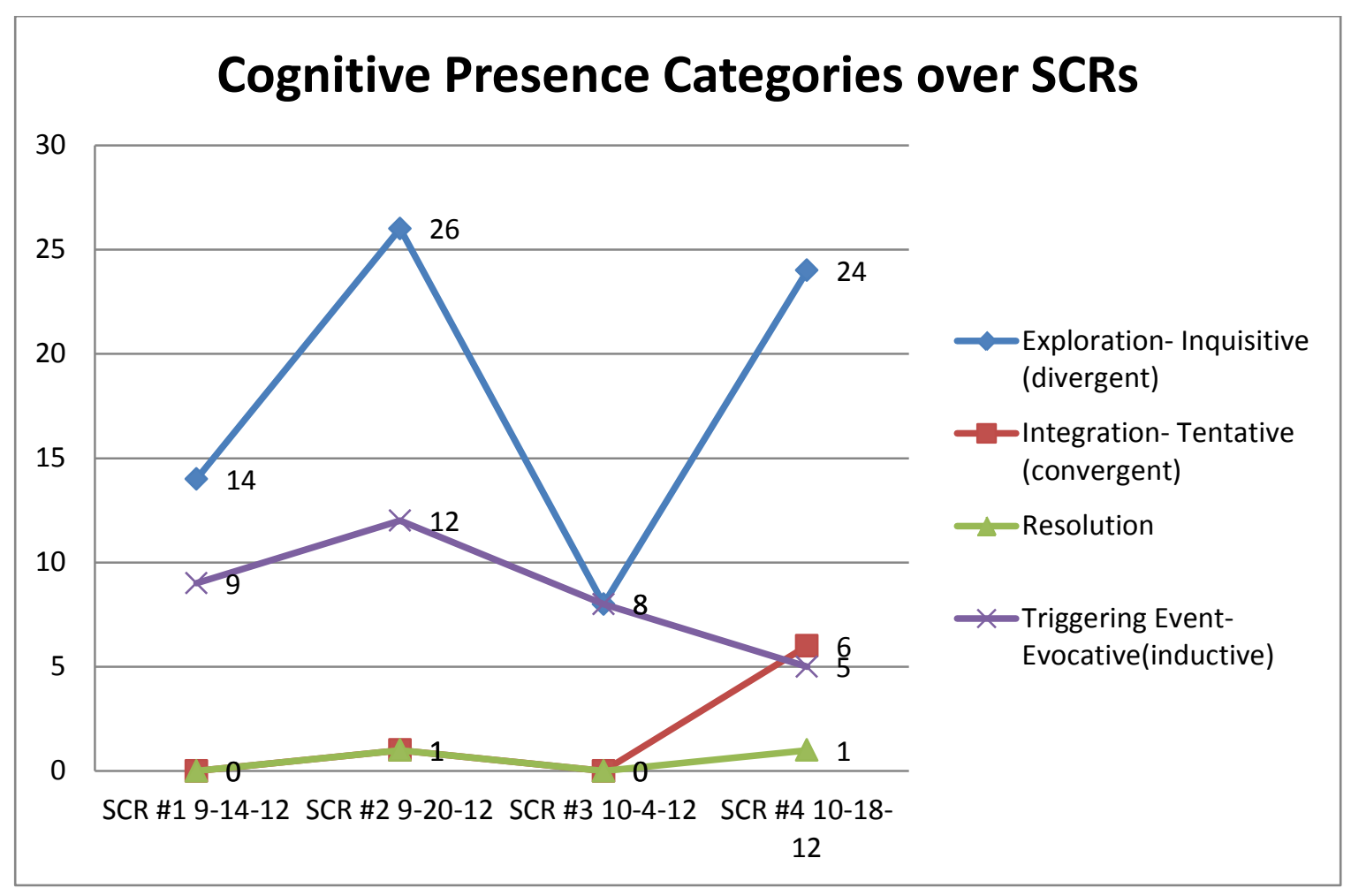

Figure 4.13: Cognitive presence category data over all SCRs.

Cognitive presence: Indicator level analysis. Figure 4.14 displays the longitudinal Cognitive presence indicator data. Looking closer at the Cognitive presence indicators in Figure 17, the increase of almost all indicators is evident in SCR 4. 


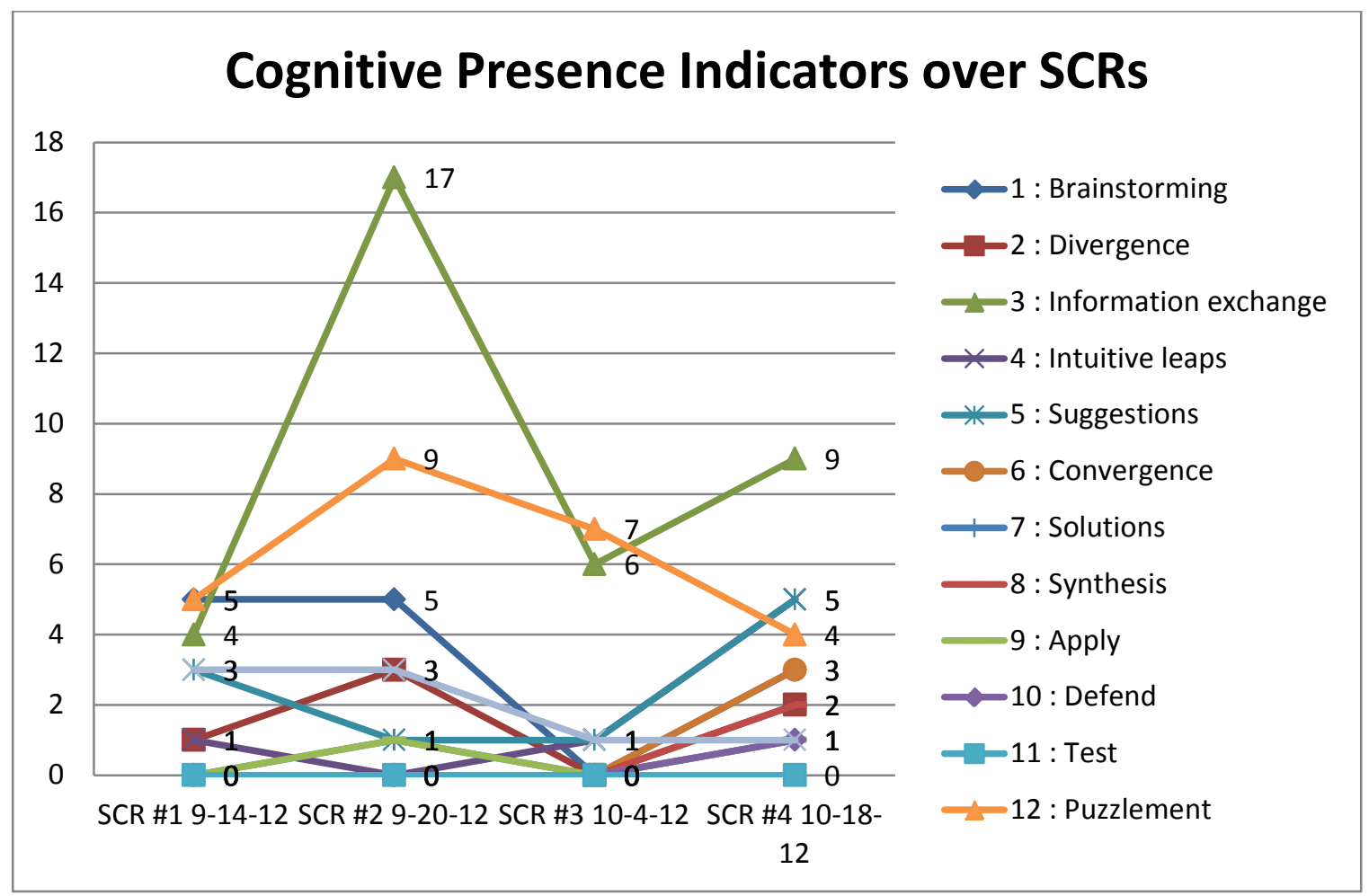

Figure 4.14: Cognitive presence indicator codes over all SCRs.

Thus, though Cognitive presence was detected at low levels throughout the study, the indicator data demonstrate a notable increase of almost all indicators for Cognitive presence in SCR 4.

Cognitive presence analysis summary. In summary, Cognitive presence was detected at low levels throughout this study. The full PI cycle was detected on two occasions in the study, and on both occasions the cycle was instigated with "genuine" questions rather than premeditated questions. Additionally, an analysis of the category level data indicated a pattern of almost all categories rising in SCR 4. Indicator-level data also illustrates a pattern of a movement towards increased levels of cognitive presence in SCR 4. Thus, it appears that Cognitive presence, in general, rose in SCR 4. 
CoI Analysis conclusion. In summary, a detailed look at all three presences gives insight into what can be described as a shift towards a more sophisticated level of each presence throughout the study. At the presence level, Social was the highest detected presence, followed by Teaching and then Cognitive. A trend line indicates that each presence was trending upward at the conclusion of SCR 4, suggesting that the CoI of this activity might have continued to develop more robustly had the activity continued. A closer look at Social presence categories reveals that there was a significant spike in all categories from SCR 1 to SCR 2. From observation as well as a look at the steady decrease in the responding to technical questions indicator, I believe this spike could be attributed to technical glitches that happened in SCR 1 being worked out as well as students becoming more familiar with the technology interface. An additional observation of Social presence is that, at the conclusion of the SCRs, both the open and cohesive categories decreased and the interpersonal communication category increased. Finally, a closer look at the interpersonal communication indicators revealed that indicators that described emotion and vulnerability increased in SCR 4 while all others decreased, describing a potential shift towards increased trust and cohesion among the group in the final SCR.

All Teaching presence categories decreased by SCR 4, suggesting a movement by the group away from a traditional teaching relational mode and more towards a discussion/ constructivist style of relation. Additionally, all Teaching presence indicators decreased in SCR 4, with the exception of summarize the discussion and drawing in participants, prompting discussion, which both rose significantly. These indicators are both related to discussion, something that is a central part of a constructivist, discussion 
based type of environment. Conversely, the teacher-centric encouraging, acknowledging, or reinforcing student contributions and confirm understanding through assessment and explanatory feedback indicators declined sharply in SCR 4, reflecting a movement from the group away from a traditional teaching relational model and more towards a discussion/ constructivist style of relating.

Finally, Cognitive presence was the lowest detected presence, with the latter two phases of the underlying PI model, integration and resolution, being especially rare in the SCRs. This low level of Cognitive presence phenomenon was noted in the literature as likely being the result of instructional activities not allowing for higher level critical thinking Garrison et al. (2010). In this way, the SCR fell in line with the literature somewhat in the fact that the SCR was a "premeditated" group-based activity, with presenters knowing the answers before they asked the questions. This led to a traditional teaching type of dynamic between presenter and peers that often stifled genuine, exploratory discussion.

There were two instances of "genuine" questions occurring, one with a technical problem and one with Trent's impromptu presentation. In both of these occasions, the interaction was documented as progressing through the entire PI cycle. Of final note, almost all Cognitive presence categories and indicators rose in SCR 4, describing a noticeable increase in Cognitive presence in SCR 4.

Several implications of the SCR CoI analysis will be discussed in Chapter Five.

\section{Interview Analysis}

The second source of data used in this study was interviews. Interviews were conducted with all six student participants in January of 2013. Interviews were conducted 
in January due to the human subjects protocol that specified interviews with student participants were to take place only after clerkship grades had been submitted. As grades were not submitted for participants until late December 2012, interviews took place in January.

All interviews took place via phone. Table 4.2 describes the subject, date and length of time of each interview.

Table 4.2

Summary of Participant Interviews

\begin{tabular}{|c|c|c|c|}
\hline Interview \# & Participant & Date & Interview length \\
\hline 1 & Jimmy & $1 / 6 / 12$ & $15: 17.7$ \\
\hline 2 & Darcy & $1 / 6 / 12$ & $10: 40.2$ \\
\hline 3 & James & $1 / 6 / 12$ & $16: 24.7$ \\
\hline 4 & Trent & $1 / 11 / 12$ & $9: 42.3$ \\
\hline 5 & Heather & $1 / 13 / 12$ & $12: 55.5$ \\
\hline 6 & Billy & $1 / 14 / 12$ & $15: 02.1$ \\
\hline
\end{tabular}

To review, interview data served to assist in answering research question 2: What is the nature of ORSP student experiences participating in the SCR? To answer this question, interview transcripts were analyzed through the process of categorical aggregation (Creswell, 2007). Common themes were clustered (Marshall and Rossman, 2011) into the following codes:

- Collaborative, connected community 
- Reduce isolation

- Technology that helps

- Technology that hinders

Phone interviews were captured with a digital recorder, and then sound files were imported into NVivo for analysis. These sound files served as my interview transcripts. I listened to the interviews several times, and as I did so I began to write down themes I heard in the data. I then examined my themes and clustered them into my master codes described above. I then reviewed the interview transcripts again and marked instances of my master codes as they occurred. The following sections will describe these codes as they relate to the nature of each student's experience in participating in the SCR.

Technology that helps. Students consistently described aspects of the technology they used in the SCRs to be positive and helpful.

Heather described herself as someone who was not "technologically savvy" yet she described the experience of using the SCR technology to be relatively simple: "There were certain aspects of it that were quite easy to use and were very user-friendly." She also described the ease of being able to connect to the Internet and communicate with her peers: "For the most part I was able to get on easily and relay information without, you know, a voice delay..." This is an interesting perspective as the very nature of the VOIP connection used in the SCRs creates an inherent voice delay. This seems to indicate that, at least to Heather, these delays were "transparent" and did not affect her ability to connect with peers. This also supports the CoI data that indicated a sharp drop-off in technical problems after SCR 1. Additionally, Heather noted that the chat box feature in 
the Adobe Connect meeting room helped her feel more connected to her peers, more so than speaking or even seeing them via their webcams.

Jimmy also commented on the usability of the Adobe Connect interface, asserting that it "worked just fine." Jimmy also noted that the ability to switch between PowerPoint presentations and webcams in the meeting room was "very effective" and enhanced his experience. Jimmy continued to discuss the effect of being able to see his peers with video chat functionality:

It enriches the conversation in ways that you can't really put your finger on. Um, but somehow, the, um, the tone- the tone of the conversation is altered somehow by the facial expressions..I mean, these are things that we know intuitively, um, but it seems like it really does, um, amp up the efficiency of the communication to be able to have those things, to be able to have gesture and facial expression. Finally, like Heather, Jimmy also noted the utility of the chat functionality, and that being able to "drag and drop an image" into the chat and "have it show up on the screen of the person you're talking to" had been a positive experience with the technology of the SCR.

Darcy echoed Jimmy's sentiments on the superior connectivity to peers the video chat capabilities of Connect provided: "I think it feels..for some reason it feels a bit more disconnected when you just have a speaker phone on the table." It is interesting that Darcy also noted having a positive experience with the Adobe Connect software, stating that it was a good way to do the meetings. She also stated that she enjoyed being able to have the Internet wherever she went via the Verizon data card. Finally, she, like Jimmy and Darcy, noted that the chat functionality was "a really good way to do it, especially 
with everyone being so remote and with the delay on the video and sound, um, I thought that was really successful."

Billy also discussed the ease of using Connect stating that "it was an easy transition to start using it, the whole program was pretty intuitive." He also noted that, though he had used software for online meetings before, it had been largely a passive experience, and that he really liked the ability to comment and "ask questions as you're going along." Thus the technology of Connect helped Billy feel more actively engaged in the SCR experience.

Billy also described the novelty of the chat functionality. Specifically, Billy described that "having that distance and, um, being able to ask questions on the side barthe chat bar- which, you don't necessarily have that ability in live presentations to do something like that." Like Jimmy, Billy also noted that "being able to share online content so fluidly" with peers was a "pretty cool" and "pretty fun" functionality of the Connect meeting room. Finally, Billy spoke to some of the potential applicability to using the technology and format of the SCRs in rural practice:

I think it would actually be a really interesting way to check in with some of your colleagues in different areas, um, which right now..I don't know if it's um, really being done that much, uh, so I think there's probably room for that and that it would actually be a pretty cool thing to try.

Trent echoed his peers' sentiments of the technology working well- if there was a good Internet connection. Trent had some difficulty with his connection during the SCRs (as described in the SCR portion of Chapter Four) and said he eventually found a coffee shop in his town with a strong Internet connection. After this, Trent said that his interface 
with the SCR technology had, "no problems, worked great." He also commented on the ease of the Adobe Connect technology: "It was pretty intuitive, pretty convenient. I didn't have any difficulty understanding the program or anything like that."

Finally, James discussed how important it was to have a competent operator (me, in this case): "If you weren't there [to troubleshoot] it would have been hard to have a cohesive meeting most of the time." James also admitted that he had never used technology like this before, and was impressed:

I didn't have any problems getting on and I thought that the quality of the audio and the video was, was really good, um, more than I would have expected because I've never done anything like that before. So, I was really pleased. I thought it was simple, I thought it was a great way to have this sort of teaching experience.

Technology that hinders. Interviews also revealed that the technology utilized for the SCRs sometimes created barriers for the student participants.

Heather described some parts of the technology as "clunky" and that it hindered her ability to connect with her peers. Specifically, the voice delay caused by the often inconsistent Internet connection hindered her experience: "I don't know, every once in a while it was kind of awkward to talk and not hear any sound or feedback." Heather also noted the format utilized when presenting the SCRs was sometimes difficult for her:

It was a little hard to um, to feel that [sense of community with peers] when I was giving the actual talk just because it was hard to look at what I was trying to present and then at the same time keep my eye on the [chat] sidebar that would have comments popping up. I found that a little difficult. 
Darcy also commented on the disorienting experience of the sound delay as well as issues surrounding being the presentation format of the SCR:

It felt a little weird when I was presenting, um, to have that delay. I wasn't really anticipating having to wait quite as long as we had to for responses and things like that. It felt a little strange to, um, be basically talking to a, like, silent wall of people, um, but once I got over than and got used to it it was no big deal and I thought it was a really helpful way of doing the project.

Billy described that the technology necessitated a "bit of a learning curve" especially with regard to the students developing the proper "etiquette" for asking questions and using the chat features. He also noted Internet connectivity as an issue that seemed to come up during the SCRs.

Trent, as previously mentioned, had difficulty in SCR 1 with his Internet connection, and cited this as an issue he had with the technology. Additionally, he noted that the small size of the netbook computers made typing awkward "for a big guy like me." Additionally, echoing Heather and Darcy, Trent noted the difficulty he felt with the presenting format:

It was a little weird as well doing the presentation because it was 10 minutes of just kind of staring at a computer and talking and knowing that people were listening but not getting any immediate feedback. And so that, I think, was a little odd, but if I did it more, you would just kind of get used to it and get over that weird feeling, I think.

James also noted the difficulty the technology posed when he was in the presenter role: 
The one part that got a little confusing maybe was asking questions. And, mostly when you were in the seat of the teacher people would sometimes chime in verbally but more often type in questions and how to answer them in order and continue to give a fluid presentation was a little difficult.

Also:

As a presenter you're trying to stay on the ball with what you're talking about and having to answer comments and answer questions like that kind of splits your brain into two pieces. That was slightly distracting and just difficult in general. Collaborative, connected community. Another code that arose from the interviews was the notion of the SCRs creating a collaborative and connected community among the students. In general, students responded that they did feel a sense of community among their peers during the SCR.

Heather described the sense of mutual support the SCR experience gave her during her rural experience:

Being able to just have eyes on the people that were going through the same thing as you and being able to interact even if it's not every day, it was really grounding and I think helped you get through the tough times and also help inspire you with thoughts either academically or emotionally to make that, just, the most, to get the most out of that experience.

Heather also commented that she felt a greater sense of community with peers when she was in the "observer" or audience role for the SCRs rather than the presenter mode, primarily due to utilizing the chat functionality: 
I actually felt more connected to the rest of us, as observers, and I felt a lot more engaged with them so I think it kind of depended on..my sense of community actually depended on if I was giving the talk or actually part of the, more, trying to figure out ways to be more interactive with the actual observation side.

Jimmy described how the SCR experience had already helped him understand that he could have a virtual community despite being in a rural location. He said he had actually already applied these concepts by contacting a child psychologist friend via video chat for advice on a patient he had seen. Additionally, Jimmy commented on the implications for possible future rural practice:

The idea that I can be in Burns [Oregon] and have something come in the door that I'm not sure I can completely be in charge of, but that I can virtually bring on board someone else who is, who is going to be an expert in that particular concern, and that I can do it without incurring a huge expense with something that I have in my pocket, and now won't have to worry alone about that, about that issue, that totally changes it.

Darcy spoke to feeling a sense of community to the extent that she missed the SCR experience after it was over:

Once it was all over...I kind of missed having that get together once a week and interacting with all the other students and um, so I definitely felt it brought us together in a way that we wouldn't have been able to because we were, um, so far away from each other. 
Like Jimmy, Darcy also spoke of seeing opportunities for this type of activity to create connectivity among colleagues in future practice and that it would be "better than a conference call."

Billy noted that the sense of community he felt during the SCRs wasn't as good as he would have felt if they were face-to-face, but that it "did pretty good" nevertheless. Like Darcy, Billy also shared that he missed his peers after the SCRs concluded:

After we stopped...and weren't having the, having the SCRs, I did kind of start missing people a little bit more and thinking that I hadn't seen them in a while, while at least when those [SCRs] were going on I felt that at least we were checking in.

Finally, Billy, like some of his peers, saw the opportunities for connecting with peers with a similar type of activity while in future rural practice:

It could actually be a pretty interesting way to check in with some of your colleagues from different areas which right now I don't know, uh, if it's really being done very much, so I think there's probably room for that and I think it could probably be a pretty cool thing to try.

Trent noted that the interactive aspect of the SCR activity supported the collaborative nature in which physicians are trained in medical school:

I think sort of the collaborative effort is something our class, our cohort, has been specifically trained, I mean that's like an integral part of our training and you can be isolated in a rural setting and so I would definitely think that this sort of technology would be great as a practicing clinician. 
Trent also noted that he could see the use of the SCR in rural practice to help with not only reducing a feeling of isolation but also helping to keep up with the medical knowledge.

Finally, James described the SCR as keeping him closely connected to his peers despite the actual physical distance they were apart:

The SCR was a way to kind of see everyone and make sure they were alive and see them smile and hear about the cool stuff they were up to so I really liked that, too.

Also:

I really think I mostly just appreciated seeing my classmates and hearing them speak and, um, and also interacting with them and asking them questions was another way to feel connected with them and I think overall the SCR and the videoconference format was a really good way, a really great way to stay connected.

Reduce isolation. The code of reducing isolation was the final code derived from the student interviews. All participants in one way or another discussed how the SCR experience reduced their feelings of isolation in rural settings. It is important to note that questions regarding reducing isolation were not directly asked in the interview (see Appendix).

Heather was in the interesting position of actually having friends and family in the rural town she was in for the ORSP program, but she still articulated how the SCR experience helped her feel less isolated: 
Being in a rural community I think the hardest part is just feeling so isolated. Even though I had my friends and family there and I was visiting people quite often- especially with our cohort where we have been with each other every day for the past two years and then to go off and then just be on your own, not that you don't have the love and support of your family, but they don't understand really what you're going through in a, um, actual way. So being able to actually have eyes on the people that are going through the same thing as you and be able to interact even if it's, um, not every day, it was really grounding and I think helped get through the tough times and kind of inspire you with thoughts either academically, or emotionally to make that the most, um- to get the most out of that experience.

What Heather described was not just feeling "grounded" by a social community, but also by a professional community that understood what she was going through as a medical student in a rural area.

Jimmy also discussed the isolation he felt while in his rural area, and how the virtual SCR activity helped him cope with this feeling:

My rural experience was more isolating than I had anticipated and more so than I was prepared for so having, uh, having those connections at a scheduled time, um, ended up being a significant support, and even though it was, you know, virtual and just, um, video- video heads on a screen, it still felt very, um, important to me especially as the time went on. I would have loved if it continued through the whole rest of the rural, experience. 
Jimmy also described that the knowledge that he could reduce his isolation with technology and activities like he experienced in the SCR had helped him come to a decision to practice in a rural area:

From a personal and professional standpoint the idea that I can keep connected with my colleagues, um, in a personal and professional way, as well as keep connected with my family and friends in a personal way with this kind of technology I think completely changes my consideration [to practice in a rural area] and is one of the reasons that I'm ready to sign on the dotted line. Like Jimmy, Darcy talked about "missing people" when the SCRs were over, indicating that the SCR weekly experience helped alleviate these feelings of being isolated from peers when they were going on. Additionally, Darcy identified that an experience like the SCR in future rural practice might help her not feel as isolated: "I think it might give me the opportunity to not feel quite as isolated depending on where I end up."

Billy also described how the conclusion of the SCRs led to him missing his peers, implying the lack of the SCR increased his feeling of isolation:

It did feel like, after we stopped doing that and we weren't having, um, the SCRs, I kinda did start missing- missing people a little bit more and thinking that I hadn't seen them in awhile, where while those [SCRs] were going on I felt at least we were checking in.

Trent also described how the SCRs helped him deal with the isolation of his area: "having no other students with me out at that site, um, you do feel sort of isolated so it [the SCR] was a positive interaction with them." Additionally, Trent touched upon the 
disconnect between being trained in a collaborative fashion in medical school and then practicing in isolation in rural areas, and that an SCR type of activity could assist with that.

Finally, James, like Billy, described that the SCR experience had given him new insight in practicing in a rural area. Interestingly, James described how the SCRs made him more open to practicing not just in a rural area, but in a very small, rural area like the one in which he did his ORSP rotation:

It [the small town he practiced in] definitely seemed small and isolated to me and I had a hard time picturing myself immediately going into practice in a place of a similar setting. I could see myself working in another rural setting that was maybe a little bit larger, but the idea of having something like the SCR program would make me feel more comfortable being in a smaller setting right off the bat and having connections with colleagues, um, and access to, um, you know other doctors that I could consult with or check in with about patients that were really complex, so I think it would be a positive to me for working in a very small community.

James essentially described how the online SCR could fill in the CoP that would otherwise be unavailable to a rural doctor in his location, potentially reducing professional isolation.

\section{Field Notes Analysis}

As a researcher, I kept field notes during each SCR session. The intention of analyzing my field notes was to help answer my second research question: What is the nature of ORSP students' experience of participating in the SCR? As I was a participant 
observer, it was difficult to take extensive notes as I was occupied with the task of technically supporting the SCR sessions. Regardless, I was able to collect field note data on all sessions.

Field notes were analyzed through the process of categorical aggregation (Creswell, 2007). Common themes were clustered (Marshall and Rossman, 2011) into the following codes:

- Technology issues

- Socializing

To derive these codes, I reviewed the text of each field note and wrote down common themes that I inferred from the data. I then clustered these themes into the two master codes that are displayed above.

Technology issues. A common theme in my field notes related to technology issues. Given my role as meeting room operator, troubleshooting technology problems was one of my primary duties. As was discussed in the SCR video portion of Chapter Four, there is some indication that as technology problems subsided after SCR 1 the social interaction increased. This is supported in the field notes, as technology became less of an issue throughout the sessions in my notes. The technology notes for the first two sessions dealt with troubleshooting major technology problems. For example, Trent did not use his data card but rather the wi-fi network of his apartment, and as a result lost his connection during his presentation during SCR 1. Dr. Day also had connectivity problems and experienced audio delays as a result. I troubleshot this issue by having her connect back into the meeting room via telephone rather than VOIP. My notes at the end 
of SCR 1 describe troubleshooting a faulty data modem with Darcy, an issue that I resolved ultimately by having a new modem shipped to her (after which there were no problems).

As was observed with the CoI coding, technology issues as experienced in SCR 1 dropped off significantly after SCR 1. My initial note for SCR 2 reads: "Good social interaction at the beginning of the session. Lots of collegiality. Tech working very well this morning." I later note: "Amazing interaction happening right now with VOIP between James and Billy." These observations help support the observations found in the CoI analysis that social interaction rose as technology issues diminished. It also supports the theme that came out of the interviews that students in general had positive experiences with the synchronous online meeting room technology.

Though technology issues subsided after SCR 1, they were indeed still a factor in my field notes. In fact, Heather could not get her data- modem to connect in SCR 3 and had to find a reliable wi-fi hotspot, causing her to join the meeting late (and give herself the meeting room name "grrr Heather," displaying her frustration). However, outside of Heather's issue in SCR 3, my notes regarding tech became much more observant of the use of the technology rather than being about problems with the technology. For example, I began to note the differences between the computer-based version of Connect and the mobile app version. I also noted how students were utilizing the technology to become more interactive with peers during presentations as well as their increasing use of the chat box to support social communication. In summary, while technology issues was a theme in my field notes, notes regarding the technology issues during earlier SCRs 
tended to be about technology troubleshooting while the technology issues notes during the later SCRs were more about interesting student use of technology.

Socializing. Another code that came out of my notes was socialization. The fact that this was a major theme of my notes correlates with the CoI analysis of Social presence being the highest among the three presences in the CoI analysis. Many of my notes relating to socializing identified consistent uses of humor among the participants, something that relates to the high level of use of humor indicators recorded in the CoI analysis. Finally, my notes describe students relating funny stories or other expressions of emotional vulnerability with one another. I noted Billy describing a patient shooting an elk from his front porch, Heather describing her personal experience with childbirth as it related to a peer's presentation, and finally Heather's final statement of SCR 4: "Miss you guys!" These observations all triangulate well with data previously described in the CoI analysis as well as the student interviews.

In conclusion, the primary themes of the field notes were technology issues and socializing. Technology issues were related to troubleshooting in SCR 1 but shifted afterwards to observations primarily about use of technology. Notes about participant socializing had to do with the sharing of personal stories and other instances of emotional vulnerability. Both codes help to triangulate observations from the CoI and interview analyses. 


\section{CHAPTER FIVE}

\section{Summary and Discussion}

Chapter Five will restate the research problem and questions for this study as well as review the study's methodology. It will conclude with a discussion of the study's conclusions, recommendations for future research, recommendations for future practice and study limitations.

\section{Problem in Practice and Methodology Summary}

As discussed in Chapter One, there is a severe shortage of rural physicians in America. One reason physicians choose not to practice, or to persist in practice, in rural areas is due to a lack of professional community, i.e., Community of Practice (CoP). Online, "virtual" CoPs enabled by now common Internet communication technology can help give rural physicians the CoP experience they traditionally have lacked, despite their remote practice locations. Therefore, it is important for rural medical education programs to provide technological experiences that give students the skills needed to create virtual CoPs in future rural contexts. The Oregon Rural Scholars Program (ORSP) provides such a technological experience in the form of the Student Clinical Round (SCR) activity. The intent of the detailed exploration of the SCR in this study was to contribute to a better understanding of how using a computer-mediated space in rural medical education may help give future rural physicians the skills needed to create virtual CoPs when in rural practice, thus contributing to the likelihood these future rural physicians may persist as rural practitioners. 
As explained in Chapter Three, this study employed an intrinsic case study design to answer the following research questions:

1. What is the impact on learners when a deliberate CMS like the SCR is used to deliver the rural medical education experience?

2. What is the nature of ORSP student experiences participating in the SCR? The case study explored one ORSP cohort's experience with the SCR activity. This cohort consisted of six third-year medical students (four male, two female), one MD faculty member and a participant observer. Recorded SCR session videos were coded using the Community of Inquiry (CoI) coding framework in order to answer research

question one. Student interviews and observer field notes were subjected to categorical aggregation (Cresswell, 2007) and common themes were clustered (Marshall and Rossman, 2011) for the data analysis to address research question two.

\section{Summary of Results for CoI Analysis}

As discussed, the CoI analysis was used to answer research question one: What is the impact on learners when a deliberate CMS like the SCR is used to deliver the rural medical education experience? As the CoI analysis generated a significant amount of data, it was important that I display the data in a meaningful fashion so as to best answer my research question. I found that displaying the data longitudinally at each hierarchy of the CoI coding framework (presence, category, indicator) was the best way to explore the impact of the SCR on the learners.

The CoI analysis revealed several intriguing results, a summary of which follows.

Result 1: CoI presences developed over time. The presence coding level of CoI data reveled that all three CoI presences were trending upwards at the conclusion of SCR 
4. The fact that all presences were trending upwards at the conclusion of the SCR experiences may suggest that the SCR activity indeed provided a robust, constructivist higher education online learning environment. The basis for this conclusion is the CoI model itself. CoI is a theoretical model, not a predictive one. It is used to guide the development of higher education level, constructivist online learning environments. According to Garrison (2011), "the CoI theoretical framework represents the process of creating a deep and meaningful (collaborative constructivist) learning experience through the development of three interdependent elements-social, cognitive and teaching presence" (page 15). The trend lines in this study represent the developmental process Garrison (2011) refers to. In this study Social, Cognitive and Teaching presences were all detected and by the conclusion of the SCR activity, all presences were on an upward trend. Therefore, the SCR activity did indeed produce a developing constructivist, collaborative online environment.

\section{Result 2: The group shifted from a traditional teaching relational mode}

towards a social constructivist environment over time. Another result was that, when looking at all three presences over the four SCRs, it seemed that the group moved from a structured, task-oriented focus to a constructivist, community focus. Though research on synchronous online spaces for student coursework is in a nascent state (Oztok, Zingaro, Brett, \& Hewitt, 2013), the literature that does exist supports the finding in this study that synchronous online environments can produce high levels of social presence, which in turn supports a constructivist, community focused learning environment. Additionally, the literature states that a learning environment with high levels of Social presence, such as the one in this study, is the ideal environment for a robust social constructivist learning 
space to form. According to Gunawardena (1995) "the development of social presence and a sense of an online community becomes key to promoting collaborative learning and knowledge building” (p. 164). Therefore, the finding that the SCR developed into a more social constructivist learning environment as the activity progressed is in line with the literature.

Further supporting the observation that the group became more social constructivist over time, the categorical level of Social presence coding revealed that, as the open and cohesive communication categories decreased in SCR 4, interpersonal communication increased. Additionally, the only indicators that increased significantly in the final SCR were those interpersonal communication indicators of affective expression and self disclosure. The pattern these data reveal is that as the group established Social presence in the first three SCRs, it moved to deeper levels of trust and vulnerability, as indicated by the sharp rise in interpersonal communication indicators in SCR 4. This suggests a movement by the group away from simply executing the individual tasks at hand (the SCR presentations) and more towards a deeper connection with other group members through increased displays of trust and vulnerability which strengthened the group's social cohesion.

Additionally, the analysis of Teaching presence revealed that the learners moved from a task-oriented, "teaching" style of academically relating to one another to a more discussion-based, constructivist-relational style over time. A closer look at the data suggests that the group moved away from Teaching presence indicators that were more representative of traditional classroom dynamics and more towards those indicators representing a discussion-based, social constructivist learning environment. Specifically, 
by SCR 4 the discussion focused indicators summarize the discussion and drawing in participants, prompting discussion, rose markedly while all other indicators subsided, lending support to the observation that the group moved towards a constructivist learning environment as time went on. The movement of the group towards a constructivist learning environment can possibly be attributed to the sharp drop-off of the direct instruction category in SCR 4. The literature suggests that too much direct instruction can discourage group participation (Garrison et al., 2010; Garrison, 2011). Thus, the fact that direct instruction dropped off notably in SCR 4 as discussion-focused indicators rose also agrees with the literature. Additionally, Dr. Day's observed teaching style tended to be of a constructivist nature, as she balanced being a moderator as well as a direct instructor. The literature notes a proper balance between "moderating and shaping the direction of the discourse" (Garrison, 2011, pp. 127-128) in the development of Teaching presence as being necessary in the development of a social constructivist learning environment. Thus, Dr. Day's adequately constructivist approach seems to have also helped develop the constructivist-relational style that emerged as the SCRs progressed.

Finally, Cognitive presence was the lowest detected presence in this study. This observation is in line with the literature that indicates that Cognitive presence is often the lowest presence detected in CoI analysis due to the nature of the online task (Garrison et al. 2010). Low levels of Cognitive presence were likely due to a tendency of learners when presenting an SCR to ask premeditated questions. Examples given in Chapter 4 illustrated how premeditated questions actually stifled the progression of the group through the PI model inherent to the development of Cognitive presence. 
Unlike premeditated questions where the presenters knew the answer to the questions prior to asking them, genuine questions were those questions where the presenters did not know the answers prior to asking. Genuine questions were rare in this study (perhaps due to the nature the of the SCR activity itself), but on the two occasions where the group moved through the full cycle of the PI model, the process was instigated by a genuine question. To review, the first occasion took place in SCR 2 as a response to a technical issue Trent was experiencing. Trent's genuine question regarding how to fix a technical problem was genuine in that he did not know the answer prior to asking it. A series of troubleshooting events took place that moved the group through the full PI model. The second movement through the PI model took place in SCR 4 with Trent's impromptu presentation to the group of an actual patient he and his preceptor were having trouble diagnosing. Here, Trent presented the group with a genuine diagnostic question and the group responded by helping him answer it.

A final result from the analysis of Cognitive presence was that almost all levels of Cognitive presence category and indicator codes increased in the fourth and final SCR. This increase may have been associated with the movement of the group away from an individual, task focus and more towards a constructivist, community focus. This is in line with the literature as Cognitive presence utilizes the PI model as a tool to describe the constructivist learning event (Garrison, 2011). The increase in Cognitive presence in SCR 4 could have been the result of Trent's impromptu presentation. Trent's impromptu presentation in SCR 4 marked an evolution in how the students were using the SCR. Specifically, rather than using the SCR as way to fulfill the assignment of the clerkship rotation, Trent used the SCR as a way to collaborate and create knowledge with his peers. 
This type of environment is social constructivist (Galloway, 2001; Vygotsky \& Cole, 1978) and it may have been that, as the group evolved into a more robust social constructivist environment, deeper learning took place and was thus reflected in heightened levels of Cognitive presence as evidenced by progression through the PI model.

Result 3: Reduction of technical issues led to increase in presences. Another result that came out of the CoI analysis was that, as technical issues diminished after SCR 1, all presences increased. This was especially evident with Social presence, with almost all levels of Social presence codes rising notably form SCR 1 to SCR 2. This steep increase in Social presence between SCR 1 and SCR 2 occurred simultaneously with a steep decrease in the indicator responding to technical concerns between SCR 1 and SCR 2. Additionally, the reduction in technical issues likely reduced the transactional distance (Moore, 1993) experienced by the group. To review, in transactional distance theory, Moore (1993) posits that the less technological "friction" experienced by users in a distance-learning environment, the more they will feel a sense of community (and thus social presence) with one another. One goal in the design of a distance-learning experience is then to reduce levels of transactional distance experienced by learners. This lines up well with the observation in this study that, as the technological issues were reduced after SCR 1, transactional distance was also reduced, thus allowing for Social, Teaching and Cognitive presences to rise.

\section{Results for Interview and Field Notes}


Student interviews and participant observer field notes were analyzed to explore research question two: What is the nature of ORSP students' experience of participating in the SCR?

\section{Interview results.}

Result 1: Students had a positive technology experience. One finding from the analysis of the interview data was that students were comfortable with the SCR technology. Interview data revealed that students generally found the Adobe Connect interface to be "simple" and "intuitive" which created a generally easy student user experience.

A positive aspect of the technology that came up frequently during interviews was the chat functionality. Students liked how the chat box allowed for multi-modal information sharing. For instance, one student said that, in addition to being able to share text in the chat box, he really liked being able to also share direct web links to images and other resources. Additionally, several students indicated that the chat interactions with peers were some of the most bonding interactions that happened in terms of creating a sense of community, more so even than seeing and hearing one another via video chat.

While technology did not prove a hindrance to the group in general, certain aspects of the technology were reported as being less than ideal. Specifically, the voice delay inherent to the 3G Internet connections proved jarring for some students. One student described speaking and then waiting for a response to be like "staring into a silent wall." An additional issue had more to do with the SCR format in the Adobe Connect meeting room. Several students reported that it was difficult to adjust to navigating the chat messages from their peers while simultaneously presenting their SCR. That said, 
students reported that the technological problems did not outweigh the technological advantages of the Adobe Connect meeting room and that they adjusted to the technical issues as the SCR sessions progressed.

Result 2: Sense of community was experienced by student participants. All students indicated that the online SCRs gave them some sense of community with their peers. Students discussed looking forward to the weekly SCRs and "missing" their peers when the SCRs concluded. Students also reported that the SCR activity reduced the feelings of isolation they experienced at their remote rural locations. As a result, exposure to the SCR appeared to give some students further motivation to go into rural practice. As the literature indicates professional isolation is a major reason physicians choose not to go into rural practice or persist in rural practice (Whitcomb, 2005), the fact that students in this study experienced reduced feelings of isolation is an important result that could have implications for reducing isolation among rural practitioners.

\section{Conclusions}

\section{Conclusion 1: The multimodal format of a synchronous online space like}

\section{Adobe Connect supports a social constructivist learning environment by allowing} for "fluid role swapping." One conclusion of this study is that a multi-modal, synchronous online space like Adobe Connect can provide an ideal social constructivist learning environment. Specifically, a synchronous online environment like Adobe Connect supports constructivist learning by allowing group members to perform "fluid role swaps.” The term "fluid role swaps" is of my own making and refers to my observations that, by using the tools of the synchronous online meeting room, participants in this study were able to switch effortlessly and instantaneously from traditional student 
to teacher roles, thus supporting a social constructivist learning environment. Though the term fluid role swaps is of my own making, the literature on using synchronous online spaces for learning environments is in agreement that the tools a synchronous online space affords (chat, document sharing, videochatting, etc) may help to support a social constructivist learning environment (Dickey, 2003). The provision of a social constructivist learning environment is important as the formation of virtual CoPs is a major aspect of the problem in practice for this dissertation, and CoPs are inherently social constructivist by nature (Johnson 2001). Thus, identifying phenomena that occur within a synchronous online space that encourage the formation of a social constructivist environment- such as fluid role swapping- is important as it can help practitioners better understand how to foster social environments within such spaces that may give rise to virtual CoPs.

Additionally, according to Johnson (2001), a central component of a CoP is "fluid peripheral-to-center movement that symbolizes the progression from being a novice to an expert" (p. 45). What Johnson (2001) describes is that in a CoP there are multiple levels of expertise, with participants able to be a novice (i.e. student) at one time and an expert (i.e. teacher) at another. In this light, the fluid role swapping observed in this study may emulate the fluid movements within a CoP, thus strengthening the likelihood of virtual CoP formation within a synchronous online space. To better illustrate the fluid role swapping phenomenon I observed, I will now describe some examples from the study.

Throughout all four SCRs I observed how fluidly a participant could swap between traditional student and teacher roles. For example, during SCR 1, Jimmy gave a presentation in which he included a hyperlink in a PowerPoint slide. In this situation, 
Jimmy was the "teacher" and his peers were the "students." However, Jimmy could not figure out how to play the video for his peers within the Adobe Connect meeting room context. He moved on and, a few seconds later, Heather noted in the chat box that everyone could access the video by simply clicking the link on the screen. In this instant, Heather swapped her role as a student for a teaching role, then swapped back to the student role just as quickly.

These types of "fluid role swaps" were also apparent with the SCR instructor, Dr. Day. During SCR 2 while Trent was presenting (and was thus in the teacher role), Dr. Day added a question to the chat box: "What are the risks for high-risk patients that you don't want to treadmill?" Dr. Day’s question was coded with the Teaching presence indicator presenting content-questions. She was clearly asking this question as an instructor by attempting to have the students either answer, or think of the answer, that she knew. A few seconds later, Trent made a joke using another student in the group's name. In response, Dr. Day chatted in the emoticon ":-)". This interaction was coded with the Social presence indicator affective expression. In using the emoticon, Dr. Day swapped roles instantly from teacher to student.

The previous example illustrates how a multi-modal online environment like Adobe Connects allows people to "fluid role swap" between roles and CoI presences. While neither asking a question nor acknowledging a student joke is unusual in a traditional classroom, what makes these exchanges unique from the perspective of a traditional classroom is that the synchronous online format allows for simultaneous instructors. Trent was the primary instructor as the SCR presenter, yet at the same time Dr. Day also played an instructor role by asking questions of the group in the chat box. 
The second unique aspect was how quickly Dr. Day was able to move from an instructor role to more of a student role with the use of an emoticon. These types of simultaneous and interchangeable actions, or fluid role swaps, are not possible in a traditional classroom yet certainly are possible in a synchronous online space, making them a unique phenomenon of the online communication medium.

The identification of fluid role swapping has implications for the use of a multimodal online environment to support constructivist educational activities such as the SCR. As previously discussed, a constructivist environment encourages the facilitation of a learning dynamic between instructor and student rather than the traditional teacherstudent power dynamic. As the SCR puts learners into instructional roles while presenting, the online activity is already supporting constructivist ideals. The instances of fluid role swapping increase the opportunities for a student to become a teacher and a teacher to become a student, therefore strengthening the constructivist nature of the activity. In this light, synchronous online environments may be ideal environments to implement social constructivist activities as their multimodal nature allows for students to fluid role swap easily and instantaneously. This ability alone may strengthen the social constructivist paradigm underlying the actual activity.

Again, the ability for synchronous online spaces to provide tools supporting social constructivist learning environments is supported by some literature (Dickey 2003) and broadens the scope as to what types of activities may be used in an online learning experience. For example, the SCR is an activity that works well within a synchronous online space because it is constructivist in nature. However, the SCR activity itself could be expanded to include different types of social constructivist activities that appeal to 
different groups, such as practicing physicians. These groups may then have similar experiences of community and constructivist learning- as the participants did in this study- while offering a level-appropriate professional activity, thus increasing the potential for virtual CoP formation.

\section{Conclusion 2: The SCR activity is capable of generating a virtual CoP. A}

notable event took place in SCR 4, and that event was the emergence of a virtual Community of Practice (CoP). To review, the aim of this study was to better understand a unique phenomenon (the employment of a deliberate CMS in rural medical education) that theoretically could, if emulated in a student's future rural practice, provide the foundation for the emergence of a virtual CoP. Virtual CoPs in rural practice could potentially assist in reducing feelings of isolation among rural providers, thus increasing the likelihood those providers persist in their rural practices. Though the scope of this study was not to predict a virtual CoP emergence from the SCR, this phenomenon did unexpectedly occur during SCR 4.

As SCR 4 began, Trent asked if he could present something, even though he was not assigned to present an SCR that day. "I have a patient that is pretty interesting," Trent typed into the chat box as the session began. A few seconds later, Trent typed "I can throw out my case really quick, very informal." Trent then proceeded to "present" the case of a child with a peculiar condition that both he and his rural physician preceptor were finding difficult to diagnose. The key difference between Trent's presentation and all other SCR presentations was that Trent was coming in without the answer to his question; rather, he was telling the group he did not know the answer and wanted guidance to help his preceptor treat the child: "I just didn't know if there was anything 
else I should be thinking about, but it's kinda interesting so I thought I would throw it out there." As has been discussed, this is an example of a genuine question.

The group (including Dr. Day) went on to give Trent many suggestions, as well as help him work through some clinical questions he was pondering in diagnosing the child's condition. Trent ended by graciously thanking the group and stating he would bring many of the group's suggestions back to his preceptor to assist with the follow up visit with the child in a few days.

To understand how Trent's actions indicate the beginning of a virtual CoP, it is worth reviewing the definition of a CoP from Chapter Two:

Wenger identifies three critical characteristics that constitute a CoP. The first is domain. A CoP differentiates itself in that its members share a common domain of interest. Membership in a CoP "implies a commitment to the domain, and therefore a shared competence that distinguishes members from other people" (Wenger, 2006, Domain section, para. 1). The second characteristic of a CoP is community. Members of a domain engage in joint activities and discussions, help each other, and share information. Their relationships enable them to learn from one another (Wenger, 2006). The third and final characteristic of a CoP is practice. Individuals that are simply interested in something similar is not enough to constitute a CoP. Rather, members of a CoP must be practitioners. These practitioners "develop a shared repertoire of resources: experiences, stories, tools, ways of addressing recurring problems — in short a shared practice. This takes time and sustained interaction." (Wenger, 2006, Practice section) 
While it can be argued that the first two aspects of CoP, domain of interest and community, are inherent to the SCR activity in general, the third and final aspect, practitioners, was lacking in the normal SCR presentations. Indeed, participants in the SCR activity were students participating in a course activity rather than practitioners sharing information to produce knowledge. However, with Trent's impromptu presentation, the group did indeed become practitioners. Each member contributed his or her thoughts on possible diagnoses and treatment plans not as students fulfilling an assignment, but as medical professionals-in-training assisting a colleague. The most knowledgeable practitioner, Dr. Day, also contributed her ideas, emulating the dynamic of a CoP where senior practitioners mentor junior practitioners by sharing expert knowledge (Wenger, 1999, 2006). Trent left the experience with new ideas that he brought back to his preceptor to help diagnose the child. In other words, knowledge was produced from this interaction. In this way, Trent's impromptu utilization of the group's collective knowledge to gain knowledge of his own lifted the group from a deliberate CMS to a virtual CoP. Additionally, the fact that this event happened on the fourth and final SCR lends weight to Wenger's assertion that the formation of CoPs "takes time and sustained interaction" (Wenger, 2006, Practice section). From this perspective, the group could not have formed the CoP without the sustained interaction of the previous three SCR sessions. In the next section I will review the virtual CoP literature of Chapter Two and how it relates to better understanding how the virtual CoP might have formed in SCR 4.

Virtual CoP formation from SCR. As discussed, one result of this study was that by SCR 4 the group had developed from a focused, task-oriented mode of interaction to a 
discussion-based, constructivist interaction style. Recall that the SCR was identified as a deliberate CMS and that Trent's presentation marked a virtual CoP forming from the deliberate CMS of the SCR.

As discussed in the literature, virtual CoPs are emergent phenomena that cannot be deliberately created. Rather, deliberate CMSs (which can be deliberately created) must precede the virtual CoP with the hope that sustained interactions may lead to the emergence of a CoP. Schwen \& Hara (2003) state that "communities of practice are about content — about learning as a living experience of negotiating meaning — not about form. In this sense they cannot be legislated into existence or defined by decree. They can be recognized, supported, encouraged, and nurtured, but they are not designable reified units" (p. 262). Johnson (2001) supports Schwen \& Hara's (2003) conclusion, positing that a deliberate CMS is the designed community and that the CoP emerges from the designed community. To this conclusion, Johnson (2001) asserts "legitimate task-oriented reasons need to exist for the community of practice to emerge in the first place. Simply setting up a deliberate CMS infrastructure without this premise will not automatically cause a community of practice to form" (p. 53). CoPs can form from deliberate CMSs, but "scaffolding is necessary" (Johnson, 2001, p. 53).

The findings of this study, therefore, are in line with the virtual CoP literature. A deliberate CMS in the form of the SCR did, over time, create the context for an emergent virtual CoP to form. A hole in the literature, however, is identifying exactly what "scaffolding" (Johnson's, 2001, p. 53) is needed to facilitate this emergent process. This case study provides insights into this question. 
Instructional scaffolding can be related to Vygotsky's (1978) constructivism, where an expert, or more knowledgeable other, helps guide a novice/learner to a higher level of competency through monitored learning activities that help move the learner to the next phase (Vygotsky \& Cole, 1978). The SCR activity, Dr. Day's facilitation style, and the multi-modal, synchronous online learning environment all were based on constructivist ideals. Given the outcome of this study, these may then be examples of the kind of scaffolding necessary to move a group from a deliberate CMS to a virtual CoP. Stated another way, this case study demonstrated how a repeated constructivist activity (the SCR), with constructivist facilitation and a constructivist online environment did indeed give rise to a virtual CoP. A repetition of a constructivist task within a multi modal, synchronous online environment coupled with ample time and constructivist facilitation techniques may be the scaffolding needed to move a deliberate CMS to a virtual CoP. A facilitator's task in this type of environment may be to pedagogically guide the group over time from an individual, task focus (core qualities of a deliberate CMS) to a community, group focus (core qualities of a social constructivist learning environment) so that a virtual CoP can potentially emerge.

Figure 5.1 represents a conceptual model facilitators of deliberate CMSs may consider when attempting to move a group from an individual, task focus inherent to a deliberate CSM to a community, social constructivist. 


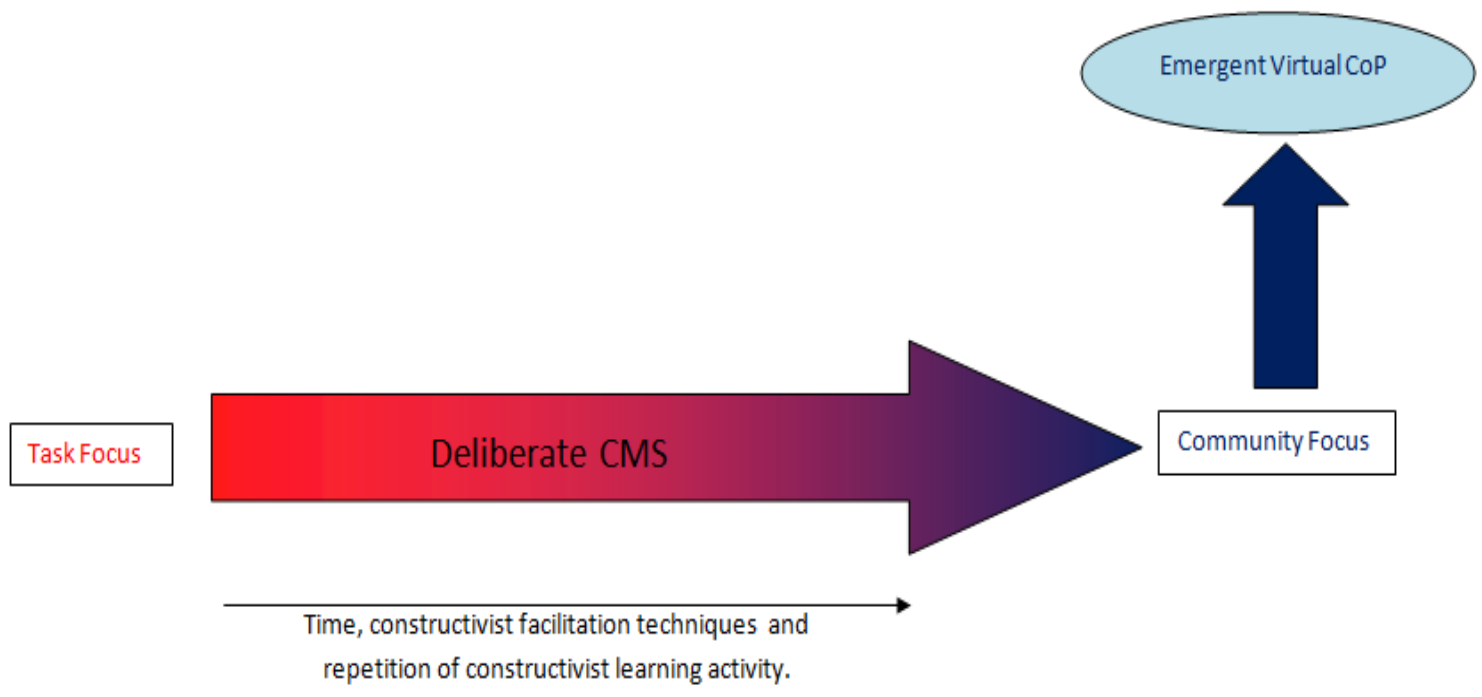

Figure 5.1: Strategy to encourage virtual CoP formation within a multi-modal online environment.

\section{Conclusion 3: A deliberate CMS activity can help to reduce feelings of} isolation by building a sense of community among participants. Reducing isolation felt by medical students during a rural rotation is important as it helps give students a more positive view of rural practice by reducing their isolation, a major deterrent to physicians in choosing rural practice (Whitcomb, 2005). James's statement that the SCR made him consider practicing in an extremely remote rural setting as well as Jimmy being ready to "sign on the dotted line" are good examples of the potential effects of this desired positive view of rural practice.

Reduction of feelings of isolation also has rural practitioner implications. The reduction in isolation described by the students in this study could also translate to a reduction in isolation experienced by rural practitioners. Thus, the feelings of community and reduction of isolation described by students in their SCR experience.could translate to practitioners participating in some type of SCR-like activity. Additionally, the high 
level of Social presence described in the CoI analysis of the SCRs lends further weight to the assertion that a multi-modal, synchronous online space can provide high levels of social interaction with colleagues. The social interaction provided by an SCR-like activity may then help rural practitioners deal with the feelings of isolation they often experience, thus increasing the likelihood they will persist in their rural practices.

\section{Recommendations}

Now that I have discussed the conclusions drawn from this study, I will move on to a series of recommendations for further research and practice.

\section{Research recommendations.}

\section{Research recommendation 1: More research is needed on the elements of a} multi-modal, synchronous online meeting room, specifically on the impact of chatting functionality on group dynamics. This recommendation derives from the intriguing finding that chatting in the SCR was one of the ways students felt most connected with one another, even more so than seeing and talking to one another in the online meeting room. This concurs with Gunawardena's (1995) findings that social presence can be experienced through text-based online activities such as email. However, Gunawardena's research explores primarily asynchronous communication in an online space whereas the communication in this study was synchronous. Oztok et al. (2013) looked at the differences between student usage of asynchronous messaging vs. synchronous messaging in nine graduate education courses. The researchers found that "the personal nature of messaging increases the sense of community among class participants and encourages more interactivity" (p. 91). Additionally, in reviewing the literature, Oztok et al. (2013) conclude that synchronous chatting can support both Cognitive and Social 
presence within an online learning environment. Thus, the observations of this study agree with the literature in that many participants commented how text chatting was the feature that they felt connected them most with peers during the SCRs. Finally, Oztok et al. (2013) assert that asynchronous communication is the dominant format in educational online education and therefore research on synchronous communication in online learning is relatively new. Therefore, a branch of future research could look specifically at the nature of the chat in the synchronous online space where learning activities such as the SCR takes place. This type of research could help to better understand how chat functions as a "scaffold" to assist in moving a group towards a social constructivist learning environment where virtual CoPs can potentially form.

Research recommendation 2: Longitudinal research on student exposure to SCR technology and use of the technology in future practice is needed. All students in this case study reported having a positive experience with the online SCR, with several of them explicitly stating they saw the utility of such an exercise in future rural practice. As one assumption in this study was that students exposed to a novel use of technology to create an online community in medical school may go on to emulate this activity in their future rural practice, it would be worthwhile to open a line of research that followed ORSP students from medical training into rural practice to see if they do indeed implement similar technology approaches to their rural practices. This type of longitudinal research could help better answer the question of how virtual CoPs can be formed in rural practice settings, and if they help reduce the feelings of isolation that have been found to deter rural practitioners from persisting in rural practice (Whitcomb, 2005). 


\section{Practice recommendations.}

Practice recommendation 1: More deliberate facilitation of the SCR is needed to move a group from task focus to community focus so that the context for a virtual

CoP forms. Now that we know it is possible for a virtual CoP to be formed as a result of the SCR activity, and that a group participating in the SCR needs to move from task focus to community focus to create the social constructivist environment for the CoP to form, there needs to be a more deliberate facilitation process to coax out and encourage these trends. The following three points are recommendations on how to go about doing so, and are in line with the model presented in Figure 5.1:

1. Genuine questions should be required as part of the SCR activity. As was discovered in the study, the students tended to focus on premeditated rather than genuine questions. This focus on premeditated questions often impeded the development of Cognitive presence. This tendency to ask premeditated questions could have been the result of a design flaw within the SCR activity. Design flaws within learning activities have been noted in the literature as leading to low levels of cognitive presence (Garrison et al. 2010). On the other hand, in those cases where genuine questions were asked, the highest levels of the PI model were often realized. Thus, a slight "tweaking" to the current format of the SCR activity may reconcile some of the current design flaws that cause students to gravitate towards premeditated, rather than genuine, questions. One possible way to do this would be during orientation to the SCR activity as well as in SCR instructional materials, including an explicitly stated requirement that students ask at least one question of their peers during their presentations to which they do not know the answer. This 
requirement will help alleviate the fear many students have of "not doing it right." It will also help overcome the tendency when presenting an SCR to ask exclusively premeditated questions, thus increasing opportunities for social constructivist, community learning to happen sooner rather than later.

2. More time is needed for the SCR activity. The literature indicates that CoPs form over time (Johnson, 2001; Squire \& Johnson, 2000; Wenger, 2006). Currently, the SCR activity for ORSP students lasts just four sessions. As was evidenced in this study, the group dynamic changed notably in SCR 4 and the CoI presences were still on an upwards trend, indicating a social constructivist learning environment was still in the process of developing. As ORSP students stay in one location for ten weeks, the SCR assignment should be extended throughout that entire time. This would give the group more opportunity to fully transition from an individual, task focus to a community, constructivist focus, allowing more opportunity for the development of a virtual CoP like the one that was witnessed during SCR 4.

3. The nature of the SCR assignment should be adjusted. Currently, the SCR is presented to students as one of many assignments they must fulfill for their Family Medicine clerkship rotation. This type of introduction may contribute to students viewing the SCR as a task to execute rather than an opportunity to meet and discuss cases with peers. Thus, the "marketing" of the SCR for ORSP students should be focused on the SCR as an opportunity to connect, collaborate, and share knowledge with peers while in an isolated rural setting. The assignment task should still be firm, but if students come into the assignment from a 
constructivist perspective rather than a task one, they may be more likely to view the assignment from a community standpoint earlier in the SCR process. This constructivist approach from the beginning of the assignment is modeled in Figure 5.1. Students begin the assignment with a strong task focus, but the approach is always constructivist in terms of facilitation and awareness of the collaborative, social knowledge building nature of the learning activity. In bringing this social constructivist awareness to the group early on rather than later, students will feel encouraged to ask genuine questions, both of themselves and others, while presenting. This constructivist focus immediately makes actively engaging with other group members of equal importance to the task at hand (execution of the SCR assignment requirement), thus helping to develop a robust constructivist learning environment early in the SCR process.

Through these three recommendations for the SCR, a more deliberate pedagogy could be developed to encourage students earlier to move their focus from the task of the SCR to the community of learners involved in the SCR process. Through this pedagogy, avenues would be opened for more robust CoI growth as well as an earlier movement towards a social constructivist environment that encourages virtual CoP formation.

Practice recommendation 2: Minimize technical difficulties/interferences. As the CoI analysis revealed, all presences rose after technical problems/transactional distance dissipated. Therefore, it is of paramount importance that the technology does not "get in the way" of a group's experience in using a synchronous online space for an activity like the SCR. Student interviews revealed that the voice delay inherent to the 3G data collections was a technological point of friction for them. Additionally, the online 
limitation of not seeing peers or directly hearing their questions but rather reading them as chat proved difficult for many students. As students used the chat box so heavily to mitigate the voice delay, it can be said that the voice delay added yet another point of friction for students.

An easy solution to alleviating the voice delay is to use the telephone connection option in Adobe Connect. This option allows for participants to use a phone rather than their computer to transmit their voice. As this method uses the telephone rather than the Internet to transmit voice, there is no voice delay. Students can then ask questions by voice instead of chatting them in, alleviating some of the presentational friction experienced by presenters. The rationale for not using telephones has been that students would either need to find a landline to communicate (an increasingly rare device to find) or use their own cell phones. There is no cost to the student in using a landline to connect to the Adobe Connect meeting room, however there is potential cost to a student using a cell phone depending on what kind of cellular minute plan a student has. It may therefore be worth reimbursing students or issuing them prepaid cell phones for their SCRs so that more robust, conversational interactions can take place during the SCRs. That said, as data connections continue to improve, VOIP may get good enough so that delays are significantly, if not completely, minimized. Another option may be to explore other synchronous online meeting software that may perform better than Adobe Connect. Regardless, effort should be put into the SCR activity in order to remove the technological friction of the voice delay so that group dynamics can grow even more robustly. 
It is important to note that, even with a reduction in the voice delay, technological friction is inherent to interactive, online technology. Therefore, group participants’ expectations should be managed so that users remain tolerant of the technological "hiccups" that are bound to happen in a synchronous online space. Further, these technological hiccups may actually support learning in a synchronous online space as participants can be involved in the active problem solving of the technological issues. This type of problem solving occurred many times in this study, and a technological issue was actually the impetus for one of the two times the group moved through the full PI model. To review, Trent had a problem in accessing his presentation slides. In asking a genuine question regarding how to solve the problem, the group actively engaged in solving the problem and the full cycle of PI was reached. Therefore, while technology problems should be mitigated as much as possible, complete elimination of technology problems in a synchronous online environment is both impractical and, perhaps, undesirable.

Practice recommendation 3: Academic medical institutions with rural missions should emulate the OHSU SCR process to support their rural missions. As discussed in Chapter Three, a poll on a national list serve of rural medical educators indicated that the ORSP SCR approach was a novel way of bringing learners together in rural medical education setting (D. Kolva, personal communication, May 08, 2012; May 10, 2012; M. Blackburn, personal communication, May 09, 2012; M. Kennedy, personal communication). Based on the findings of this study, other institutions could benefit from adopting a similar format. As previously described, the ORSP process is highly scalable, so other institutions should have the resources to adopt a similar operational framework. 
Pedagogically, the SCR is straightforward and applicable to any rural medical program that puts students into rural practice areas for training. The lessons learned from this study regarding moving a group of learners from task focus to community focus could all be taught to other programs. The result would be many institutions implementing activities that connect rural learners with a robust, collaborative online learning activity that can reduce isolation, increase a sense of community, and positively influence rural practice choice among learners. Additionally, more programs exposing rural medical education students to a deliberate CMS activity capable of creating a virtual CoP gives learners a technological "template" to apply to their own future rural practices. Indeed, this study provides evidence that some students had already internalized the template, with some participants stating that the possibility of using similar SCR types of activities in rural practice made going into rural practice more attractive to them. In essence, an SCR type of activity experienced in rural medical education can be viewed as virtual CoP skills training that students might later apply to their future practices. If they do so, virtual CoPs become more possible in rural practice, potentially reducing professional isolation (Whitcomb, 2005) and ultimately addressing the severe rural practitioner shortage in the United States (Rabinowitz et al., 2008). Increasing rural workforce is a core mission of any US rural medical program, and thus implementing the ORSP SCR model may be an innovative way for institutions to help meet their rural missions.

Practice recommendation 4: The deliberate SCR format should be applied to current rural practitioners to help reduce feelings of isolation as well as give opportunities for virtual CoPs to form. This recommendation is perhaps the most important of this study as it could have a direct impact on the attrition rates of rural 
physicians due to professional isolation. The emergence of a virtual CoP from a deliberate CMS in this study actually has greater implications for rural practitioners than it does for rural medical students. Recall that CoPs are formed by professionals (Wenger, 1999, 2006). Medical students are not yet true professionals so, while it is important to expose medical students to activities that they can emulate in future practice, it is perhaps more important to apply the lessons learned from the virtual CoP formation described in this study to actual rural physicians who are professionals and can thus more immediately benefit from participation in a virtual CoP. As previously discussed, there is nothing preventing the emulation of the SCR activity in a professional context (with perhaps a more appropriate professional social constructivist activity, e.g a virtual journal club), and then using the lessons learned in this study to provide better scaffolding so that rural practitioners participating in a deliberate CMS can potentially become a part of an emergent virtual CoP.

Recall that virtual CoPs emerge from deliberate CMSs (Johnson 2001). According to Johnson (2001) "legitimate task-oriented reasons need to exist for the community of practice to emerge in the first place. Simply setting up a virtual community infrastructure without this premise will not automatically cause a community of practice to form" (p. 53). Therefore, an online SCR-type activity may be a model of a "legitimate task-oriented reason" (Johnson 2001, p. 53) rural practitioners could have to meet up online on a consistent basis for a specific task, thus laying the groundwork for the formation of a virtual CoP. Therefore, effort should be made in applying the ORSP SCR format to a professional environment, with small groups of rural practitioners possibly 
meeting in task-focused deliberate CMSs on a consistent basis with the hope that, as with the study group in this dissertation, virtual CoPs form over time.

To successfully apply the SCR to a professional group, I recommend the following criteria be met. These criteria are also captured in the pedagogical model for encouraging virtual CoP formation described in Figure 5.1:

- The activity must be moderated. By moderated I mean there must be one member of the group that can successfully navigate the synchronous online meeting software as well as technically troubleshoot, especially during the initial session when participants are normalizing to the online environment. The rationale behind sound moderation is to reduce the transactional distance (Moore, 1993) experienced by the group, thus allowing for an increased Social presence to form, as was observed with the participants in this study. This moderator could be a physician or could be an IT "expert" that performs my role in the SCR as the operator. Regardless, technical friction can impede group bonding, so it is important that any attempt to implement this activity among professionals be run by some participant with the technical prowess to troubleshoot and help technologically support the sessions.

In addition to technical moderation, instructional moderation of a constructivist nature is necessary. This recommendation is based on the understanding that synchronous online spaces can support social constructivist learning environments (Dickey, 2003; Oztok et al., 2013) 
and therefore an understanding of facilitation techniques necessary to encourage a social constructivist learning environment is necessary (e.g., teacher as facilitator of learning style rather than imparter of knowledge style). CoPs are also social constructivist, with learning being a social, group facilitated effort (Wenger, 1999, 2006). Therefore the goal in any activity that is to emulate the SCR should be to develop a social constructivist learning environment. Group members need to eventually move beyond assigned tasks towards a social constructivist community learning environment, from which a virtual CoP may form.

- The task must be consistent. This recommendation is based on Johnson's (2001) notion a "legitimate task-oriented reason" (p. 53) being necessary for a virtual CoP to form out of the context of a deliberate CMS. Therefore, though the practitioner sessions may utilize a different social constructivist activity than the SCR (such as a journal club), whatever they do must be consistent in task throughout. This task focus gives the group an initial "reason" to meet. Though the goal is to eventually move away from the task and more towards the community, the task itself provides the initial purpose for the group to continue meeting.

With the highly busy lifestyle of rural practitioners and the distinctive nature of the ORSP SCR, it is unrealistic to believe that a rural practitioner herself could organize an activity meeting the criteria described previously. Therefore, academic medical institutions may need to lead in this area, providing their rural preceptors with the 
facilitation, coordination, and technological infrastructure needed to help rural practitioners form deliberate CMSs. From this initial investment, practitioners would be taught how to use the technology and facilitate the groups, eventually taking over and becoming independent of the university. Additionally, the medical students that are exposed to the SCR activity while in training will, though that exposure, gain the skill set necessary to attempt similar practices when they become rural practitioners. With active alumni tracking, academic medical institutions could continue to support their former students' practice efforts by assisting them in setting up their own kind of practice-based SCR activities, thus fulfilling their rural workforce missions.

\section{Limitations}

A primary limitation of this study relates to the CoI coding process. Garrison et al. (2006) cite the variety of ways one can approach CoI coding, from a lone coder to coding in teams. Garrison et al. (2006) suggest coding in teams is a superior methodology to coding alone due to the various ways an event can be coded within the CoI framework (e.g. a joke to one person may not be perceived as a joke by another). As such, Garrison et al. (2006) recommend coding teams be assembled so that disagreements in coding can be discussed and decided upon so there is greater reliability employed in the coding framework.

As a lone coder in this dissertation study, I did not have other team members to assist with my coding process. Also, due to the great amount of data (over 9.5 hours of recorded SCRs), I did not go back and re-assess my codes to check for consistency. However, I strove for utmost consistency in mapping out and studying the CoI coding framework in detail prior to the beginning of my coding process. This process included 
personal email communication with Dr. Garrison, who verified that the coding framework I used for this study was up-to-date. Thus, I felt confident as a researcher as I proceeded that my coding criteria stayed consistent, and do not believe a second pass through my data would significantly change the coding numbers presented in this dissertation. That said, I do believe that a coding team would have been the most accurate way to ensure a consistency of codes across all SCRs and would recommend this process be used instead of the lone coder method in a future study such as this one.

The other limitation of this study is that, as an intrinsic case study, the results cannot be readily generalized. While the scope of this study was never to have results be broadly generalizable, some of the results that have come out of the study are intriguing and could have significant implications for rural medical education and practice. More research, such as broader multi-cohort comparative case studies as well as longitudinal tracking of ORSP student technology usage when in professional rural practice are needed to further explore the results and conclusions of this study.

\section{Conclusion}

This dissertation has explored online community among rural medical education students participating in the ORSP program's online SCR activity. Owing to the novel nature of the SCR, an intrinsic case study design was used to explore the both the impact of the SCR on the group as well as the perspective of the students who participated in the SCR. Specifically, this study posed two research questions in exploring the deliberate CMS of the SCR:

1. What is the impact on learners when a deliberate CMS like the SCR is used to deliver the rural medical education experience? 
2. What is the nature of ORSP student experiences participating in the SCR? Research question one utilized the lens of the CoI theoretical framework for analysis. CoI analysis revealed a robust higher education online learning environment with all presences trending upward at the conclusion of the SCR activity. The analysis of each presence revealed that each presence began to differentiate notably by the fourth and final SCR. The differentiation of the presences indicated a movement away from an individual, task focus (the SCR assignment) towards a social constructivist, community focus. The formation of a social constructivist online environment is important for two reasons. One, a social constructivist learning environment is ideal for higher education-level critical thinking, and therefore the movement of the group to this type of environment indicates that the SCR is a successful pedagogical strategy for producing higher education level critical discourse among spatially dispersed rural medical education students. Second, from a workforce perspective, a social constructivist environment is important because it is the necessary foundation of a CoP. Specific to this study, a social constructivist environment must be present to foster a virtual CoP. As virtual CoPs are preceded by deliberate CMSs (which are not necessarily social constructivist ), an important strategy in fostering virtual CoP formation is to move a group from an individual, task focus that is inherent to a deliberate CMS to a social constructivist, group focus inherent to a virtual CoP. A proposed model to facilitate this movement is introduced in Figure 5.1 of this study.

Another finding of the CoI analysis was that a reduction of technical problems after SCR 1 seemed to have given rise to all CoI presences, especially Social presence. A recommendation for any future attempt to emulate this type of activity is then to 
minimize technical difficulties early on so Social and other presences can flourish. On the other hand, a complete elimination of technical difficulties in a synchronous online environment is unrealistic, and user expectations should be managed accordingly. Additionally, this study demonstrated that some technical difficulties actually assisted in increasing Cognitive presence as the group was involved in the active problem solving of the technical issue. This active group engagement in solving a shared problem supports a social constructivist learning environment and therefore should be encouraged when technical problems do inevitably arise in a similar online environment.

Interviews and field notes were the data sources used to explore question two of the study. Results revealed that the students found the technology was not a hindrance even though some parts of it could be improved. Additionally, interview data revealed students did experience a sense of community among peers within the online learning environment. This sense of community led to reduced feelings of isolation as well as making some students feel more inclined to go into rural practice.

Three conclusions can be drawn from this study. The first conclusion is that a synchronous online space is a medium well suited for supporting social constructivist learning environments. Specifically, the observed phenomenon of fluid roles swaps enabled by the online medium serves as a strong example of the possibilities for social constructivist learning in synchronous online spaces. The second conclusion is that the SCR activity is capable of yielding virtual CoPs, as was witnessed with Trent's impromptu presentation in SCR 4. Trent's presentation marked a major shift in how the learners were approaching the SCR activity, moving from executing an assignment to utilizing the group for professional support and knowledge creation. The final conclusion 
is that the online SCR activity is capable of giving participants a sense of community through reducing feelings of isolation. As isolation is a key reason rural health practitioners choose not to practice, or persist in practice, in rural areas, the results of this study are of significant and worthy of noting by those looking to boost persistence among rural practitioners in the US.

Two recommendations for further research emerge from this study. The first is that more research is needed on the elements of a multi-modal, synchronous online meeting room, specifically related to the impact of chatting functionality on group dynamics. Phenomena such as fluid role swapping and the community building aspects of chat inherently reinforce higher education level, social constructivist learning environments. Therefore, it is important for higher education in general, and rural medical education specifically, to look to synchronous online spaces as opportunities for creating rich learning opportunities for spatially dispersed students. Robust research must accompany these opportunities so that a better understanding of the potential for synchronous online spaces in higher education is realized.

The second recommendation for future research is that there should be longitudinal research to verify if students exposed to the online SCR activity in medical school go on to employ similar techniques in rural practice. As the workforce implication of this study is that a deliberate CMS activity similar to the SCR executed among rural practitioners may lead to the formation of virtual CoPs among the participating physicians, tracking the students exposed to the SCR in medical school into their rural practice is important to see if they do, in fact, go on to emulate the SCR and if that does, indeed, lead to virtual CoP formation in practice. 
In addition to recommendations for future research, there are also several recommendations for future practice that emerge from this study. The first recommendation is that more deliberate facilitation of the SCR is needed to move a group from task focus to community focus so that a context for a virtual CoP forms. The definition of a deliberate CMS is a group meeting online around a shared goal or task. Therefore the focus on task initially will be strong, and so skill is needed in guiding the group from the strong task focus to a social constructivist environment so that a virtual CoP can form. From this study a model has been developed that visualizes this process (Figure 5.1), and continual effort must be put into refining the guiding process. Outside of pedagogy, another recommendation is that technical interferences be reduced (though not necessarily eliminated) so that the presences, especially Social, can flourish.

The final two recommendations for practice from this study pertain to academic medical institutions as well as rural practitioners. Regarding the former, academic medical institutions with rural missions should consider emulating the online SCR. The scalability and applicability of the ORSP SCR makes it relatively easy to implement in any rural medical education program, and the actual activity itself can be modified to meet the specific needs of individual programs. By implementing an online SCR type activity, institutions with rural missions might provide their spatially dispersed learners with an opportunity to engage in higher education level social constructivist learning. Additionally, rural medical education students exposed to an ORSP SCR-type format can reduce their feelings of isolation and may internalize the SCR process for their future rural practice, thus creating more possibilities for virtual CoPs to form among rural practitioners. 
Regarding rural physicians, the final- and perhaps most importantrecommendation from this study is that the ORSP SCR format should be incorporated into the professional lives of current rural practitioners. As stated, the SCR activity can be substituted for a more appropriate professional activity, so long as the substituted activity is social constructivist by design. Then, by utilizing the model described in Figure 5.1, there can be a process implemented for moving these practitioner-based deliberate CMSs from a task focus to a social constructivist focus from which virtual CoPs can potentially emerge. Universities with rural missions can play a role in providing the initial infrastructures to support these practitioner cohorts via facilitation training, technical support, and logistics. As the technology utilized for the ORSP program is neither complex nor cost prohibitive, rural practitioners themselves can eventually take ownership of the process, thus enabling a robust community of virtual CoPs in rural practice settings.

In conclusion, although this study takes place in an educational setting, its primary implication is for the current and future rural physician workforce. Specifically, the primary focus of this study is to help solve a disturbing problem in practice: not enough rural practitioners in Oregon. Unfortunately, this is a problem in practice that continues. Recent data indicate a 7.8\% drop in Oregon's primary care physician workforce between 2010-2012 (Office for Oregon Health Policy and Research, 2013). Additionally, two thirds of Oregon's 36 counties (the majority of which are rural) lost physicians between 2010-2012. This includes Sherman county, which lost its only physician and remains without a replacement at the time of writing (Office for Oregon Health Policy and Research, 2013). Additionally, Oregon's physician workforce is aging, 
with an average physician age of 51 and 39\% of Oregon's physicians over the age of 55 in 2012 (Office for Oregon Health Policy and Research, 2013). Thus, not only does rural Oregon need to replace the physicians it is losing now and will rapidly lose to retirement later, but it also needs to replace them with a generally younger workforce.

A younger generation born into a world of pervasive technology and constant connectivity could be the ideal next generation Oregon rural physician workforce. This study explores a possible process aided by technology that could help this new generation of physicians stay connected with one another despite the physical distance between them inherent to rural practice. While myriad issues remain for the rural practitioner (e.g., Medicare reimbursement issues), isolation is something that can be addressed through a process similar to that described in this study. In short, rural physicians no longer need to feel professionally isolated. Virtual CoPs are indeed possible in a rural setting, and this knowledge has grand implications for meaningfully connecting spatially dispersed rural physicians to one another as well as to their metropolitan colleagues. Robust virtual CoPs among Oregon's rural practitioners could reduce isolation and create a sense of community in ways previously not possible. The knowledge that practicing in rural Oregon does not necessarily mean a life of professional isolation may help a new generation better regard a life in rural practice. More satisfied rural physicians will persist in their practices longer and thus become value added to their rural communities. The potential reality of connected rural physicians participating in thriving virtual CoPs would be good for Oregon's rural physician workforce, good for Oregon's rural communities and, most importantly, good for the healthcare and wellbeing of Oregon's rural citizens. 


\section{References}

Akyol, Z., Arbaugh, J. B., Cleveland-Innes, M., Garrison, D. R., Ice, P., Richardson, J. C., \& Swan, K. (2009). A response to the review of the Community of Inquiry framework. Journal of Distance Education, 23(2), 123-135.

Akyol, Z., \& Garrison, D. R. (2008). The development of a Community of Inquiry over time in an online course: understanding the progression and integration of Social, Cognitive and Teaching presence. Journal of Asynchronous Learning Networks, 12(3-4), 3-22.

Arbaugh, J. B. (2007). An empirical verification of the Community of Inquiry framework. Journal of Asynchronous Learning Networks, 11(1), 73-85.

Arbaugh, J. B. (2008). Does the Community of Inquiry framework predict outcomes in online MBA courses? International Review of Research in Open \& Distance Learning, 9(2), 1-21.

Arbaugh, J. B., Cleveland-Innes, M., Diaz, S. R., Garrison, D. R., Ice, P., Richardson, J. C., \& Swan, K. P. (2008). Developing a Community of Inquiry instrument: testing a measure of the Community of Inquiry framework using a multi-institutional sample. The Internet and Higher Education, 11(3-4), 133-136.

doi:10.1016/j.iheduc.2008.06.003

Chang, C.-F., Paulus, T. M., Pawan, F., \& Yalcin, S. (2003). Online learning: patterns of engagement and interaction among in-service teachers. Language, Learning \& Technology, 7(3), 119. 
Charalambos, V., Michalinos, Z., \& Chamberlain, R. (2004). The design of online learning communities: critical issues. Educational Media International, 41(2), 135-143. doi:10.1080/09523980410001678593

Chen, F., Fordyce, M., Andes, S., \& Hart, L. G. (2010). Which medical schools produce rural physicians? A 15-Year Update. Academic Medicine, 85(4), 594-598. doi:10.1097/ACM.0b013e3181d280e9

Confessore, S. J. (1997). Building a learning organization: communities of practice, self-directed learning, and continuing medical education. Journal of Continuing Education in the Health Professions, 17(1), 1-11. doi:10.1002/chp.4750170101

Crandall, M., \& Weber, B. (2005). Defining rural Oregon: an exploration. Retrieved from http://ruralstudies.oregonstate.edu/sites/default/files/pub/pdf/rsp_reports/rsp0503.pdf

Creswell, J. W. (2007). Qualitative inquiry and research design: choosing among five traditions. Thousand Oaks: Sage Publications.

Curran, V., \& Rourke, J. (2004). The role of medical education in the recruitment and retention of rural physicians. Medical Teacher, 26(3), 265-272. doi:10.1080/0142159042000192055

DeMaria, R., \& Bongiovianni, T. (2010). The 10 biggest myths about synchronous online teaching. EDUCAUSE. Retrieved November 19, 2011, from http://www.educause.edu/EDUCAUSE+Quarterly/EDUCAUSEQuarterlyMagazi neVolum/The10BiggestMythsAboutSynchron/213702 
Dewey, J. (1910). How we think. Lexington, MA: DC Heath \& Company. Retrieved from https://play.google.com/store/books/details?id=FmhIrCNdttsC

Dickey, M. (2003). Teaching in 3D: pedagogical affordances and constraints of 3D virtual worlds for synchronous distance learning. Distance Education, 24(1), 105.

Dickey, M. (2004). The impact of web-logs (blogs) on student perceptions of isolation and alienation in a web-based distance-learning environment. Open Learning, 19(3), $279-291$.

Free Online Medical Dictionary, Thesaurus and Encyclopedia. (n.d.). Teaching rounds. Retrieved May 3, 2012, from http://medicaldictionary.thefreedictionary.com/teaching+rounds

Galloway, C. (2001). Vygotsky’s constructivism. Emerging Perspectives on Learning, Teaching and Technology. Retrieved December 10, 2010, from http://projects.coe.uga.edu/epltt/index.php?title=Vygotsky\%27s_constructivism

Garrison, D. R. (2007). Online Community of Inquiry review: Social, Cognitive, and Teaching presence issues. Journal of Asynchronous Learning Networks, 11(1), $61-72$.

Garrison, D. R. (2009). Implications of online learning for the conceptual development and practice of distance dducation. Journal of Distance Education, 23(2), 93-103.

Garrison, D. R., (2011). E-learning in the 21st century: a framework for research and practice. New York, N.Y.: Routledge.

Garrison, D. R., Anderson, T., \& Archer, W. (1999). Critical inquiry in a text-based environment: computer conferencing in higher education. The Internet and Higher Education, 2(2-3), 87-105. doi:10.1016/S1096-7516(00)00016-6 
Garrison, D. R., Anderson, T., \& Archer, W. (2001). Critical thinking, cognitive presence, and computer conferencing in distance education. American Journal of Distance Education, 15(1), 7-23. doi:10.1080/08923640109527071

Garrison, D. R., Anderson, T., \& Archer, W. (2010). The first decade of the Community of Inquiry framework: a retrospective. The Internet and Higher Education, 13(12), 5-9. doi:10.1016/j.iheduc.2009.10.003

Garrison, D. R., \& Arbaugh, J. B. (2007). Researching the Community of Inquiry framework: review, issues, and future directions. The Internet and Higher Education, 10(3), 157-172. doi:10.1016/j.iheduc.2007.04.001

Garrison, D. R., \& Archer, W. (2000). A transactional perspective on teaching and learning: a framework for adult and higher education. Amsterdam: Pergamon.

Garrison, D. R., Cleveland-Innes, M., \& Fung, T. S. (2004). Student role adjustment in online communities of inquiry: model and instrument validation. Journal of asynchronous learning networks, 8(2), 61-74.

Garrison, D.R., Cleveland-Innes, M., Koole, M., \& Kappelman, J. (2006). Revisiting methodological issues in transcript analysis: negotiated coding and reliability. The Internet and Higher Education, 9(1), 1-8. doi:10.1016/j.iheduc.2005.11.001

Gazewood, J. D., Rollins, L. K., \& Galazka, S. S. (2006). Beyond the horizon: the role of academic health centers in improving the health of rural communities. Academic Medicine, 81(9), 793-797.

Geyman, J. P., Hart, L. G., Norris, T. E., Coombs, J. B., \& Lishner, D. M. (2000). Educating generalist physicians for rural practice: how are we doing? The Journal of Rural Health, 16(1), 56-80. doi:10.1111/j.1748-0361.2000.tb00436.x 
Gunawardena, C. N. (1995). Social presence theory and implications for interaction and collaborative learning in computer conferences. International Journal of Educational Telecommunications, 1(2), 147-166.

Gunawardena, C. N., \& Zittle, F. J. (1997). Social presence as a predictor of satisfaction within a computer-mediated conferencing environment. American Journal of Distance Education, 11(3), 8-26. doi:10.1080/08923649709526970

Hillman, D. C. A., Willis, D. J., \& Gunawardena, C. N. (1994). Learner-interface interaction in distance education: an extension of contemporary models and strategies for practitioners. American Journal of Distance Education, 8(2), 30-42. doi:10.1080/08923649409526853

Jeffe, D. B., Whelan, A. J., \& Andriole, D. A. (2010). Primary care specialty choices of United States medical graduates, 1997-2006. Academic Medicine, 85(6), 947958.

Johnson, B., \& Christensen, L. (2012). Educational research: quantitative, qualitative, and mixed approaches. Thousand Oaks, Calif.: SAGE Publications.

Johnson, C. (2001). A survey of current research on online communities of practice. The Internet and Higher Education, 4(1), 45-60. doi:10.1016/S1096-7516(01)00047-1

Kear, K. L. (2011). Online and social networking communities: a best practice guide for educators. New York: Routledge.

Kim, B. (2001). Social constructivism. Emerging Perspectives on Learning, Teaching and Technology. Retrieved December 10, 2010, from http://projects.coe.uga.edu/epltt/index.php?title=Social_Constructivism 
Kimble, C., \& Hildreth, P. M. (2004). Communities of practice: going one step too far? SSRN eLibrary. Retrieved from http://papers.ssrn.com.proxy.lib.pdx.edu/sol3/papers.cfm?abstract_id=634642

Lueg, C. (2000). Where is the action in virtual communities of practice. In D-CSCW 2000 Verteiltes Arbeiten - Arbeit der Zukunft. Retrieved from http://citeseerx.ist.psu.edu/viewdoc/summary?doi=?doi=10.1.1.23.7502

Marshall, C., \& Rossman, G. B. (2011). Designing qualitative research. Los Angeles, Calif.: Sage.

McBrien, J. L., Cheng, R., \& Jones, P. (2009). Virtual spaces: employing a synchronous online classroom to facilitate student engagement in online learning. The International Review of Research in Open and Distance Learning, 10(3), Article 10.3.5.

Moore, M. G. (1993). Theory of transactional distance. Theoretical Principles of Distance Education (pp. 22-38). New York: Routledge.

Morris, C. G., \& Chen, F. M. (2009). Training residents in community health centers: facilitators and barriers. The Annals of Family Medicine, 7(6), 488 -494. doi:10.1370/afm.1041

Morris, C. G., Johnson, B., Kim, S., \& Chen, F. M. (2008). Training family physicians in community health centers: a health workforce solution. Family Medicine, 40(4), 271-276.

Office for Oregon Health Policy and Research. (2013). Oregon health professions: occupational and county profile. Lake Oswego, Oregon. 
Oztok, M., Zingaro, D., Brett, C., \& Hewitt, J. (2013). Exploring asynchronous and synchronous tool use in online courses. Computers \& Education, 60(1), 87-94. doi:10.1016/j.compedu.2012.08.007

Palmer, R., \& Dodson, L. (2011). Distance learning in the cloud: using 3G enabled mobile computing to support rural medical education. Journal of the Research Center for Educational Technology, 7(1), 106-116.

Parboosingh, J. T. (2002). Physician communities of practice: where learning and practice are inseparable. Journal of Continuing Education in the Health Professions, 22(4), 230-236. doi:10.1002/chp.1340220407

Perse, E. M., Burton, P. I., Kovner, E. S., Lears, M. E., \& Sen, R. L. (1992). Predicting computer-mediated communication in a college class. Communication Research Reports, 9(2), 161-170.

Primary Care. (n.d.). American Academy of Family Physicians. Retrieved November 29, 2011, from http://www.aafp.org/online/en/home/policy/policies/p/primarycare.html\#Parsys00 02

Rabinowitz, H. K., Diamond, J. J., Markham, F. W., \& Hazelwood, C. E. (1999). A program to increase the number of family physicians in rural and underserved areas. JAMA: The Journal of the American Medical Association, 281(3), 255 260. doi:10.1001/jama.281.3.255

Rabinowitz, H. K., Diamond, J. J., Markham, F. W., \& Wortman, J. R. (2008). Medical school programs to increase the rural physician supply: a systematic review and 
projected impact of widespread replication. Academic Medicine, 83(3), 235-243. doi:10.1097/ACM.0b013e318163789b

Rosenthal, T. C. (2000). Outcomes of rural training tracks: a review. The Journal of Rural Health, 16(3), 213-216. doi:10.1111/j.1748-0361.2000.tb00459.x

Rourke, J., Incitti, F., Rourke, L., \& Kennard, M. (2005). Relationship between practice location of Ontario family physicians and their rural background or amount of rural medical education experience. Canadian journal of rural medicine : the official journal of the Society of Rural Physicians of Canada = Journal canadien de la medecine rurale : le journal officiel de la Societe de medecine rurale du Canada, 10(4), 231-240.

Rourke, L., Anderson, T., Garrison, D. R., \& Archer, W. (1999). Assessing Social presence in asynchronous text-based computer conferencing. Journal of Distance Education, 14(2), 50-71.

Rourke, L., \& Kanuka, H. (2009). Learning in communities of inquiry: a review of the literature. Journal of Distance Education, 23(1), 19-47.

Rovai, A. P. (2002). Building sense of community at a distance. The International Review of Research in Open and Distance Learning, 3(1). Retrieved from http://www.irrodl.org.proxy.lib.pdx.edu/index.php/irrodl/article/view/79/152

Saba, F., \& Shearer, R. L. (1994). Verifying key theoretical concepts in a dynamic model of distance education. American Journal of Distance Education, 8(1), 36-59. doi:10.1080/08923649409526844

Schwen, T., \& Hara, N. (2003). Community of practice: a metaphor for online design? Information Society, 19(3), 257. 
Short, J., Williams, E., \& Christie, B. (1976). The social psychology of telecommunications. London; New York: Wiley.

So, H.-J., \& Brush, T. A. (2008). Student perceptions of collaborative learning, social presence and satisfaction in a blended learning environment: relationships and critical factors. Computers \& Education, 51(1), 318-336. doi:10.1016/j.compedu.2007.05.009

Social Constructivist Theories. (n.d.). Retrieved December 10, 2010, from http://viking.coe.uh.edu/ ichen/ebook/et-it/social.htm

Squire, K. D., \& Johnson, C. B. (2000). Supporting distributed communities of practice with interactive television. Educational Technology Research and Development, 48(1), 23-43. doi:10.1007/BF02313484

Swan, K. (2002). Building learning communities in online courses: the importance of interaction. Education, Communication \& Information, 2(1), 23-49. doi:10.1080/1463631022000005016

Tu, C.-H. (2002). The measurement of social presence in an online learning environment. International Journal on E-Learning, 1, 34-45. doi:Article

Vygotsky, L. S., \& Cole, M. (1978). Mind in society the development of higher psychological processes. Cambridge, Mass. [u.a.: Harvard Univ. Press.

Wenger, E. (1999). Communities of practice: learning, meaning, and identity. Cambridge, U.K.; New York: Cambridge University Press.

Wenger, E. (2006). Communities of practice. Retrieved March 14, 2012, from http://www.ewenger.com/theory/ 
Whitcomb, M. E. (2005). The challenge of providing doctors for rural America. Academic Medicine, 80(8), 715-716.

Woloschuk, W., \& Tarrant, M. (2002). Does a rural educational experience influence students' likelihood of rural practice? Impact of student background and gender. Medical Education, 36(3), 241-247. doi:10.1046/j.1365-2923.2002.01143.x

Yin, R. (2009). Case study research: design and methods. Los Angeles, Calif.: Sage Publications. 
Appendix

\section{Open Ended Initial Interview Questions}

The interview style was open-ended as the intention was to better understand the subject's experience of having participated in the SCR activity. Open-ended questions addressed the following:

- What was your experience of participating in the SCR?

- What was your experience with the online technology used to participate in the SCR?

- Did the interactive nature of the SCR make you feel any sense of community with your peers?

- Would you ever consider using a similar technology and SCR type of approach to connect with peers when in your future rural practice?

- How does knowing you can connect with others with activities like the SCR make you feel about practicing in a rural area? 